\title{
Guía de práctica clínica para el manejo del cáncer de mama en estadios tempranos, localmente avanzados y metastásicos
}

\author{
Brenda Carbajal-Saldaña ${ }^{1}$, Antonio Maffuz-Aziz², Jorge Alberto Guadarrama-Orozco ${ }^{3}$, \\ José Luis Mayorga-Butrón ${ }^{4,5,6,}$ Gregorio Quintero Beuló7, María de la Luz García-Tinoco3, \\ Samuel Rivera-Rivera ${ }^{3}$, Francisco Javier Ochoa-Carrillo ${ }^{8}$, Juan Enrique Bargalló-Rocha ${ }^{8}$, \\ Federico Maldonado-Magos ${ }^{8}$, Raymundo Hernández-Montes de Oca ${ }^{1}$, Felipe Villegas-Carlos ${ }^{1}$, \\ Marytere Herrera-Martínez ${ }^{1}$, Luis Alfonso Romero-Robles ${ }^{1}$, Zuratzi Deneken-Hernández ${ }^{1}$, \\ Daniel Rivera-Sánchez ${ }^{8}$, Claudia Haydeé Arce-Salinas ${ }^{1,8}$, Rocío Crystal Grajales-Álvarez ${ }^{3}$, \\ Nathaly García-Orozco ${ }^{1}$, Ricardo Villalobos-Valencia ${ }^{9}$, Francisco Javier Lozano-Ruiz ${ }^{8}$, \\ Betsabé Hernández-Hernández ${ }^{1}$, Juan Alberto Tenorio-Torres ${ }^{1}$, Carlos Alberto Domínguez-Reyes ${ }^{1}$, \\ Miguel Ángel Pluma-Jiménez ${ }^{3}$, Yanin Chavarri-Guerra ${ }^{10}$, Rubí Ramos-Prudencio ${ }^{8}$, \\ Cynthia Mayté Villarreal-Garza ${ }^{11}$, Mónica Blake-Cerda ${ }^{8}$, Fabiola Flores-Vázquez ${ }^{8}$, \\ Georgina Garnica-Jaliffe ${ }^{12}$, Manuel Ernesto Magallanes-Maciel2 ${ }^{2}$ Yolanda Bautista-Aragón ${ }^{3}$, \\ Jaime Alonzo Reséndiz Colosia ${ }^{13}$, Liliana Velasco Hidalgo ${ }^{4}$, Marta Margarita Zapata Tarres ${ }^{7}$, \\ Marco Rodrigo Aguilar Ortíz ${ }^{4}$, Gibert Maza Ramos ${ }^{4}$, Bertha Beatriz Montaño Velázquez ${ }^{5,9}$, \\ Marco Antonio Figueroa-Morales ${ }^{14}$ y Alejandro González-Garay ${ }^{4}$
}

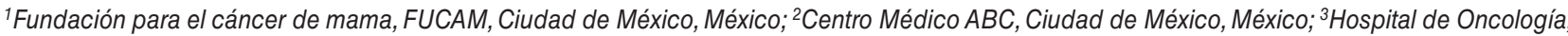
Centro Médico Nacional Siglo XXI, IMSS, Ciudad de México, México; ${ }^{4}$ Instituto Nacional de Pediatría, SSA, Ciudad de México, México; ${ }^{5}$ Programa de Maestría y Doctorado en Ciencias Médicas, Unidad de Posgrado, Facultad de Medicina, Universidad Autónoma de México (UNAM), Ciudad de México, México; ${ }^{6}$ Steering Comitee, Guidelines International Network North America, New York Academy of Medicine, Nueva York, EE.UU.; ${ }^{7}$ Hospital General de México, Ciudad de México, México; ${ }^{8}$ Instituto Nacional de Cancerología (INCan), Ciudad de México, México; ${ }^{9} \mathrm{Centro}$ Médico Nacional La Raza, IMSS, Ciudad de México, México; ${ }^{10}$ Instituto Nacional de Ciencias Médicas y Nutrición Dr. Salvador Zubirán, SSA, Ciudad de México, México; ${ }^{11}$ Centro de Oncología, Centro de Cáncer de Monterrey, Monterrey, Nuevo León, México; ${ }^{12}$ Centro Oncológico Internacional, Ciudad de México, México; ${ }^{13}$ Unidad Médica de Alta Especialidad (UMAE) Centro Médico Nacional Siglo XXI, IMSS, Ciudad de México, México; ${ }^{14}$ IMSS, Ciudad de México, México

\section{Resumen}

Introducción: El cáncer de mama es uno de los tumores malignos más frecuentes y una de las principales causas de mortalidad en nuestro país y alrededor del mundo. Implica alteraciones en la calidad de vida de las pacientes y un alto costo en el tratamiento tanto de las instituciones públicas como de las privadas. Es importante contar con recomendaciones basadas en evidencia que, al ser incorporadas en la toma de decisiones clínicas de forma rutinaria, ayuden a mejorar la calidad de la atención médica en estas pacientes. Objetivos: Esta guía de práctica clínica (GPC) contiene recomendaciones clínicas desarrolladas de forma sistematizada para asistir en la toma de decisiones de médicos especialistas, pacientes, cuidadores de pacientes y elaboradores de políticas públicas involucrados en el manejo de pacientes con cáncer de mama en estadios tempranos, localmente avanzados y metastásicos. Material y métodos: Este documento fue desarrollado por parte de la Sociedad Mexicana de Oncología en colaboración con el Centro Nacional de Excelencia Tecnoló-

\section{Correspondencia:}

Francisco Javier Ochoa-Carrillo

E-mail: ochoacarrillo@ prodigy.net.mx
Fecha de recepción: 15-03-2018

Fecha de aceptación: 30-04-2018

DOI: 10.24875/j.gamo.M18000161
Gac Mex Oncol. 2018;17:123-181

www.gamo-smeo.com 1665-9201/@ 2018 Sociedad Mexicana de Oncología. Publicado por Permanyer México SA de CV. Este es un artículo Open Access bajo la licencia CC BY-NC-ND (http://creativecommons.org/licenses/by-nc-nd/4.0/). 
gica en Salud (CENETEC) a través de la dirección de integración de GPC en cumplimiento a estándares internacionales, como los descritos por el Instituto de Medicina de EE.UU. (IOM), el National Institute for Clinical Excellence, «Instituto Nacional para la Excelencia Clínica» del Reino Unido (NICE), la Red Colegiada para el Desarrollo de Guías de Escocia (SIGN), la Guideline International Network, «Red Internacional de Guías» (GIN) y el Centro Nacional de Excelencia Tecnológica de México, entre otros. Se integró en representación de la Sociedad Mexicana de Oncología un grupo de desarrollo de la guía (GDG) de manera interdisciplinaria, considerando oncólogos médicos, cirujanos oncólogos, radiooncólogos, y metodólogos con experiencia en revisiones sistemáticas (RS) de la literatura médica y GPC. Resultados: Se consensuaron 51 preguntas clínicas que abarcaron lo establecido previamente por el GDG en el documento de alcances de la guía. Se identificó la evidencia científica que responde a cada una de estas preguntas clínicas y se evaluó críticamente la misma, antes de ser incorporada en el cuerpo de evidencia de la guía. El GDG acordó mediante la técnica de consenso formal de expertos Panel Delphi la redacción final de las recomendaciones clínicas. Conclusión: Esta GPC pretende proveer recomendaciones clínicas para el manejo de los distintos estadios de la enfermedad y que asistan en el proceso de toma de decisiones compartida. EI GDG espera que esta guía contribuya a mejorar la calidad de la atención clínica en las pacientes con cáncer de mama.

Palabras clave: Cáncer de mama. Cáncer de mama en estadios tempranos. Cáncer de mama localmente avanzado. Cáncer de mama metastásico. Guías de práctica clínica. Medicina basada en evidencia.

\section{Clinical practice guide for the management of breast cancer in early, locally advanced and metastatic stages}

\section{Abstract}

Introduction: Breast Cancer is one of the most prevalent tumors and one of the main mortality causes in our country and around the world. Burden of the disease considers Health Related Quality of Life impairment and elevated direct costs of his treatment. Evidence based clinical recommendations are of great value to support decision-making on daily practice improving health care quality. Objectives: This Clinical Practice Guideline (CPG) contains systematically developed recommendations to support clinicians, patients and carers, policy makers and other stakeholders in the diagnostic and management of patients with early, advanced and metastatic stages of Breast Cancer. Methodology: This document was an initiative of the Mexican Society of Oncology (SMEO) in collaboration with Mexican Center of Clinical Excellence (CENETEC) according to International Standards. Such standards were those being developed by IOM, NICE, SIGN and GI-N. An interdisciplinary Guideline Development Group (GDG) was put together and considered oncologist, oncologic surgeons, radiation therapist, and methodologists with expertise in systematic reviews and clinical practice guidelines. Results: 51 clinical questions were agreed between the GDG. With the evidence identified from systematic reviews, GDG developed clinical recommendations using a Modified Delphi Panel technique. Patients' representatives validated them. Conclusions: This Clinical Practice Guideline aims to support share decision-making process for patients with different stages of Breast Cancer. Our goal is to improve health-care quality on these patients.

Key words: Breast neoplasm. Early Breast Caner. Locally Advanced Breast Cancer. Metastatic Breast Cancer. Clinical Practice Guidelines. Evidence Based Medicine.

\section{Glosario de términos}

- Adherencia: La manera en la que el paciente se adhiere a las recomendaciones de su médico.

- Ajuste: Procedimiento estadístico en el cual el efecto de las diferencias en la composición de la población en estudio ha sido comparado para minimizarlas.

- Aleatorización: Consiste en asignar aleatoriamente (al azar) a los participantes en un ensayo a dos o más grupos de tratamiento o de control. La aleatorización es una de las formas de evitar los sesgos de selección, y su propósito es posibilitar las comparaciones en los grupos de asignación de los tratamientos.

- Algoritmos: Diagrama de flujo en la toma de decisiones clínicas para apoyar la incorporación de las recomendaciones a la práctica cotidiana.

- Aplicabilidad: El grado en el que las recomendaciones contenidas en una GPC o un documento de consenso puedan ser incorporadas a un escenario clínico en particular.

- Appraisal of Guidelines, Research and Evaluation (AGREE): Colaboración internacional de investigad 
ores con el objetivo de mejorar la calidad de las GPC. El instrumento AGREE fue diseñado para evaluar la calidad de las GPC (http://www.agreecollaboration. org).

- Asociación: Relación estadística entre dos o más eventos, características u otras variables. La relación puede ser o no causal.

- Calidad de vida relacionada con la salud (Health-related quality of life): La percepción que la persona tiene del impacto que ha provocado la enfermedad o su tratamiento sobre su sentimiento de bienestar y la capacidad de actuación (funcionalismo). Estas dimensiones básicas deben ser analizadas en los dominios físico, emocional y social.

- Cáncer de mama: El cáncer de seno (o cáncer de mama) se origina cuando las células en el seno comienzan a crecer de forma descontrolada. Estas células normalmente forman un tumor que a menudo se puede observar en una radiografía o se puede palpar como una protuberancia (masa o bulto). El tumor es maligno (cáncer) si las células pueden crecer penetrando (invadiendo) los tejidos circundantes o propagándose (metástasis) a áreas distantes del cuerpo. El cáncer de seno ocurre casi exclusivamente en las mujeres, pero los hombres también lo pueden padecer.

- Carcinoma ductal in situ (CDIS): Afección no invasiva en la que se encuentran células anormales en el revestimiento de un conducto de la mama. Las células anormales no se diseminaron fuera del conducto hasta otros tejidos de la mama. En algunos casos, el CDIS se puede transformar en cáncer invasivo y diseminarse hacia otros tejidos. Por ahora, no hay forma de saber qué lesiones se volverán invasivas. También se llama carcinoma intraductal y CDIS.

- Cegamiento: La manera en la que los investigadores, el equipo de investigación o los participantes del estudio evitaron conocer el modo en que las intervenciones fueron asignadas durante el estudio de investigación.

- Comorbilidad: Coexistencia de dos o más condiciones patológicas o enfermedades en un mismo individuo.

- Crisis visceral: Disfunción orgánica severa evaluada por datos clínicos y de laboratorio, y con rápida progresión de la enfermedad. No sólo implica la extensión metastásica, sino que además corresponde a una falla severa de la función.

- Desenlace: Medición de los posibles resultados relevantes para considerar mejoría del padecimiento con la exposición a la intervención terapéutica.
- Efectividad: La efectividad clínica es la medición del beneficio positivo de un tratamiento concreto en la práctica médica.

- Efecto absoluto: Diferencia entre el riesgo de la ocurrencia de algún evento entre dos grupos (uno en relación con el otro) en un estudio comparativo.

- Eficacia: La eficacia clínica es una medición del resultado positivo de un tratamiento concreto en el contexto de un estudio de investigación controlado.

- Estado basal: Conjunto de características y variables al inicio del estudio y con las que los resultados subsecuentes serán comparados.

- Estándar de referencia: Prueba diagnóstica más cercana a la veracidad del fenómeno en estudio con la que se puede disponer en un momento determinado, y que será utilizada para comparar con las características de la prueba diagnóstica que se desea evaluar.

- Estudio de casos y controles: Estudio observacional en el que el investigador selecciona a los individuos que han experimentado algún evento de interés y otros que no lo han presentado, para después evaluar si fueron expuestos a una posible causa.

- Estudio de cohorte: Estudio prospectivo o retrospectivo. Un grupo de individuos que comparten características y que se definen por su exposición o no exposición a un factor de riesgo.

- Estudio clínico controlado: Se trata de un experimento o estudio en el que el investigador «manipula» uno o más factores de estudio ( $p$. ej., decide qué tratamiento, con qué pauta y durante cuánto tiempo lo recibirán los sujetos de cada uno de los grupos de estudio) con objeto de valorar posteriormente los efectos producidos (o respuesta, resultado, variable dependiente) basándose en un plan preestablecido. Su objetivo es evaluar la eficacia y seguridad de cualquier intervención, ya sea preventiva, curativa o rehabilitadora, y es el diseño que proporciona la evidencia de mayor calidad acerca de la relación causal entre una intervención y el efecto observado.

- Equitativo: Distribución justa de beneficios 0 recursos.

- Evidencia: Cúmulo de información en la que una decisión clínica es sustentada. Es obtenida de fuentes que incluyen estudios clínicos controlados, estudios observacionales, estudios de prueba diagnóstica, revisiones sistemáticas y consensos de expertos.

- Ganglio centinela: El primer ganglio linfático que encuentran las células tumorales al intentar diseminarse a través de la linfa. 
- Grupo de control: En un ensayo clínico, el grupo de participantes que no recibe la intervención experimental objeto de estudio. El grupo testigo puede recibir una intervención que se considera eficaz (normal) o un placebo, o no recibir ninguna. Los resultados del grupo testigo se comparan con los del grupo experimental para determinar si hay diferencias estadísticas.

- Heterogeneidad: En el metaanálisis la heterogeneidad se refiere a la variabilidad o a las diferencias en las estimaciones de los efectos entre los estudios. En ocasiones se distingue entre «heterogeneidad estadística» (diferencias en los efectos declarados) y «heterogeneidad metodológica» (diferencias en el diseño de estudios).

- Homogeneidad: La noción de homogeneidad define a la igualdad mayor o menor de los valores de una variable o de una combinación de características en un conjunto geográfico. Los parámetros de dispersión estadística, en particular la varianza, miden su inversa, la heterogeneidad.

- Intervalo de confianza (IC): Un IC es un rango de valores, derivado de los estadísticos de la muestra, que posiblemente incluya el valor de un parámetro de población desconocido. Debido a su naturaleza aleatoria, es poco probable que dos muestras de una población en particular produzcan IC idénticos.

- Intervención: Acción terapéutica o de algún otro tipo que modifica el estado basal del paciente.

- Mastectomía: Extirpación de la mama completa. Existen diferentes tipos de mastectomía: mastectomía "simple» o «total», mastectomía radical modificada, mastectomía radical, mastectomía parcial y mastectomía subcutánea (con preservación de pezón).

- Médico clínico: Médico que se encarga de proveer atención clínica.

- Metaanálisis: Conjunto de herramientas estadísticas útiles para sintetizar los datos de una colección de estudios. El metaanálisis se inicia recopilando estimaciones de un cierto efecto (expresado en un índice de tamaño del efecto, como la diferencia de medias tipificada, la razón de riesgo o la correlación) de cada estudio. El metaanálisis permite valorar estos efectos en contexto: si el tamaño del efecto es consistente, el efecto del tratamiento puede ser considerado como fuerte y el tamaño del efecto se estima con mayor precisión que con un solo estudio. Si el tamaño del efecto varía, esa variación puede ser descrita y, potencialmente, explicada.

- Metástasis: Cuando ocurre una metástasis, las células cancerosas se separan del tumor original (primario), viajan a través del sistema sanguíneo o linfático y forman un tumor nuevo en otros órganos o tejidos del cuerpo. El nuevo tumor metastásico es el mismo tipo de cáncer que el tumor primario.

- Método de consenso: Toma de decisiones en común acuerdo por parte de todos los miembros de un grupo, y no por la mayoría o por una representatividad. Lo que caracteriza al consenso es el proceso por el que el grupo ha de pasar para llegar a un acuerdo. El método de consenso es deseable cuando es improbable forzar el cumplimiento de la decisión, igual como si cada participante adoptara independientemente una misma decisión unánime. Por ello, algunos grupos reservan el método de decisión por consenso para decisiones particularmente complejas, arriesgadas o importantes.

- Número necesario a tratar (Number needed to treat): El número (de pacientes) que es necesario tratar (también conocido por los calcos «número necesario a tratar» y «número necesario para tratar») es el recíproco de la reducción del riesgo absoluto. Es un valor 0 indicador específico para cada tratamiento.

- $p$ values: El valor de $p$ (a veces conocido simplemente como el $p$-valor, $p$, valor de $p$ consignado o bien directamente en inglés $p$-value) se define como la probabilidad de obtener un resultado al menos tan extremo como el que realmente se ha obtenido (valor del estadístico calculado), suponiendo que la hipótesis nula es cierta, en términos de probabilidad condicional.

- Placebo: Sustancia que carece de acción curativa pero que produce un efecto terapéutico si el enfermo la toma convencido de que es un medicamento realmente eficaz; tiene el mismo aspecto, gusto y forma que un medicamento verdadero, pero está elaborado con productos inertes y sin ningún principio activo.

- Posología: Determinación de las dosis en que deben administrarse los medicamentos.

- Pronóstico: El pronóstico, generalmente de una enfermedad, es el conjunto de datos que posee la ciencia médica sobre la probabilidad de que ocurran determinadas situaciones en el transcurso del tiempo o historia natural de la enfermedad. Es la predicción de los sucesos que ocurrirán en el desarrollo de una enfermedad en términos estadísticos. Es un tipo de juicio clínico.

- Quimioterapia (QT): Tratamiento con medicamentos para detener el crecimiento de las células cancerosas, ya sea mediante su destrucción o impidiendo su multiplicación. La QT se puede administrar por la boca (vía oral), en inyección (intramuscular intravenosa, subcutánea), por infusión o sobre la piel, de acuerdo con el tipo y estadio del cáncer tratado. Se 
puede administrar sola o con otros tratamientos, como cirugía, radioterapia o terapia biológica.

- Radioterapia: La radiación puede venir de una máquina fuera del cuerpo (radioterapia de haz externo) 0 de un material radiactivo colocado en el cuerpo cerca de las células cancerosas (radioterapia interna o braquiterapia). La radioterapia sistémica usa una sustancia radiactiva, como un anticuerpo monoclonal radiomarcado.

- Razón de momios (Odds ratio [OR]): La razón de momios, razón de oportunidades o razón de probabilidades -en inglés, odds ratio (OR) - es una medida estadística utilizada en estudios epidemiológicos transversales y de casos y controles, así como en los metaanálisis. En términos formales, se define como la posibilidad de que una condición de salud o enfermedad se presente en un grupo de población frente al riesgo de que ocurra en otro. En epidemiología, la comparación suele realizarse entre grupos humanos que presentan condiciones de vida similares, con la diferencia de que uno se encuentra expuesto a un factor de riesgo (mi) y el otro carece de esta característica (mo). Por lo tanto, la razón de momios o de posibilidades es una medida de tamaño de efecto.

- Recurrencia locorregional: Clínicamente definido como un tumor o nódulos múltiples en la pared torácica o subcutáneos o cerca de la cicatriz de la mastectomía o en los pliegues cutáneos. La piel de la pared torácica también puede tener involucramiento difuso con cambios inflamatorios sin un tumor palpable.

- Resumen: Conjunto de datos denominado «Resumen» de un estudio que pudo haber sido publicado solo o con el trabajo en extenso.

- Revisión Cochrane: Revisión sistemática de la literatura médica de estudios clínicos controlados que responde a una pregunta clínica a través de un protocolo explícito y que fue producido por el grupo colaborativo Cochrane. Disponible en la Biblioteca Cochrane.

- Revisión sistemática (RS): Artículos científicos integrativos ampliamente usados en disciplinas del área de la salud que siguen un método explícito para resumir la información que se conoce acerca de determinado tema o problema de salud. Revisan y pueden combinar principalmente ensayos clínicos controlados, que son los estudios primarios. Se distinguen de las revisiones narrativas en que provienen de una pregunta estructurada y de un protocolo de investigación previo. La Colaboración Cochrane es la principal organización que produce y financia RS. Además, la búsqueda de la evidencia se ha desarrollado de manera sistemática con una declaración de los criterios de selección y se ha hecho una evaluación crítica de los artículos primarios y una síntesis basada en la calidad metodológica de los estudios. Cuando una RS termina de manera cuantitativa en un estimador estadístico, se denomina metaanálisis.

- Riesgos: Eventos adversos de una intervención.

- Riesgo relativo (RR): Medida relativa del efecto porque indica cuántas veces más tiende a desarrollar el evento en el grupo de sujetos expuestos al factor de exposición o al factor de riesgo en relación con el grupo no expuesto. El RR no tiene dimensiones. El RR es una razón.

- Serie de casos: Reporte de un número de casos de un padecimiento en particular en el que se describe la evolución del padecimiento y la respuesta al tratamiento.

- Sesgo: Desviación sistemática de la verdad en los resultados del estudio y que es causada por la manera en la que éste fue diseñado o conducido.

- Variables confusoras: También llamadas terceras variables, son variables que el investigador no controló o no eliminó y que dañan la validez interna de un estudio de investigación.

\section{Introducción}

\section{Cáncer de mama}

El cáncer de mama representa un problema de salud pública, ya que ocupa el primer lugar como causa de morbimortalidad en la mujer, tanto a nivel mundial como nacional ${ }^{1}$. Las tasas de incidencia varían por región y están relacionadas con diferentes causas en la aparición y ocurrencia del cáncer de mama. En América Latina, el cáncer de mama es el cáncer más frecuente, con 152,059 casos diagnosticados anualmente, una cuarta parte $(24.9 \%)$ de los casos de cáncer en mujeres. La tasa de incidencia regional es de 47.2, la cual es más alta en países del cono sur, principalmente Argentina y Uruguay, donde las tasas son semejantes a las de países desarrollados (71.2 y 69.7 defunciones por 100,000 mujeres, respectivamente). Es también la principal causa de muerte por un tumor maligno en la mujer latinoamericana, con 43,208 defunciones y tasas de mortalidad de 13, que varía de 5.0 en Guatemala a 22.6 defunciones por 100,000 mujeres en Uruguay².

En México, según cifras del Instituto Nacional de Estadística y Geografía, se reportaron 14.8 casos nuevos por cada 100,000 mujeres de 20 años o más, 
alcanzando un máximo de 68.0/100,000 en mujeres de 60 a 64 años de edad. Con respecto a la tasa de mortalidad, se reporta un alza en el periodo de 2011 a 2016; solamente en el año 2013 se registraron 5,405 defunciones en mujeres, con una tasa de 16.3 defunciones por 100,000 mujeres ${ }^{3}$. Las entidades con mayor mortalidad por cáncer de mama en 2015 fueron Chihuahua (29.9), Nuevo León (22.4), Ciudad de México (21.4), Sonora (22.6) y Nuevo León (22.4) 3 . Al estratificar por grupos de edad, la mortalidad mostró un incremento de 15.7 muertes por cada 100,000 mujeres de 40 a 49 años de edad, 28.3 de 50 a 59 años, 34.7 muertes entre los 60 y 64 años de edad y 65.3 defunciones por cada 100,000 mujeres de 80 años y más.

El cáncer de mama se origina por un crecimiento anormal y descontrolado de las células del epitelio de los conductos y lobulillos de la glándula mamaria. Se considera que tanto factores de tipo genético como ambientales pueden estar implicados en su etiología. Una minoría que va del 5 al $10 \%$ de todos los cánceres son causados por mutaciones en la línea germinal; dentro de estas alteraciones, las mutaciones de los genes $B R C A 1$ y $B R C A 2$ son las más comunes, lo cual da pautas para la prevención y el estudio molecular de esta enfermedad.

El tratamiento del cáncer de mama es complejo y debe ser multidisciplinario para ofrecer el mejor tratamiento en cada caso. Existen diferentes factores a considerar en el tratamiento del cáncer de mama, aunque el más importante es el estadio clínico; sin embargo, las consideraciones van de la mano de las características patológicas, moleculares, la determinación de los receptores hormonales, la determinación de la proteína HER2, el estado general de la paciente o el estatus de menopausia, entre muchas otras que contribuyen a la necesidad de un equipo de expertos.

\section{Medicina basada en evidencia y objetivos de la guía}

La definición actual de medicina basada en evidencia es el «uso juicioso, explícito y concienzudo de la mejor evidencia científica disponible, aunado con la mejor experiencia clínica, los valores y preferencias de los pacientes y considerando los costos para el mejor cuidado de los pacientes» ${ }^{4}$. La experiencia clínica lleva un proceso de aprendizaje e integración del conocimiento que requiere de tiempo y que se va perfeccionando progresivamente hasta obtener las habilidades diagnósticas y terapéuticas para un mejor cuidado de los pacientes ${ }^{4-6}$. La medicina basada en evidencia, sin duda, requiere de herramientas que faciliten la incorporación de todo el conocimiento científico que va surgiendo a la toma de decisiones clínicas en nuestros pacientes $^{4}$. Las RS de la literatura médica contienen protocolos de investigación explícitos, rigurosos y exhaustivos para identificar y evaluar de forma crítica, así como para sintetizar los estudios relevantes ${ }^{7}$. Después de casi cuatro décadas de desarrollar una metodología que persigue la disminuición de sesgo en las conclusiones, las RS de la literatura médica se han convertido en la piedra angular de la medicina basada en eviden$\mathrm{cia}^{4,7}$ (Fig. 1).

Al inicio de la década de 1990 se produce un impulso clave a otro instrumento que se situará como pieza clave en la medicina basada en evidencia: las GPC basadas en evidencia ${ }^{8-10}$. El reporte del IOM define las GPC como «recomendaciones desarrolladas sistemáticamente para asistir a los clínicos y los pacientes en su toma de decisiones para una mejor calidad en la atención de la salud en condiciones específicas». El objetivo primordial de las GPC es cerrar la brecha entre el conocimiento científico y la toma de decisiones por parte de profesionales de la salud y pacientes, apoyar en los procesos de educación médica, auxiliar a los desarrolladores de políticas públicas y administradores para hacer más eficiente el uso de recursos y decidir sobre las tecnologías en salud más costo-eficientes ${ }^{11-13}$ (Fig. 2).

Las GPC requieren un protocolo bien establecido para su desarrollo, así como que a la mejor evidencia disponible se incorpore la mejor experiencia clínica, los puntos de vista de los usuarios finales, entre los que se deben contemplar pacientes y cuidadores, administrativos, médicos familiares, realizadores de políticas en salud y cualquier organización que se desarrolle en el campo de la atención médica ${ }^{13-15}$.

La clasificación de la evidencia científica se llevó a cabo tomando en cuenta la clasificación desarrollada por la SIGN (Tabla 1), en la que se otorga el nivel más alto de evidencia a las RS de estudios clínicos controlados (ECA) con muy bajo riesgo de sesgo, y así va disminuyendo la calidad de la evidencia, pasando por ECA con alto riesgo de sesgo, estudios de cohortes, casos y controles hasta llegar a los estudios no analíticos, como las series de casos y los reportes de casos, y en el nivel inferior de la evidencia la opinión de los expertos ${ }^{16}$.

Los objetivos de esta GPC para el manejo del cáncer de mama se enfocaron en brindar recomendaciones basadas en evidencia para el tratamiento quirúrgico, médico y radiológico de todas las fases de la enfermedad, 


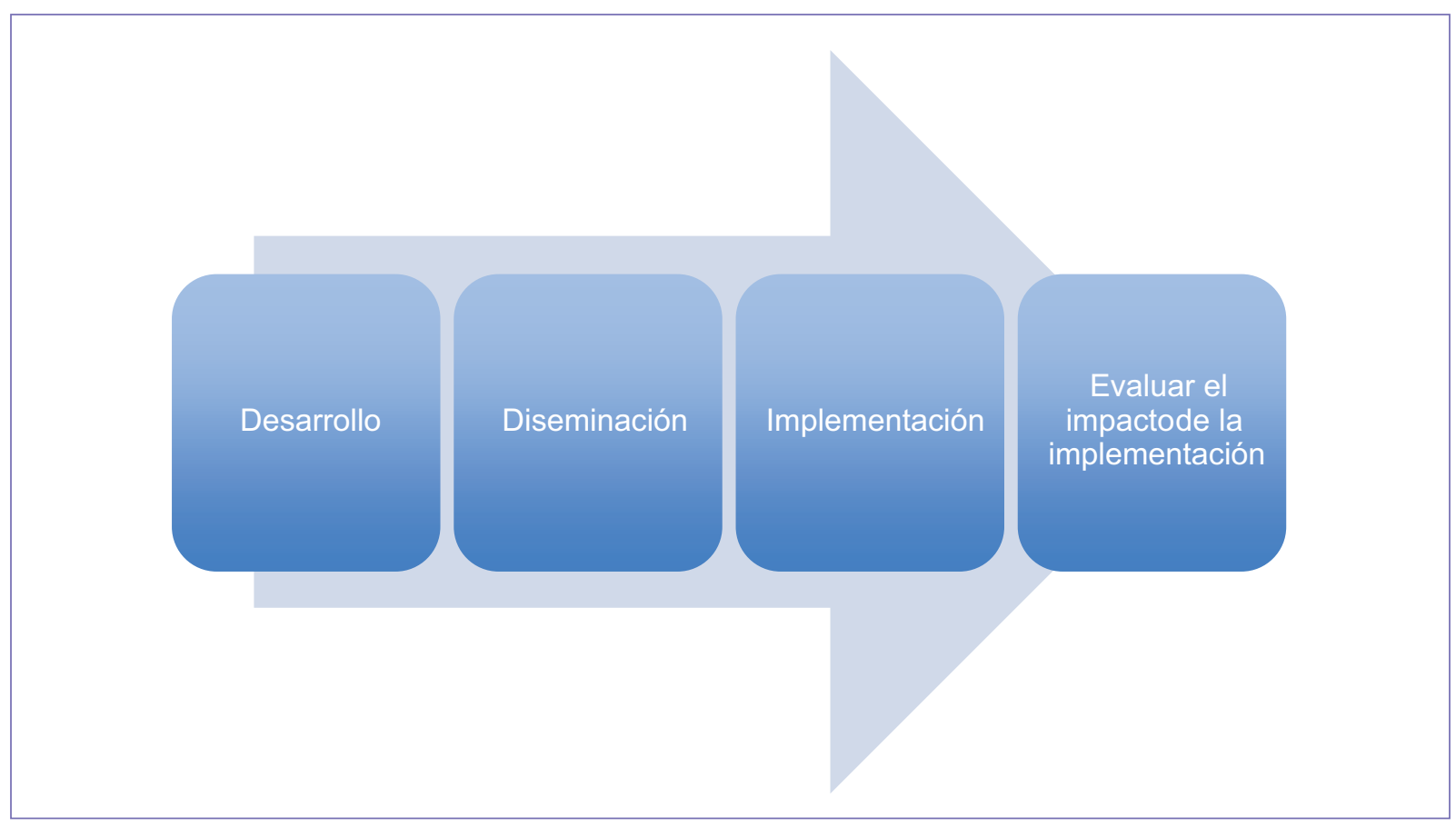

Figura 1. Ciclo de vida Guías de práctica clínica

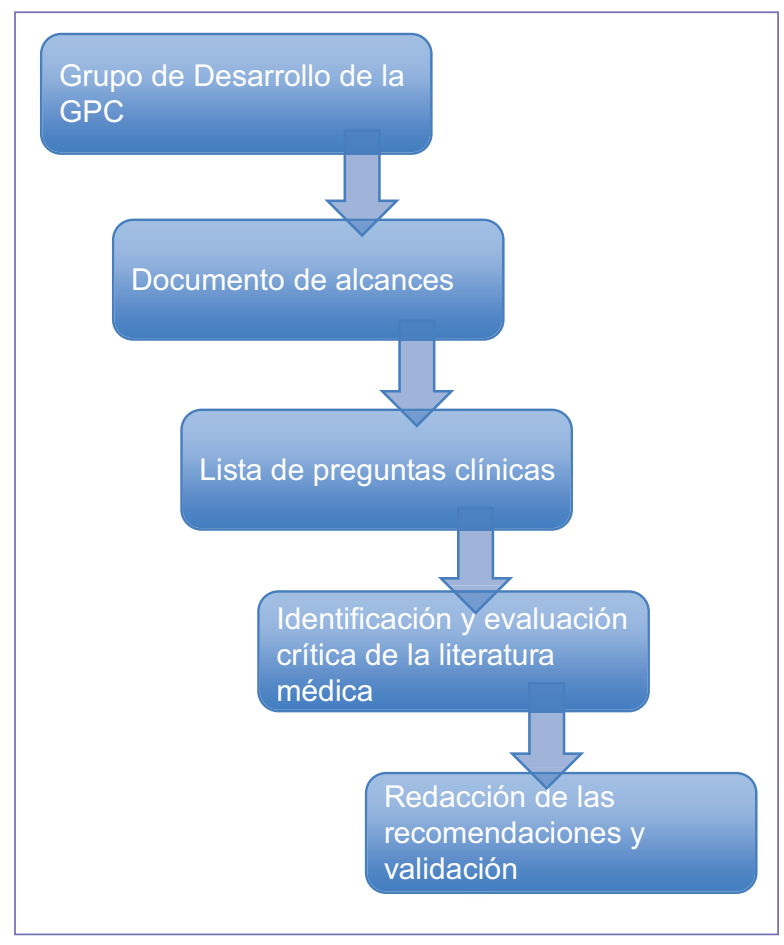

Figura 2. Diagrama de flujo. Desarrollo de la Guía de práctica clínica

con la intención de brindar más herramientas a los clínicos y de esta forma mejorar los desenlaces de las pacientes que padecen esta enfermedad tan prevalente a nivel mundial.

\section{Material y métodos}

\section{Grupo de desarrollo de la guía}

De forma interdisciplinaria se integró el GDG, compuesto por expertos clínicos en oncología médica, cirugía oncológica y radiooncología representantes de la Sociedad Mexicana de Oncología; también se incluyeron expertos metodológicos con experiencia en el desarrollo de RS de la literatura médica y GPC. Un grupo base (core group) se reunió en múltiples ocasiones para definir el modo de trabajo, los tiempos y la distribución de las responsabilidades, así como los aspectos importantes en la definición de alcances generales de la GPC y la lista de preguntas clínicas estructuradas.

\section{Definición de alcances}

El GDG llevó a cabo la definición de los alcances generales de la GPC, y se acordaron las características de la población incluida a tratar, así como también las características de la población que no se incluiría en el documento. El documento de alcances provee el marco general en el cual el trabajo de desarrollo de la 
Tabla 1. Recomendaciones clínicas, síntesis y niveles de evidencia para el carcinoma ductal in situ (CDIS)

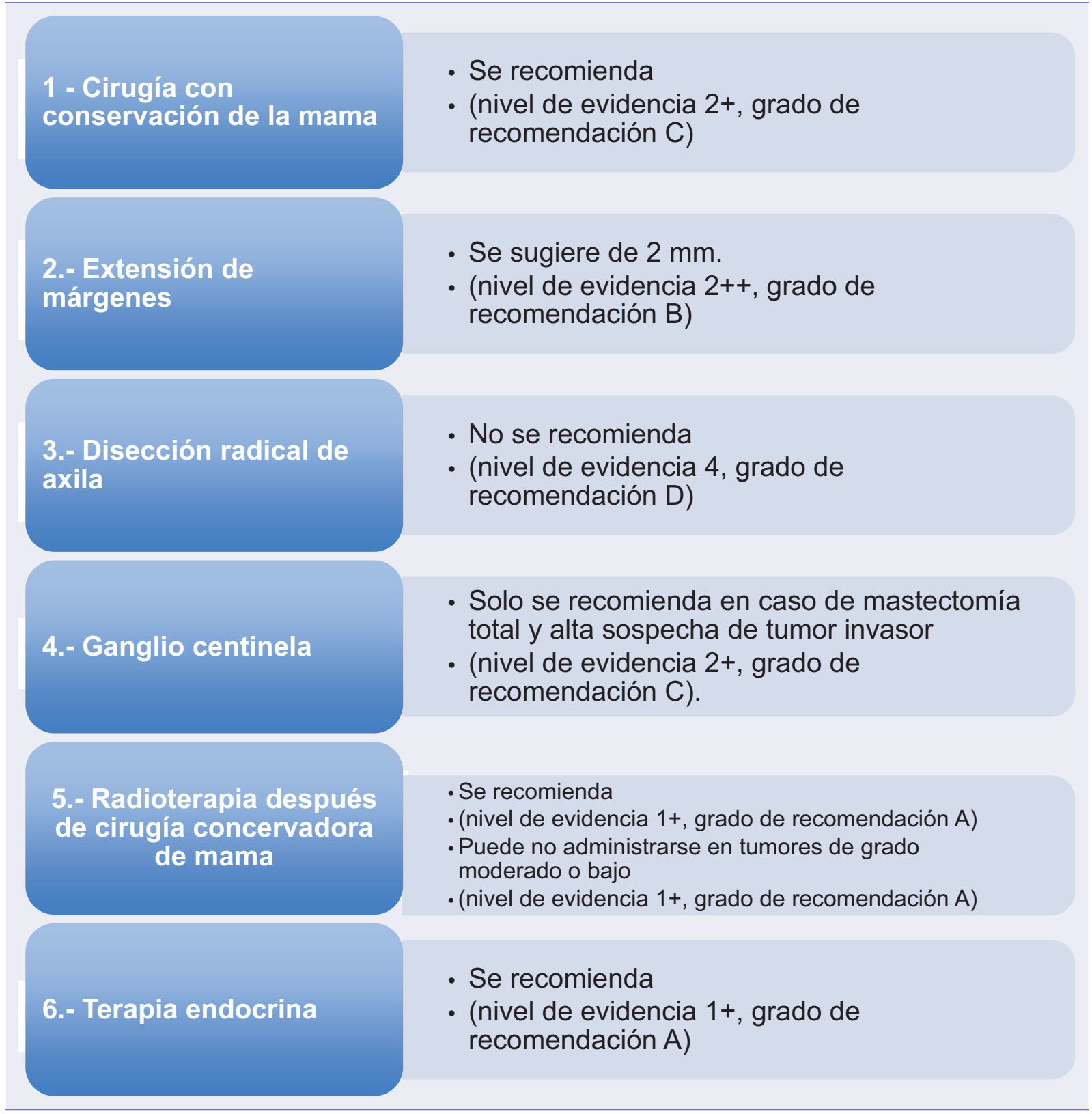

GPC se va a conducir. Describe brevemente los aspectos generales de la enfermedad y define los aspectos clínicos que la GPC va a cubrir, así como los aspectos que no serán cubiertos por la misma. De igual forma, el documento de alcances describe la audiencia blanco que se considera de interés para la GPC y a la cual se dirigen las recomendaciones clínicas (Anexo A).

Los aspectos más importantes del documento de alcances se enumeran a continuación:

- Características de la población que será incluida.

- Definición de la población que no será cubierta por la GPC.
- Escenario o escenarios clínicos en los cuales se planea que las recomendaciones de la GPC serán implementadas.

- Diferentes tipos de aspectos clínicos que serán evaluados durante el desarrollo de la GPC y en los cuales se contemplan pruebas diagnósticas, intervenciones médicas, intervenciones quirúrgicas, entre otras.

- Información específica para los usuarios.

- Desenlaces clínicos que serán considerados para evaluar las distintas intervenciones terapéuticas y diagnósticas.

- Aspectos en los cuales la GPC se espera que contribuirá para el manejo de la enfermedad. 


\section{Preguntas clínicas estructuradas}

El GDG, una vez que acordó el contenido del documento de alcances, prosiguió a desarrollar la lista de preguntas clínicas estructuradas.

El objetivo de esta fase fue elaborar el listado completo de preguntas clínicas que desarrollen el tema para abordar la guía. La respuesta a estas preguntas originará recomendaciones para los usuarios de la GPC. Se aseguró que las preguntas clínicas abordaran brechas en el conocimiento y temas clínicos relevantes de acuerdo a los miembros del GDG. Todos los problemas clínicos definidos en el alcance de la guía se vieron reflejados en esta etapa a través de las preguntas clínicas, para garantizar así que la GPC se desarrollara conforme a los objetivos planteados. Por tanto, se intentó que las preguntas clínicas fueran claras, precisas y específicas para facilitar la búsqueda y la revisión de la evidencia científica, y así evitar recomendaciones poco ajustadas a los problemas clínicos que plantea la GPC (Anexo B).

El listado de preguntas contempló la población, las intervenciones y los comparadores estipulados en el documento de alcances. El GDG evitó introducir aspectos nuevos que no estaban incluidos en el alcance de la guía.

Se consideró el esquema Población, Interveción, Comparador y Outcome (PICO), y de acuerdo a éste se tomaron en cuenta los siguientes componentes:

- Paciente: grupos de edad, estadio de la enfermedad, comorbilidad, etc.

- Intervención: intervención, factor pronóstico, agente etiológico, prueba diagnóstica, tratamiento habitual o placebo, ausencia de un factor de riesgo, ausencia de agente etiológico, patrón de oro o de referencia de una prueba diagnóstica, etc.

- Comparación: se refiere a la alternativa a la intervención a estudio, tales como tratamiento habitual o placebo, ausencia de un factor de riesgo, ausencia de agente etiológico, patrón de oro o de referencia de una prueba diagnóstica, etc.

- Desenlaces (outcomes): variables de resultado clínicamente importantes en el caso de estudios sobre eficacia, pronóstico o etiología, y estimadores de rendimiento o validez.

\section{Búsqueda exhaustiva de la evidencia científica}

La evidencia fue identificada siguiendo algoritmos y estrategias validadas internacionalmente. Se identificaron y emplearon términos MeSH (Medical Subject
Headings) para de esta forma ensamblar una estrategia de búsqueda sensible y específica, además de explícita para que sea reproducible en un futuro ${ }^{5}$. De acuerdo a la naturaleza de la pregunta clínica a responder, se estableció el tipo de estudio que fuera más confiable para contestarla, y partiendo de ahí, otros tipos de estudio que pudieran responderla aunque con menos confianza en los resultados, siguiendo los modelos de clasificación de la evidencia. Entre estos criterios se consideraron las variables de desenlaces importantes para clínicos y pacientes, y seleccionar el diseño de estudio más adecuado en función de la pregunta que se debe responder (Anexo $\mathrm{C}$ ).

La búsqueda se llevó a cabo a partir de las preguntas clínicas estructuradas. La revisión bibliográfica preliminar incluyó la localización de GPC relevantes que ya existían sobre el mismo tema. Esto permitió facilitar el ensamblaje del documento de alcances y la identificación de preguntas clínicas relevantes sobre el tema. Además, esto nos ayudó en la identificación, la evaluación y la síntesis de la evidencia científica.

Las RS juegan un papel crucial en el proceso de elaboración de una GPC. Los estándares internacionales actuales proponen la utilización de las RS como las herramientas indispensables para la localización y selección de la evidencia científica que alimente las recomendaciones clínicas. Dependiendo del tipo de pregunta clínica, será el tipo más adecuado de estudio clínico para responderla y, de ahí, para formar una conclusión y formular recomendaciones clínicas (Anexo C).

Una vez que los elementos de la búsqueda y selección fueron claramente definidos, se seleccionaron las bases de datos en función del tipo de publicación que se quiere buscar y el tema objeto de cada pregunta clínica. Para el resto de publicaciones (RS o estudios originales), las bases de datos bibliográficas son las herramientas idóneas para recuperar información, al agrupar conjuntos de referencias de documentos almacenadas electrónicamente y que se pueden buscar y seleccionar de manera interactiva a través de un lenguaje de consulta o interrogación.

Las bases de datos que recopilan GPC fueron consultadas usando los términos MeSH. Las distintas bases de datos que fueron consultadas para localizar las distintas GPC publicadas y relevantes para nuestra GPC se enumeran a continuación:

- Organismos recopiladores: el más completo es el National Guideline Clearinghouse ("Centro Nacional de Guías») de EE.UU., de cobertura internacional, perteneciente a la Agency for Health Research and 
Quality («Agencia para la Investigación y la Calidad en Salud»). En el Reino Unido destaca el Guidelines Finder National Electronic Library for Health («Localizador de Guías de la Biblioteca Electrónica Nacional de Salud»). El catálogo de guías realizadas en España se recoge en Guiasalud. La base de datos Trip Database es un motor de búsqueda útil que ofrece una idea rápida del volumen de GPC existentes. Se consultaron también las bases de datos de las principales sociedades y academias del área de especialidad a nivel internacional en búsqueda de GPC publicadas.

- Organismos elaboradores: NICE, SIGN, Institute for Clinical System Improvement («Instituto para la Mejora de los Sistemas Clínicos») en EE.UU., National Health and Medical Research Council («Consejo Nacional de Salud e Investigación Médica») de Australia y New Zealand Guidelines Group («Grupo sobre Guías de Nueva Zelanda»).

- Centros de metodología: destacan por su interés el GIN, la colaboración AGREE y el GRADE Working Group como grupo de trabajo que desarrolla el sistema emergente GRADE: bases de datos generales. En bases como Medline se indexan también GPC y existen filtros que se pueden aplicar en las búsquedas; no obstante, no es la forma más eficiente de localizarlas. Para la búsqueda exhaustiva de RS se ensamblaron diferentes estrategias de búsquedas y se utilizaron distintas bases de datos generales y especializadas en RS. Se emplearon estrategias de búsquedas publicadas y validadas que han demostrado ser sensibles y especíicas, así como los términos MeSH.

Las bases de datos consultadas para identificar RS se enumeran a continuación: Cochrane Library (contiene RS de ECA de alta calidad, independientes y confiables para ser incluidas en el cuerpo de evidencia), Best practice, The Campbell Collaboration Library of Systematic Reviews, Centre for Reviews and Dissemination databases (incluido DARE), Centre for Reviews and Dissemination, National Institute for Health Research (Reino Unido), Database of Promoting Health Effectiveness Reviews The Database of Promoting Health Effectiveness Reviews, TripDatabase, The Evidence for Policy and Practice Information and Co-ordinating Centre, Medline, PubMed (biblioteca nacional de medicina en los EE.UU.), Scopus Large international y Embase a través de OVID, NICE y National Institute for Health Research del Reino Unido para identificar HTA de alta calidad.

Solamente en los casos en los que las preguntas clínicas no encontraron una RS de la literatura médica para ser respondidas o las GPC no hubieran identificado evidencia científica de alta calidad, se llevaron a cabo búsquedas exhaustivas de la bibliografía para identificar estudios clínicos que respondieran a esa pregunta.

Las bases de datos que se consultaron para identificar estudios clínicos publicados fueron: The Cochrane Library hasta 2017, Cochrane Central Register of Controlled Trials, Cochrane Database of Systematic Reviews y Database of Abstracts of Reviews of Effects (Issue 1 2017), Medline 1950-2017 (OVID), Embase 1980-2017 (OVID), Cinahl 1982-2017 (NLH Search 2.0), Health Economic and Evaluations Database hasta 2017, Cumulative Index to Nursing y Allied Health Literature (de 1982 a 2017), LILACS (de 1998 a 2017), ARTEMISA (de 1999 a 2017) y Scielo (de 1999 a 2017).

\section{Evaluación de calidad y jerarquización de la evidencia}

Se emplearon herramientas diseñadas y validadas internacionalmente para evaluar la calidad de la evidencia científica considerando el tipo de documento evaluado. En el caso de las GPC se empleó la herramienta AGREE II (The Appraisal of Guidelines for Research \& Evaluation), que fue diseñada para evaluar la calidad metodológica y variabilidad de las GPC. En el caso de las RS de la literatura médica se empleó la herramienta AMSTAR II (Assessing the Methodological Quality of Systematic Reviews). Para el caso en el que se condujo una RS de estudios clínicos se utilizaron las siguientes herramientas validadas: CONSORT (Consolidated Standards of Reporting Trials) («Lineamientos para Estudios Clínicos Controlados»), MOOSE (Meta-analysis Of Observational Studies in Epidemiology), QUADAS (Quality Assessment of Diagnostic Accuracy Studies) para estudios de prueba diagnóstica y STROBE (Strengthening the Reporting of Observational Studies in Epidemiology) para estudios observacionales (Tabla 2).

Cada una de estas herramientas califica distintos rubros y usa diferentes escalas. Se emplearon de manera individual y calificadas por pares, con un tercer evaluador en caso de que hubiera poca concordancia entre los revisores.

Se han publicado una gran cantidad de clasificaciones para evaluar la calidad de la evidencia, pero nosotros decidimos por consenso utilizar la escala desarrollada por SIGN, la cual utiliza dos atributos para evaluar la calidad de la evidencia científica (nivel de evidencia): el diseño del estudio y el riesgo de sesgo. Para la clasificación del diseño del estudio se utilizan los números del 


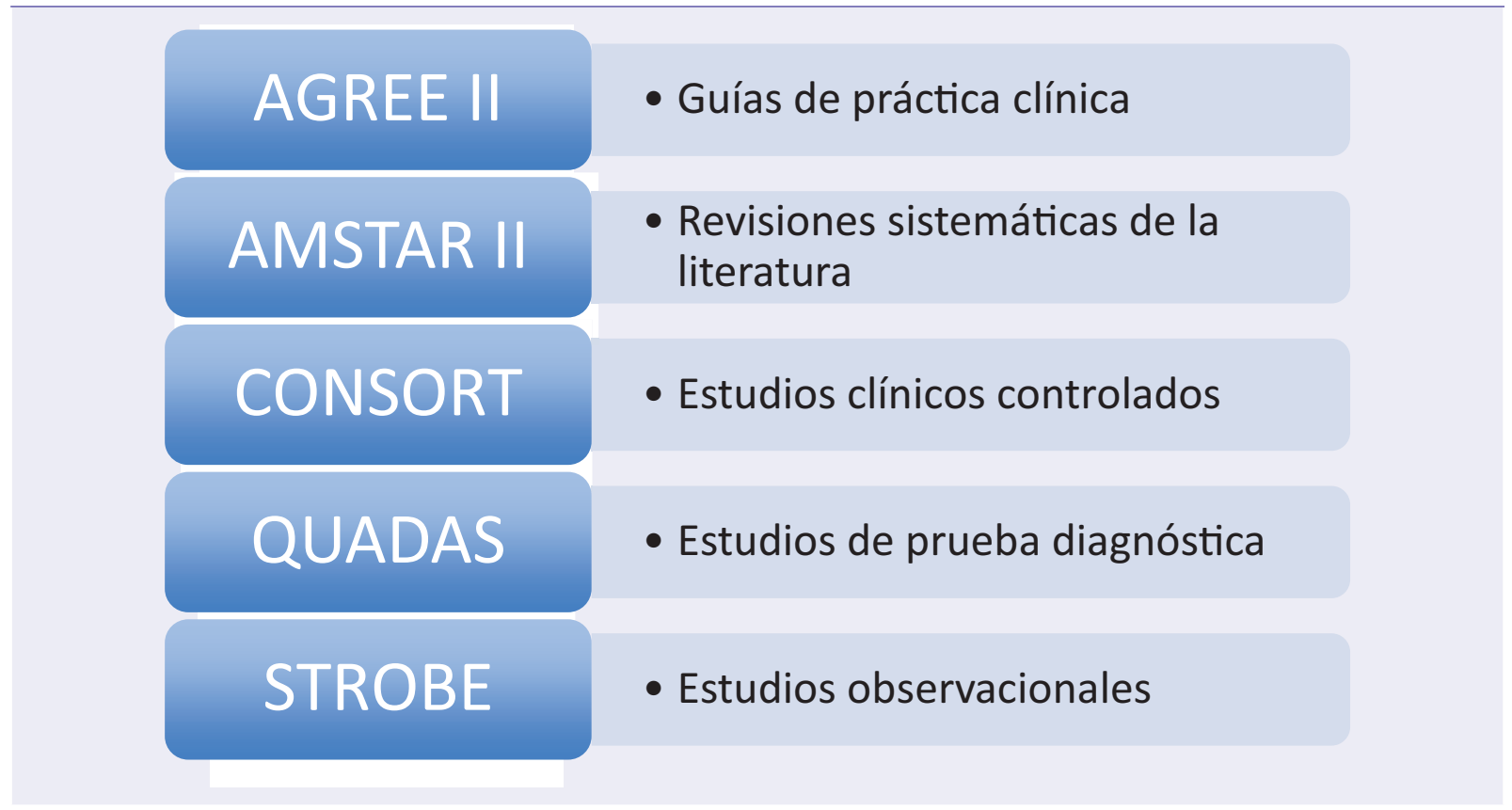

En el caso de las GPC se empleó la herramienta AGREE II (The Appraisal of Guidelines for Research \& Evaluation), para las revisiones sistemáticas de la literatura se empleó la herramienta AMSTAR II (assessing the methodological quality of systematic reviews), CONSORT (Consolidated Standards of Reporting Trials) son lineamientos de reporte para estudios clínicos controlados, QUADAS (Quality Assessment of Diagnostic Accuracy Studies) para estudios de prueba diagnóstica y STROBE (Strengthening the Reporting of Observational Studies in Epidemiology) para estudios observacionales (Tomado de http://www.equator-network.org).

1 al 4. El número 1 corresponde a ensayos clínicos o a RS de estos ensayos, y el 4 a la opinión de expertos. Para evaluar el riesgo de sesgo se utilizan signos que informan sobre el grado de cumplimiento de los criterios clave relacionados con ese potencial riesgo $(++,+\mathrm{y}-)$. De esta forma, con la ayuda de la plantilla de lectura crítica se evalúa cada estudio, ya sean estudios individuales (ECA, cohortes, etc.) o RS. Esta valoración de la calidad de la evidencia científica de los diferentes estudios disponibles para responder a las preguntas formuladas será posteriormente utilizada en la graduación de la fuerza de las recomendaciones (Tabla 1).

\section{Extracción de la evidencia y análisis}

Las GPC preferentemente tienen que incorporar RS para sostener las recomendaciones clínicas. Una vez que las RS fueron evaluadas en su calidad e incorporadas al cuerpo de evidencia científica, se llevaron a cabo reuniones con el GDG para revisar el texto completo de cada una de ellas para poder extraer los resultados. Se consideraron las medidas de asociación resultado de los metaanálisis reportados en las mismas para determinar el tamaño del efecto global, ya fuere de la razón de momios (odds ratio [OR]), el riesgo relativo (relative risk [RR]) o la diferencia de los promedios ponderados de los efectos (weighted mean estimate of the effect) de acuerdo a los distintos desenlaces definidos por el GDG. Para estudios de prueba diagnóstica es importante considerar otras medidas de asociación, tales como la sensibilidad, la especificidad y los valores predictivos positivos y predictivos negativos.

En los casos de las preguntas clínicas para las cuales no se encontraron RS publicadas de buena calidad, se llevó a cabo la RS para identificar estudios clínicos. Una vez realizada la evaluación de calidad y de posibilidad de sesgo, se llevó a cabo el metaanálisis.

Lo primero que se hizo fue definir la naturaleza de los valores de acuerdo al tipo de desenlace a estudiar. Una vez extraídas las medidas de asociación, se determinó el grado de hererogeneidad entre los resultados de los estudios, para lo cual se utilizó la prueba $Q$ de Der Simonian y Laird. Una vez demostrada que la heterogeneidad no es significativa, se llevó a cabo el metaanálisis bajo el modelo de efectos fijos, cuando se asumió que no existía heterogeneidad entre los estudios incluidos en la revisión, y el modelo de efectos aleatorios, cuando se asumió que los estudios incluidos en la revisión constituían una muestra aleatoria de todos los estudios existentes. En los casos pertinentes, se presenta la información en una gráfica de forest plot, en la que se pretendió mostrar el efecto 
Tabla 2 A. Recomendaciones Clínicas, síntesis y niveles de evidencia para el cáncer de mama temprano.

\begin{tabular}{|c|c|}
\hline 7 - Cirugía & $\begin{array}{l}\text { - Se recomienda la cirugía conservadora de } \\
\text { mama } \\
\text { - (nivel de recomendación } 2++, \text { grado de } \\
\text { recomendación B) }\end{array}$ \\
\hline $\begin{array}{l}\text { 8.- Margen quirúrgico en } \\
\text { pacientes con cirugía } \\
\text { conservadora de mama }\end{array}$ & $\begin{array}{l}\text { - Se recomienda lograr ausencia de células } \\
\text { tumorales (tinta con la que se tiñe la pieza } \\
\text { quirúrgica) } \\
\text {-(nivel de evidencia } 1++, \text { grado de recomendación } \\
\text { A). }\end{array}$ \\
\hline $\begin{array}{l}\text { 9.- Disección radical } \\
\text { axilar }\end{array}$ & $\begin{array}{l}\text { - Se recomienda en casos seleccionados } \\
\text { - (nivel de evidencia } 1+, \text { grado de } \\
\text { recomendación } \mathrm{A} \text { ) }\end{array}$ \\
\hline 10.- Ganglio centinela & $\begin{array}{l}\text { - Se recomienda en aquellas mujeres con cáncer } \\
\text { de mama tremprano y axila clínicamente negativa } \\
\text {-(nivel de evidencia } 1++ \text {, grado de recomendación } \\
\text { A). }\end{array}$ \\
\hline $\begin{array}{l}\text { 11.- Disección Radical } \\
\text { Axilar con BGC negativo }\end{array}$ & $\begin{array}{l}\text { - No se recomienda en pacientes cuyo resultado de } \\
\text { patologia de BGC sea negativo para metástasis } \\
\text {-(nivel de evidencia } 1++ \text {, grado de recomendación } \\
\text { A) }\end{array}$ \\
\hline $\begin{array}{l}\text { 12.- Mastectomía reductora } \\
\text { de riesgo contralateral }\end{array}$ & $\begin{array}{l}\text { - No se recomienda } \\
\text { - (nivel de evidencia 3, grado de } \\
\text { recomendación C) }\end{array}$ \\
\hline $\begin{array}{l}\text { 13.- Mastectomía } \\
\text { reductora de riesgo con } \\
\text { mutación BRCA10 } \\
\text { BRCA2 }\end{array}$ & $\begin{array}{l}\text { - Si se recomienda } \\
\text { - (nivel de evidencia } 2+\text {, grado de } \\
\text { recomendación } B \text { ) }\end{array}$ \\
\hline
\end{tabular}

estimado en cada estudio junto con el valor obtenido combinando los resultados de todos los estudios, acompañados por sus respectivos intervalos de confianza (IC). La gráfica también contiene la línea vertical del valor correspondiente a la ausencia de efectos (RR = 1 o diferencia de medias $=0$ ) y los límites de relevancia clínica, determinando si las diferencias, además de alcanzar significancia estadística, son de una magnitud relevante.

\section{Consenso formal de expertos}

El método Delphi de consenso formal es el recomendado en el escenario de desarrollo de una GPC. Es un método sistemático, interactivo, iterativo y que se basa 
TABLA 2B. Recomendaciones Clínicas, síntesis y niveles de evidencia para el cáncer de mama temprano.

\begin{tabular}{|c|c|}
\hline $\begin{array}{l}14 \text { - Radiación parcial } \\
\text { acelerada (RPA) vs. } \\
\text { radioterapia externa a } \\
\text { toda la mama }\end{array}$ & $\begin{array}{l}\text { - Se recomienda la radioterapia externa a toda la } \\
\text { mama en pacientes que fueron llevadas a cirugía } \\
\text { conservadora de mama } \\
\text { - (nivel de evidencia } 1++ \text {, grado de recomendación A) }\end{array}$ \\
\hline $\begin{array}{l}\text { 15.- Sobreimpresión de } \\
\text { radiación (boost) al lecho } \\
\text { quirúrgico }\end{array}$ & $\begin{array}{l}\text { - Se sugiere } \\
\text { (nivel de evidencia } 1+, \text { grado de } \\
\text { recomendación } A) \text {. }\end{array}$ \\
\hline $\begin{array}{l}\text { 16.- Herramientas (firmas } \\
\text { genómicas y plataformas } \\
\text { electrónicas) de } \\
\text { estratificación de riesgo }\end{array}$ & $\begin{array}{l}\text { - Se recomienda el uso de pruebas validadas } \\
\text { (nivel de evidencia } 2++ \text {, grado de } \\
\text { recomendación B) }\end{array}$ \\
\hline $\begin{array}{l}\text { 17.- Terapia endocrina en } \\
\text { pacientes } \\
\text { posmenopáusicas }\end{array}$ & $\begin{array}{l}\text { - Se recomienda el uso de Inhibidores de } \\
\text { aromatasa } \\
\text { - (nivel de evidencia } 1++, \text { grado de } \\
\text { recomendación A) }\end{array}$ \\
\hline $\begin{array}{l}\text { 18.- Supresión ovárica } \\
\text { adyuvante sumada a la } \\
\text { terapia endocrina } \\
\text { estándar en pacientes } \\
\text { premenopáusicas }\end{array}$ & $\begin{array}{l}\text { - Se recomienda el uso de terapia endocrina, con } \\
\text { un inhibidor de aromatasa más supresión ovárica } \\
\text { con agonistas de LHRH } \\
\text { - (nivel de evidencia } 1++ \text {, grado de recomendación } \\
\text { A) }\end{array}$ \\
\hline $\begin{array}{l}\text { 19.- Supresión ovárica en } \\
\text { pacientes } \\
\text { premenopáusicas } \\
\text { receptores hormonales } \\
\text { positivos }\end{array}$ & $\begin{array}{l}\text { - Se recomienda exemestano combinado con } \\
\text { supresión ovárica } \\
\text { - (nivel de evidencia } 1++, \text { grado de } \\
\text { recomendación } \mathrm{A} \text { ) }\end{array}$ \\
\hline $\begin{array}{l}\text { 20.- Tratamiento } \\
\text { endocrino extendido }\end{array}$ & $\begin{array}{l}\text { - Se recomienda en pacientes con alto riesgo: } \\
\text { >T3 y/o ganglios positivos } \\
\text { - (nivel de evidencia } 1++, \text { grado de } \\
\text { recomendación A) }\end{array}$ \\
\hline
\end{tabular}

en la reunión de un grupo de expertos. Cada uno de los expertos contesta unas preguntas, las cuales pueden ser ajustadas de acuerdo a las respuestas en distintas rondas posteriores. En cada una de estas rondas de preguntas y respuestas, a las cuales se les puede dar un carácter cualitativo y/o cuantitativo, un grupo más reducido perteneciente al GDG, en el que se encuentran los coordinadores generales y los coordinadores metodológicos de la GPC, lleva a cabo la integración de las respuestas de todos los expertos de la ronda previa y hace el ajuste del texto para mejorar el porcentaje de común acuerdo. Es deseable que los expertos revisen su respuesta previa y consideren la nueva respuesta para dirigirse a un porcentaje más alto de acuerdo. Finalmente, el proceso se detiene cuando se alcanza un grado mínimo de consenso entre los expertos. 
Tabla 2C. Recomendaciones clínicas, síntesis y niveles de evidencia para el cáncer de mama temprano.

\section{1 - Bisfosfonatos en \\ las pacientes que \\ reciben inhibidores de \\ aromatasa adyuvante}

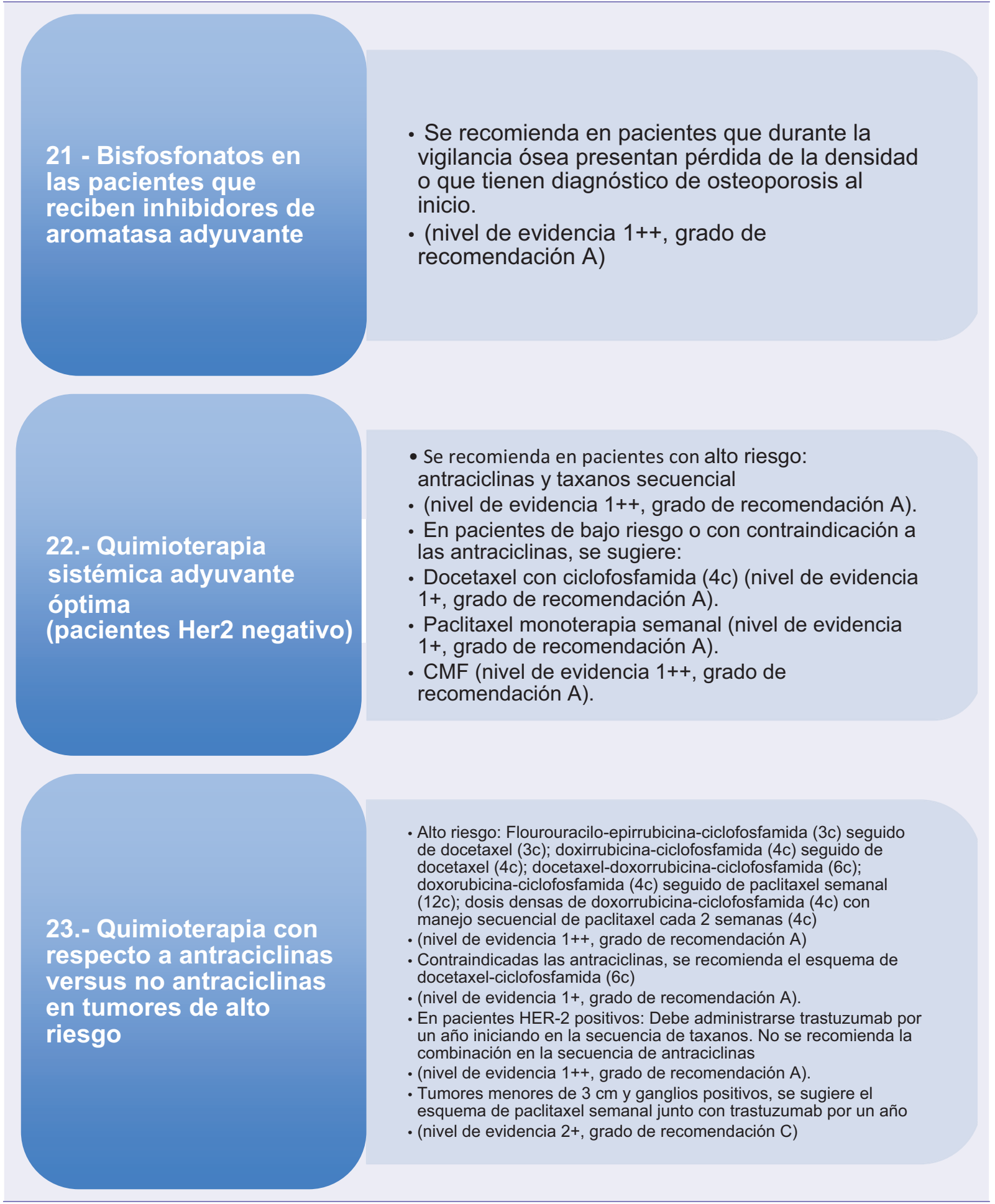

Los coordinadores del GDG establecieron un grupo nuclear (core group) que trabajó de cerca cada uno de los documentos y pasos clave en el desarrollo de esta GPC. De igual forma, los coordinares metodológicos apoyaron durante todo el proceso. Las recomendaciones clínicas fueron redactadas y propuestas por el grupo nuclear en base a la evidencia científica identificada, evaluada, extraída y sintetizada. La estructura que se le dio a la información permitió que las contribuciones de los expertos fueran consensuadas y recogidas de manera que se pudieran desarrollar los textos que se exponen a consideración al resto del GDG. El grupo 
nuclear llevó el control de la interacción entre los participantes procesando la información y filtrando el contenido relevante. Esto nos permitió reducir de manera importante el efecto negativo de las discusiones cara a cara entre los expertos y resolvió los problemas que se observan en las dinámicas de grupo habitualmente.

Una vez que los miembros del GDG han revisado la redacción de las recomendaciones clínicas y la evidencia científica identificada y evaluada en su calidad, determinarán el grado de acuerdo en el texto utilizando una escala de Likert. La escala de Likert empleada va del 1 al 9 , en la que el número 1 determina que el experto está «Totalmente en desacuerdo» con el planteamiento de la recomendación y el número 9 determina que el experto está «Totalmente de acuerdo» con la misma. Los números intermedios manifiestan que el experto no tiene una postura en el planteamiento o la redacción de la recomendación.

Internacionalmente, se ha definido el $70 \%$ como un porcentaje mínimo deseable de acuerdo entre los expertos participantes en un panel Delphi. Cuando al menos el $70 \%$ de los expertos han manifestado estar de acuerdo con la recomendación clínica (calificación entre 7 y 9), se considera que se ha llegado a un consenso. Además de evaluar el porcentaje de expertos que califican la recomendación, se llevó a cabo el cálculo de las medidas de tendencia central y de dispersión. Se calculó la media, mediana, moda, desviación estándar y recorrido de los rangos intercuartiles. Se estableció un mínimo de 7.0 en la media como criterio para alcanzar un grado mínimo de consenso. Se empleó un sistema electrónico anónimo para que los integrantes del GDG calificaran cada recomendación de manera anónima permitiéndonos obtener la estadística de las mismas en tiempo real.

\section{Redacción de las recomendaciones}

Los miembros del GDG nuclear se reunieron en diversas ocasiones para revisar el cúmulo de evidencia que responde a las preguntas clínicas estructuradas y, de acuerdo al nivel de evidencia, poder determinar el grado de recomendación y la redacción de las mismas. Las recomendaciones clínicas deben proveer guía para los tomadores de decisión, es por ello que el GDG tuvo cuidado en que la redacción de las mismas evitara ambigüedades en el momento de la redacción. Se tomó en cuenta la evidencia científica, pero el GDG también consideró su experiencia clínica en la redacción de las recomendaciones. Las recomendaciones consideraron también la relación riesgo-beneficio para establecer la toma de decisiones.

\section{Programa de involucramiento de los pacientes}

La importancia de recabar los valores y preferencias de los pacientes durante el desarrollo de una GPC es cada vez más patente en la literatura médica internacional. Cada vez más organizaciones internacionales elaboran programas para facilitar el involucramiento de los pacientes en el proceso de desarrollo de ésta. La Sociedad Mexicana de Oncología, comprometida por mejorar la calidad de la atención clínica en todos los padecimientos oncológicos, hizo extensiva la invitación a participar en el desarrollo de la GPC a una de las asociaciones de pacientes con mayor trayectoria en el manejo de padecimientos oncológicos. Se solicitó que la asociación propusiera un grupo de representantes para validar y proponer modificaciones en las recomendaciones clínicas y el documento final. Los pacientes fueron parte de las mesas de discusión, junto con los expertos clínicos, durante el desarrollo de la GPC.

\section{Recomendaciones clínicas y evidencia científica}

La siguiente sección presenta las recomendaciones que se hacen con respecto a los tópicos mencionados previamente.

\section{Cuerpo de la evidencia}

Se llevaron a cabo búsquedas para identificar GPC en las bases de datos descritas anteriormente. Además, se llevaron a cabo 25 estrategias de búsqueda exhaustiva de la literatura médica en PubMed y Embase (Anexo C) para identificar RS de la bibliografía con o sin metaanálisis de acuerdo a estrategias validadas internacionalmente. Se elaboró un diagrama de flujo de los estudios que se encontraron y los cuales fueron eliminados en la primera ronda de revisión (Fig. 3).

\section{Recomendaciones clínicas}

\section{Carcinoma ductal in situ}

Pregunta Clínica 1. ¿Cuál es el beneficio de la CIRUGía CON CONSERVACIÓN DE LA MAMA EN COMPARACIÓN CON OTROS TRATAMIENTOS EN PACIENTES CON CARCINOMA DUCTAL IN SITU?

Recomendación. La evidencia de estudios observacionales recomienda que la cirugía conservadora 
24 - Cirugía

conservadora de mama posterior a

neoadyuvancia
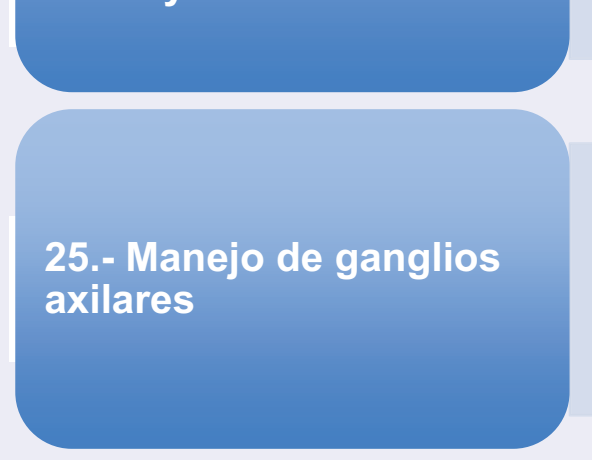

\section{6.- Radiación}

locoregional comparado con radiación completa a mama
- Si se sugiere en pacientes bien seleccionados

- (nivel de evidencia 4, grado de recomendación $\mathrm{D}$ ).

- Se sugiere en casos con ganglios linfáticos positivos cN2 o cN3 previo al tratamiento neoadyuvante.

- (nivel de evidencia 2+, grado de recomendación C).

- En casos con cN1 o N0 positiva o ganglio centinela previo al tratamiento, dependerá de respuesta.

-(nivel de evidencia 2+, grado de recomendación C).

- Se recomienda radiación a pared torácica y áreas ganglionares ipsilaterales.

- (nivel de evidencia 1++, grado de recomendación $\mathrm{A}$ )

27.- Radioterapia en

pacientes con respuesta patológica completa a la terapia neoadyuvante
- Se sugiere radiación a mama o pared torácica y áreas ganglionares ipsilaterales.

- (nivel de evidencia 3, grado de recomendación $\mathrm{D}$ ).

\section{8.- Quimioterapia \\ adyuvante en pacientes \\ con enfermedad residual \\ patologica posterior a \\ quimioterapia \\ neoadyuvante con \\ antraciclinas y taxanos}

- No se sugiere el uso de quimioterapia adyuvante posterior al manejo con neoadyuvancia.

- (nivel de evidencia 4, grado de recomendación $\mathrm{D}$ ) debe ofrecerse con radioterapia y la mastectomía puede considerarse en algunas pacientes. Nivel de evidencia 2+, grado de recomendación $\mathbf{C}$.

Revisión de la literatura médica y análisis. No hay estudios aleatorios que comparen la cirugía conservadora con la mastectomía total. Sin embargo, en el estudio NSABP B-06, un análisis de subgrupos en pacientes con carcinoma ductal in situ (CDIS) encontró una tendencia a una mayor tasa de recurrencia ipsilateral en pacientes que recibieron cirugía conservadora de mama (CCM) sola (9/21 43\%]), en comparación con aquéllas que recibieron cirugía conservadora y radioterapia $(2 / 277 \%])$ o mastectomía $(0 / 280 \%])^{17}$. Aunque la mastectomía logra reducir la recurrencia tumoral ipsilateral (RTI) en menos del 1\%, se considera un tratamiento agresivo. En un estudio observacional de 
Tabla 3B. Recomendaciones clínicas, síntesis y niveles de evidencia para el cáncer de mama localmente avanzado.

\begin{tabular}{|c|c|}
\hline $\begin{array}{l}29 \text { - Cirugía } \\
\text { Conservadora de mama } \\
\text { vs la mastectomía en } \\
\text { pacientes con buena } \\
\text { respuesta a } \\
\text { quimioterapia } \\
\text { neoadyuvante }\end{array}$ & $\begin{array}{l}\text { - Si se sugiere el manejo con Cirugía } \\
\text { Conservadora de la mama. } \\
\text { - (nivel de evidencia } 2+\text {, grado de } \\
\text { recomendación C). }\end{array}$ \\
\hline $\begin{array}{l}\text { 30.- Terapia anti-HER2 en } \\
\text { el tratamiento } \\
\text { neoadyuvante con } \\
\text { sobreexpresión de Her2 }\end{array}$ & $\begin{array}{l}\text { - Se recomienda: Trastuzumab con quimioterapia (nivel de } \\
\text { evidencia 1++, A), Pertuzumab con trastuzumab con } \\
\text { quimioterapia (nivel de evidencia 1+, grado de } \\
\text { recomendación A) } \\
\text { - No se recomienda el uso de lapatinib (nivel de evidencia } \\
1++, \text { grado de recomendación A), ni la terapia de antiHER2 } \\
\text { con antraciclinas (nivel de evidencia } 1++, \text { grado de } \\
\text { recomendación A) }\end{array}$ \\
\hline $\begin{array}{l}\text { 31.- Neoadyuvancia } \\
\text { sistémica con } \\
\text { quimioterapia }\end{array}$ & $\begin{array}{l}\text { - La neoadyuvancia sistémica se recomienda } \\
\text { en pacientes con cáncer de mama } \\
\text { localmente avanzado. } \\
\text { - (nivel de evidencia } 1+\text {, grado de } \\
\text { recomendación } \mathrm{A} \text { ) }\end{array}$ \\
\hline $\begin{array}{l}\text { 32.- Neoadyuvancia } \\
\text { sistémica con terapia } \\
\text { endocrina en pacientes } \\
\text { RH-, HER2- }\end{array}$ & $\begin{array}{l}\text { - Se sugiere el uso de Inhibidores de aromatasa sobre } \\
\text { tamoxifeno, donde se ha visto mayo beneficio en } \\
\text { pacientes postmenopáusicas con expresión de } \\
\text { receptores de estrógeno } \\
\text {-(nivel de evidencia 1+, grado de recomendación A) }\end{array}$ \\
\hline $\begin{array}{l}\text { 33.- Estrategia quirúrgica } \\
\text { de manejo en recurrencia } \\
\text { local ipsilateral en } \\
\text { pacientes con cirugía } \\
\text { conservadora previa }\end{array}$ & $\begin{array}{l}\text { - Se sugiere realizar la mastectomía al } \\
\text { presentarse la recurrencia ipsilateral. } \\
\text { - (nivel de evidencia } 3, \text { grado de } \\
\text { recomendación } C \text { ) }\end{array}$ \\
\hline
\end{tabular}

108,196 pacientes con CDIS, la comparación de la cirugía conservadora (con o sin radioterapia) frente a la mastectomía demostró una mortalidad relacionada con el cáncer a 10 años similar (hazard ratio [HR]: 1.2; IC 95\%: 0.96-1.50; $p=0.11$ ), así como una reducción del riesgo de recurrencia ipsilateral a 10 años del 1.3\% para la mastectomía versus el $3.3 \%$ en las pacientes con cirugía conservadora (HR: 0.81; IC 95\%: 0.73-0.90; $\mathrm{p}<0.001)^{18}$ (Tabla 1).
Pregunta clínica 2. ¿Cuál debe ser la EXTENSIÓN DE MÁRGENES PARA LAS PACIENTES CON CARCINOMA DUCTAL IN SITU QUE SON LlEVADAS A CIRUGÍA CONSERVADORA DE MAMA?

Recomendación. El margen actual sugerido para un menor riesgo de recurrencia local $(R L)$ es de $2 \mathrm{~mm}$. Nivel de evidencia $2++$, grado de recomendación B. 
Tabla 3C. Recomendaciones clínicas, síntesis y niveles de evidencia para el cáncer de mama localmente avanzado.

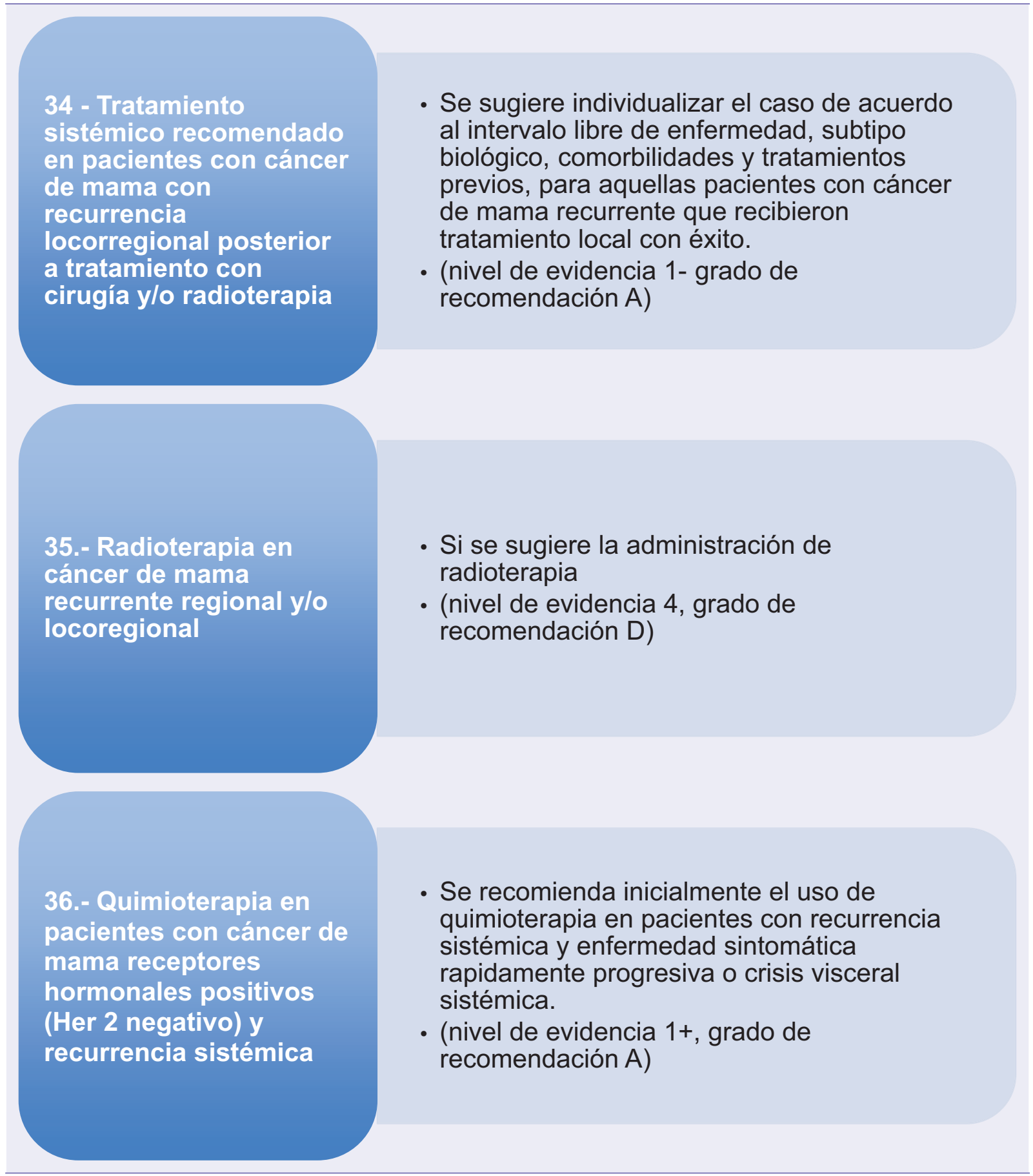

Revisión de la literatura médica y análisis. Aunque la evaluación de los márgenes está determinada por diversos elementos, se ha puesto mucho empeño en definir las medidas de los márgenes negativos. En un metaanálisis reciente $^{19}$, en el que se incluyeron 7,883 pacientes de 20 estudios con un seguimiento de 6.5 años, se comparó la amplitud de los márgenes con el riesgo de RL. En la metarregresión logística los resultados de OR para $2 \mathrm{~mm}$
$0.18-0.97 ; p=0.04)$ y $10 \mathrm{~mm}(0.60$; IC $95 \%$ : 0.33-1.08; $p=0.09)$ mostraron una reducción similar en la posibilidad de riesgo de RTI comparada con márgenes $<1-0 \mathrm{~mm}$. La comparación pareada entre las diferentes medidas (2, $3,5010 \mathrm{~mm}$ ) no encontró diferencias significativas en el riesgo de RTI (all $p>0.40$ ). En este modelo, el valor predictivo de probabilidad de RTI a 10 años para márgenes negativos de $2 \mathrm{~mm}$ es del 10.1\% (IC 95\%: 6.3-16.0\%), en comparación con el $8.5 \%$ para $3-5$ mm (IC 95\%: 


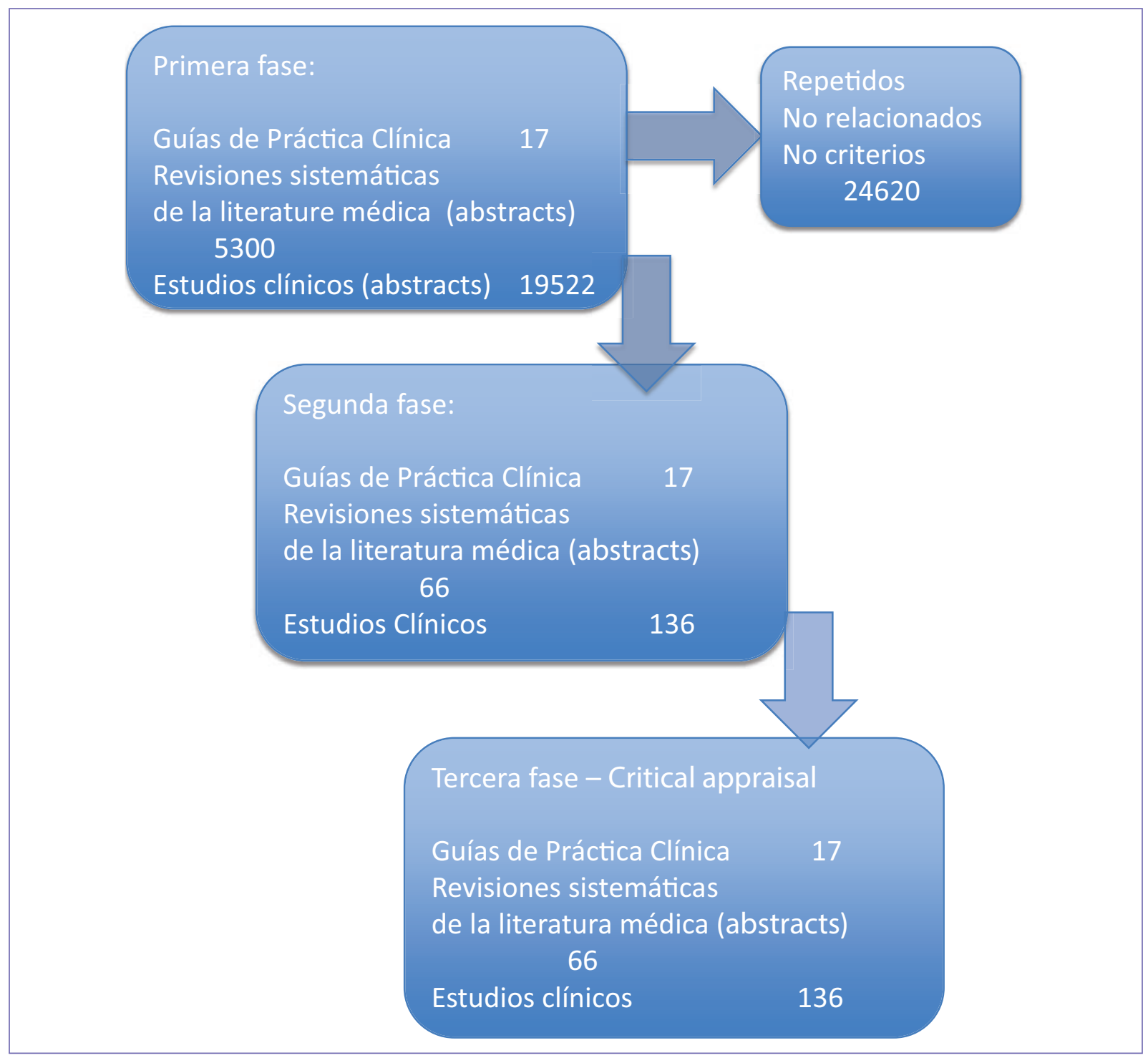

Figura 3. Diagrama de flujo evidencia científica.

3.6-18.9\%) y el 11.7\% (IC 95\%: 6.7-19.4\%) para márgenes de $10 \mathrm{~mm}$. En el estudio RTOG 9804 los pacientes con $\geq 3 \mathrm{~mm}$ fueron llevados a excisión sola o con radioterapia a toda la mama, mostrando tasas de recurrencia ipsilateral del 6.7 y $0.9 \%(p=0.0003)$, respectivamente ${ }^{20}$.

Pregunta clínica 3. ¿Cuál es el beneficio de la DISECCIÓN RADICAL DE AXILA EN PACIENTES CON CARCINOMA DUCTAL IN SITU?

Recomendación. No se recomienda la disección axilar ganglionar en pacientes con CDIS. Nivel de evidencia 4 , grado de recomendación $D$.

Revisión de la literatura médica y análisis. EI CDIS se considera una lesión preinvasiva, siendo los ganglios axilares raramente positivos, incluso en casos de enfermedad de alto grado multifocal ${ }^{21}$. En consecuencia, no se recomienda una disección axilar ganglionar completa a menos que exista evidencia de cáncer invasivo 0 enfermedad axilar metastásica corroborada.

Pregunta clínica 4. ¿Cuándo está justificado REALIZAR EL GANGLIO CENTINELA EN PACIENTES CON CARCINOMA DUCTAL IN SITU?

Recomendación. Sólo se recomienda cuando se realice mastectomía total y exista alta sospecha de carcinoma invasor asociado. Nivel de evidencia 2+, grado de recomendación $\mathrm{C}$. 
Revisión de la literatura médica y análisis. EI CDIS se considera una lesión preinvasiva, siendo los ganglios axilares raramente positivos, incluso en casos de enfermedad de alto grado multifocal. Para las pacientes con CDIS puro, el riesgo de metástasis ganglionar pN1 (mic) o pN1 de la AJCC es inferior al $1 \%$. Por lo tanto, se considera que la biopsia de ganglio centinela (BGC) no afectará a los desenlaces importantes ${ }^{22}$. Sin embargo, cerca del $15 \%$ de los pacientes inicialmente diagnosticados con CDIS en la biopsia por aguja presentan cáncer invasor en el espécimen excisional o la mastectomía ${ }^{23}$. Un metaanálisis ${ }^{24}$ estimó la incidencia de metástasis detectada por ganglio centinela en un 3.7\% (IC 95\%: 2.8-4.8) en pacientes con diagnóstico de CDIS postoperatorio contra un 7.4\% (IC 95\%: 6.2-8.9) en pacientes con diagnóstico de CDIS preoperatorio. En una RS de la literatura médica con metaanálisis reciente ${ }^{25}$, en la que se evaluaron 9,803 pacientes con diagnóstico de CDIS y que fueron llevados a BGC, se demostró que la incidencia de BGC positivo fue mayor en el grupo de diagnóstico preoperatorio, con una media del $5.9 \%$ (rango del $0-16.9 \%$ ), en comparación con el $3.02 \%$ en el grupo con diagnóstico postoperatorio (rango del 0-7\%).

Pregunta clínica 5. ¿Cuál es el beneficio de la RADIOTERAPIA POSTERIOR A CIRUGÍA CONSERVADORA DE MAMA EN PACIENTES CON CARCINOMA DUCTAL IN SITU?

Recomendación. Se recomienda la radioterapia posterior a CCM en pacientes con CDIS, pues la evidencia científica ha mostrado que disminuye la $R L$, invasora y no invasora, aunque no aumenta la supervivencia global (SG). Nivel de evidencia 1+, grado de recomendación $\mathrm{A}$.

La radioterapia posterior a CCM en pacientes con CDIS puede omitirse en pacientes de grado intermedio o bajo. Nivel de evidencia 1-, grado de recomendación A.

Se sugiere el tratamiento mediante radioterapia parcial acelerada de mama posterior a CCM en pacientes con CDIS de buen pronóstico (detectados por tamiz, grado nuclear intermedio o bajo, tamaño $<2.5 \mathrm{~cm}$ y márgenes resecados $>3 \mathrm{~mm}$ ). Nivel de evidencia 3 , grado de recomendación $\mathrm{D}$.

Revisión de la literatura médica y análisis. El beneficio de la radioterapia postoperatoria en pacientes con CDIS sometidas a CCM consiste en la reducción de recurrencias ipsilaterales tanto de tumor in situ como de recurrencias invasoras. Según la RS de Cochrane ${ }^{26}$, el HR es de 0.49 (IC 95\%: 0.41-0.48; $p<0.00001$ ) para eventos ipsilaterales, de 0.50 (IC 95\%: 0.32-0.76; $p=$ $0.001)$ para recurrencias invasoras ipsilaterales y de 0.61 (IC 95\%: 0.39-0.95; $p=0.03$ ) para recurrencias in situ ipsilaterales. No se encontraron diferencias en la $S G$ ni causa de muerte relacionada. Este estudio evaluó 3,925 pacientes, concluyendo que sí existe beneficio en el control local en este subgrupo de pacientes. También se evaluó la toxicidad tardía, y no se encontró incremento de la misma por el uso de radioterapia. No se evaluó la toxicidad aguda.

Un estudio retrospectivo ${ }^{27}$ en una cohorte de pacientes con CDIS estratificó a los pacientes en riesgo alto, medio y bajo por tres características principales (edad, tamaño tumoral y grado histológico), y observó un beneficio en la sobrevida de la radioterapia sólo en pacientes con alto grado tumoral, edad joven y gran tamaño tumoral. Un estudio prospectivo ${ }^{20}$ en pacientes con grado intermedio o bajo por mastografía, $<2.5 \mathrm{~cm}$ y márgenes $\geq 3 \mathrm{~mm}$, quienes fueron aleatorizadas a recibir radioterapia versus observación posterior a la cirugía, observó una RL ipsilateral mayor en el brazo de observación (0.9 vs. $6.7 \%$ ) (HR: 0.11; IC 95\%: 0.03-0.47); sin embargo, el riesgo no es tan amplio como para justificar los riesgos asociados a la RT. Por lo que en estos pacientes es una opción razonable omitir la RT.

Una RS con metaanálisis de estudios retrospectivos ${ }^{28}$ no encontró diferencia en la RT estándar y la parcial acelerada a mama en pacientes con CDIS (OR $=0.78$; IC 95\%: 0.58-1.03); sin embargo, se considera de baja evidencia. Existen estudios prospectivos y consensos que determinan que cierto grupo de pacientes se benefician de la radioterapia parcial acelerada de mama ${ }^{28-30}$. Sin embargo, no existen MA o RS que permitan aumentar el nivel de evidencia de esta recomendación.

Pregunta clínica 6. ¿Cuál es el beneficio de la TERAPIA ENDOCRINA POSTERIOR A CIRUGÍA DE MAMA (ADYUVANTE) EN PACIENTES CON CARCINOMA DUCTAL IN SITU?

Recomendación. En pacientes con CDIS con receptores hormonales positivos posterior a cirugía de mama, se recomienda el uso de tamoxifeno por el beneficio en la reducción del riesgo de cáncer invasivo. Nivel de evidencia 1+, grado de recomendación A.

El anastrozol (un inhibidor de aromatasa [IA]) es una alternativa al tamoxifeno en pacientes posmenopáusicas. 
Revisión de la literatura médica y análisis. Una RS con metaanálisis del grupo Cochrane ${ }^{31}$, que incluía dos ensayos aleatorios -NSABP B-24 y UK/ANZ DCIScon 3,375 pacientes, encontró que el tamoxifeno posterior a la cirugía del CDIS reduce la recurrencia del CDIS ipsilateral (HR: 0.75; IC 95\%: 0.61-0.92) y contralateral (RR =0.50; IC 95\%: 0.28-0.87), tiende a disminuir el riesgo de carcinoma invasor ipsilateral (HR: 0.79; IC 95\%: 0.61-1.01) y reduce el riesgo de cáncer invasor contralateral ( $R R=0.57$; IC 95\%: 0.39-0.83), aunque no se observa beneficio en la mortalidad (RR = 1.11; IC 95\%: 0.89-1.39).

No existen a día de hoy RS o MA que hablen del beneficio de los IA en el CDIS; sin embargo, un ensayo clínico y aleatorizado -el NGR Oncology/NSABP B-3532-, que enroló a 3,104 pacientes, aleatorizándolos a dos grupos (1,552 con tamoxifeno y 1,552 en anastrozol, con una mediana de seguimiento de nueve años [IQR: 8.2-10.0]), demostró una menor incidencia de eventos relacionados con el cáncer (recurrencia del CDIS o cáncer de mama invasor) en el grupo de anastrozol (90 pacientes) versus el grupo de tamoxifeno (120 pacientes) (HR: 0.73; IC 95\%: 0.56-0.96). También se observó mejoría en la sobrevida libre de cáncer a los 10 años (93.1 vs. 89.1\%). Sin embargo, no se encontró diferencia en la sobrevida libre de enfermedad (SLE) (HR: 0.89; IC 95\%: 0.75-1.07) o en la SG (HR: 1.11; IC 95\%: 0.83-1.48), con un estimado de sobrevida del 92.1\% (IC 95\%: 90.1-93.7) para el grupo de tamoxifeno y del 92.5\% (IC 95\%: 90.8-93.9) para el grupo de anastrozol, sin diferencia para ambos grupos.

\section{Cáncer de mama temprano}

\section{Pregunta clínica 7. ¿Cuál es la mejor opción DE MANEJO QUIRÚRGICO EN EL CÁNCER DE MAMA TEMPRANO?}

Recomendación. En las mujeres con cáncer de mama temprano (CMT) la CCM con radioterapia presenta un beneficio similar en la SG respecto a la mastectomía. Nivel de recomendación 2++, grado de recomendación $B$.

Si bien la CCM es una alternativa a la mastectomía, no puede ser aplicable a todas las pacientes. Nivel de recomendación 2++, grado de recomendación B.

Revisión de la literatura médica y análisis. Un metaanálisis reciente ${ }^{33}$ que toma estudios entre los años 1997 y 2002 ha analizado 5,102 pacientes con CMT llevadas a mastectomía en comparación con la CCM, y ha demostrado la existencia de un ligero beneficio en la SG con la mastectomía respecto a la CCM, con un HR global de muerte de 1.09 (IC 95\%: 1.01-1.19; $p=0.03)$, correspondiente a una reducción general del $9 \%$ del riesgo con mastectomía y una SLE equivalente en ambos grupos. Sin embargo, con las técnicas actuales de radioterapia y la quimioterapia (QT) adyuvante, en estudios observacionales recientes se ha mostrado que la CCM tiene una mejora en la sobrevida de las pacientes. En una cohorte de 112,154 pacientes, con un seguimiento de 110.6 meses, se encontró que las pacientes con CCM más radioterapia presentaron una mejor SG (HR: 0.81; IC 95\%: 0.80-0.83), en comparación con las pacientes con mastectomía y sin radioterapia ${ }^{34}$. Un estudio cohorte de 37,207 pacientes ${ }^{35}$ demostró una mejoría a 10 años en la SG para pacientes con CCM más radioterapia, en comparación con la mastectomía (HR ajustado: 0.81; IC 95\%: 0.78-0.85). Otro estudio de cohorte de 132,149 pacientes comparó la sobrevida específica a cáncer a 10 años, siendo mayor para la CCM más radioterapia (94\%), mastectomía sola (90\%) y mastectomía con radioterapia (83\%), con una $p<0.001$. En el análisis multivariado las pacientes con mastectomía sola presentaron mayor riesgo de muerte comparadas con las que fueron sometidas a CCM (HR: 1.31; IC 95\%: 1.25-1.39) ${ }^{36}$. Una cohorte noruega de 13,015 pacientes con CMT presentó datos en los que la mastectomía confiere un riesgo de muerte por cáncer mayor (HR: 1.64; IC 95\%: 1.43-1.88), en comparación con las pacientes llevadas a CCM más radioterapia $^{37}$ (Tabla $2 \mathrm{~A}$ ).

\section{Pregunta clínica 8. ¿Cuál es el margen QUIRÚRGICO RECOMENDADO EN PACIENTES CON CÁNCER DE MAMA TRATADAS CON CIRUGÍA CONSERVADORA?}

Recomendación. Se recomienda obtener la ausencia de células tumorales en la tinta con la que se tiñe la pieza quirúrgica para su análisis al microscopio; márgenes mayores a esto no han demostrado mejores resultados en cuanto a RL. Nivel de evidencia 1++, grado de recomendación A.

Revisión de la literatura médica y análisis. En un metaanálisis de Houssami, et al. ${ }^{38}$, que incluyó 33 estudios con 28,162 pacientes y 1,506 recidivas locales con un seguimiento medio de 79.2 meses, se informó de la relación entre el ancho del margen y la $R L$ en mujeres con cáncer de mama invasivo en estadios I y II. Se observó un riesgo mayor de $\mathrm{RL}(\mathrm{OR}=2.44$; IC 95\%: 1.97-3.03; $p<0.001$ ) para los márgenes positivos (definidos como «con tinta en tumor») frente a los 
negativos; sin embargo, los autores reconocen que la distancia para declarar débiles negativos en los estudios tiene una asociación débil o no se relaciona con el riesgo de RL. No se identificó ninguna relación entre el ancho del margen negativo, definido como 1 frente a 2 frente a $5 \mathrm{~mm}$, y la RL.

\section{Pregunta clínica 9. ¿Cuál es la indicación de LA DISECCIÓN RADICAL AXILAR EN PACIENTES CON CÁNCER DE MAMA EN ESTADIO TEMPRANO?}

Recomendación. La disección ganglionar axilar (DGA) sigue siendo el enfoque estándar para las mujeres con cáncer de mama en estadio temprano que presentan los siguientes escenarios: ganglio axilar palpable o sospechoso (incluso si presentó buena respuesta a neoadyuvancia), tres o más ganglios centinela positivos o aspiración positiva con aguja fina de un ganglio linfático axilar e irán a mastectomía y no recibirán radioterapia. Nivel de evidencia 1+, grado de recomendación A.

Disección ganglionar:

\section{A cN1 o más.}

B Tres o más ganglios centinelas positivos.

C Si no es candidata a radioterapia.

Revisión de la literatura médica y análisis. En una RS de la bibliografía por el grupo Cochrane ${ }^{39}$, al comparar la no realización de cirugía axilar contra la DGA no se encontró diferencia significativa en la SG entre ambos grupos (HR: 1.06; IC 95\%: 0.96-1.17; 3,849 participantes; 10 estudios); sin embargo, el hecho de no realizar cirugía axilar se relacionó con un incremento del riesgo de recurrencia locorregional (HR: 1.10-3.06; 20,863 pacientes-año de seguimiento en cuatro estudios). Fue incierto que la no realización de cirugía axilar estuviera relacionado con el riesgo de matástasis a distancia (HR: 1.06; IC 95\%: 0.87-1.30; 946 pacientes de dos estudios). En esta misma revisión se estudió la comparación de la técnica de muestreo axilar (SA) versus DGA, encontrando seis estudios que involucraban a 1,559 pacientes. La baja calidad de la evidencia sólo permitió determinar una efectividad similar entre SA versus DGA en términos de SG (HR: 0.94; IC 95\%: 0.73-1.21; 967 pacientes de tres estudios), siendo dudoso si el SA estaba relacionado con un incremento en la recurrencia locorregional comparado con la DGA (HR: 1.41; IC 95\%: 0.94-2.12; 1,404 pacientes de tres estudios). La eficacia relativa del SA y la DGA para la recurrencia locorregional (HR: 0.74; IC 95\%: 0.46-1.20; 406 pacientes de solo un estudio) y de la recurrencia a distancia
(HR: 1.05; IC 95\%: 0.74-1.49; 406 pacientes de un solo estudio) fueron inciertas. En este estudio de 2017 también se comparó la BGC versus la DGA en siete estudios de 9,426 pacientes, mostrando similitudes en la SG (HR: 1.05; IC 95\%: 0.89-1.25; en 6,352 pacientes de tres estudios con calidad de la evidencia moderada), pero siendo no valorables las diferencias en la RL (HR: 0.94; IC 95\%: 0.24-3.77; 516 participantes, un estudio), recurrencia locorregional (HR: 0.96; IC 95\%: 0.74-1.24; 5,611 participantes; un estudio) y metástasis a distancia (HR: 0.80; IC 95\%: 0.42-1.53; 516 participantes, un estudio).

Pregunta clínica 10. ¿Es recomendable realizar UNA BIOPSIA DE GANGLIO CENTINELA EN PACIENTES CON CÁNCER DE MAMA EN ESTADIO TEMPRANO?

Recomendación. La BGC se considera el mejor método de evaluación ganglionar en aquellas mujeres con CMT y axila clínicamente negativa. Nivel de evidencia 1++, grado de recomendación A.

Revisión de la literatura médica y análisis. En una RS con metaanálisis Cochrane ${ }^{39}$ se valoró el uso de la $B G C$ versus DGA en siete ensayos con 9,426 participantes. La evidencia mostró una SG similar entre la BGC y la DGA (HR: 1.05; IC 95\%: 0.89-1.25, 6,352 participantes, tres estudios, evidencia de calidad moderada). Las diferencias en la RL (HR: 0.94; IC 95\%: 0.24-3.77, 516 participantes, un estudio), recidiva locorregional (HR: 0.96; IC 95\%: 0.74-1.24, 5,611 participantes y un estudio) y metástasis a distancia (HR: 0.80; IC 95\%: 0.42-1.53, 516 participantes y un estudio) fueron inciertas. Tres estudios que incluyeron 1,755 participantes informaron sobre la calidad de vida: en dos estudios los investigadores encontraron una mejoría en la calidad de vida después de BGC respecto a las pacientes sometidas a DGA, y en el otro estudio no observaron diferencias.

\section{Pregunta clínica 11. ¿Podría omitirse la} DISECCIÓN RADICAL AXILAR EN LAS PACIENTES CON CÁNCER DE MAMA EN ESTADIO TEMPRANO CON REPORTE DE BIOPSIA DE GANGLIO CENTINELA NEGATIVO PARA METÁSTASIS?

Recomendación. No se recomienda completar la disección radical axilar (DRA) en pacientes con cáncer de mama en estadio temprano cuyo resultado de patología de BGC sea negativo para metástasis. Nivel de evidencia 1++, grado de recomendación A. 
Adicionalmente se puede omitir la DRA en aqueIlas pacientes con ganglio centinela positivo que cumplan con los siguientes criterios: ganglios metastásicos negativos, tumores T1 o T2, menos de tres ganglios centinelas positivos, no ruptura capsular en reporte de BGC y pacientes que serán llevadas a CCM seguida de radioterapia adyuvante.

Revisión de la literatura médica y análisis. En la GPC de la American Society of Clinical Oncology (ASCO) de $2014^{40}$ se realizó una RS de la literatura de siete ensayos clínicos que indagaban en la pregunta de si la DRA podía ser evadida en pacientes con resultado negativo para tumor en la determinación de BGC. En cinco estudios que determinaban la $S G$ no se encontraron diferencias significativas. El mismo resultado se obtuvo en cuatro estudios que no reportaron diferencias en la SLE.

Existen dos ensayos ${ }^{41}$ clínicos que buscaron determinar si era posible evitar la DRA en pacientes con uno o dos ganglios positivos a metástasis, siendo analizados en una $\mathrm{RS}^{41}$. Los estudios se presentan por separado para documentar la recomendación. El ensayo ACOSOG Z-0011 ${ }^{42}$ fue diseñado para abordar la necesidad de completar la DRA para los pacientes con cáncer de mama T1 o T2 con ganglios clínicamente negativos y menos de tres ganglios centinela positivos. En este caso, la BGC presentó tasas de SG a cinco años similares (91.9 vs. $92.5 \%$ ), así como tasas de SLE (82.2 vs. $83.9 \%)$.

Por otro lado, el estudio IBCSG $23-01^{43}$ asignó a las pacientes con tumor primario $<5 \mathrm{~cm}$ y ganglios axilares positivos por BGC a DRA versus no realizar más tratamiento axilar. Las características de las pacientes fueron: uno o dos ganglios centinelas en el $85 \%$ de las pacientes, todas tenían micrometástasis ganglionares $<$ de $2 \mathrm{~mm}$ y el $67 \%$ tuvo micrometástasis < de $1 \mathrm{~mm}$. A los cinco años, no hubo diferencias estadísticamente significativas entre los grupos, tanto en las tasas de SLE, con un $84.4 \%$ para las llevadas a DRA versus el 87.8\% sin DRA (HR: 0.78; IC 95\%: 0.55-1.11), como en las tasas de SG (98 vs. $97.6 \%$ ).

Pregunta clínica 12. ¿Cuál es el beneficio de la MASTECTOMÍA REDUCTORA DE RIESGO CONTRALATERAL EN PACIENTES CON CÁNCER DE MAMA?

Recomendación. No se recomienda la mastectomía reductora de riesgo contralateral (MRRC) en esta población, pues no ha mostrado beneficio en la SG. Nivel de evidencia 3, grado de recomendación C.
Debe plantearse ante ciertas situaciones, como cáncer de mama hereditario, mutación confirmada de genes de alto riesgo para cáncer de mama y cáncer de mama familiar, y todo ello previa valoración genética.

Revisión de la literatura médica y análisis. Una RS con metaanálisis ${ }^{44}$ que comparó pacientes que se sometieron a MRRC versus aquéllas que no se sometieron mostró una reducción en el riesgo de recurrencia a distancia en las primeras pacientes $(R R=0.64$; IC 95\%: 0.51-0.81), pero sin tener impacto en la sobrevida (RR = 1.09; IC 95\%: 1.06-1.11). Esto basado en estudios retrospectivos y comentando los diferentes sesgos que pueden contener.

Recientemente un análisis del SEER ${ }^{45}$ incluyó a 496,488 pacientes diagnosticadas con cáncer de mama unilateral, en estadios I-III, llevadas a cirugía, entre las cuales se encontró un $7.0 \%$ que se realizaron MRRC. Se comparó este último grupo con las que no se habían sometido a cirugía de reducción de riesgo (59.6\% de las pacientes), pero no se encontró mejoría significativa en la sobrevida cáncer específica (HR: 1.08; IC 95\%: 1.01-1.16) ni en la SG (HR: 1.08; IC 95\%: 1.03-1.14).

Pregunta clínica 13. ¿Cuál es el beneficio de LA MASTECTOMÍA REDUCTORA DE RIESGO EN

PACIENTES EN QUIENES SE HA DETECTADO UNA MUTACIÓN EN BRCA1 O BRCA2?

Recomendación. En pacientes portadoras de mutaciones en BRCA1 o BRCA2 la mastectomía reductora de riesgo bilateral (MRRB) y la MRRC se asocian a una reducción del riesgo de aparición de cáncer de mama o incidencia contralateral, respectivamente. Nivel de evidencia 2+, grado de recomendación B.

Esta reducción del riesgo de aparición de cáncer de mama se estima en aproximadamente el $90 \%$ con mastectomía reductora de riesgo únicamente y en el $95 \%$ cuando ésta se realiza junto con salpingooforectomía bilateral reductora de riesgo.

Revisión de la literatura médica y análisis. Una RS con metaanálisis ${ }^{46}$ que evaluó 15 estudios, incluyendo pacientes con diagnóstico de cáncer de mama y portadoras de mutaciones de riesgo en BRCA1 o BRCA2, analizó 2,555 pacientes llevadas a MRRB versus aquéllas que no se sometieron a la cirugía reductora de riesgo, encontrando entre las que se sometieron a MRRB un menor riesgo de aparición de cáncer de mama en pacientes con BRCA1 (RR = 0.13; IC 95\%: 0.01-0.9) y en los portadores de BRCA2 $(\mathrm{RR}=0.18$; 
IC 95\%: 0.07-0.4), aunque sin encontrar impacto en la mortalidad (HR: 0.22; IC 95\%: 0.05-1.01). Se realizó la comparación en pacientes que ya habían presentado cáncer de mama y fueron llevadas a MRRC versus no realizada, y la MRRC, análisis realizado en 1,672 pacientes, mostró una reducción en la incidencia de cáncer de mama (RR = 0.07; IC 95\%: 0.035-0.148) e influyó en la mortalidad en este grupo de pacientes (HR: 0.51; IC 95\%: 0.36-0.74). Estos estudios no analizaron diferencias entre BRCA1 o BRCA2.

Una $\mathrm{RS}^{47}$ corroboró los datos de reducción de riesgo de cáncer de mama en mujeres portadoras de $B R C A$ con ovarios intactos en un 90\% (HR: 0.09; IC 95\%: $0.02-0.38$ ) y en aquellas mujeres con salpingooforectomía bilateral del 95\% (HR: 0.05; IC 95\%: 0.01-0.22).

\section{Pregunta clínica 14. ¿Cuál es la mejor opción DE MANEJO ENTRE LA RADIACIÓN PARCIAL ACELERADA \\ Y LA RADIOTERAPIA EXTERNA A TODA LA MAMA (WHOLE BREAST RADIOTHERAPY) EN PACIENTES CON CÁNCER DE MAMA EN ESTADIO TEMPRANO QUE FUERON LLEVADAS A CIRUGÍA CONSERVADORA DE MAMA?}

Recomendación. Se recomienda la radioterapia externa a toda la mama en pacientes con cáncer de mama en estadio temprano que fueron llevadas a CCM. La evidencia actual no nos permite evaluar la superioridad de alguna modalidad en particular en comparación al estándar de referencia. Nivel de evidencia 1++, grado de recomendación A.

La radiación parcial acelerada (RPA) de mama se recomienda en pacientes mayores de 50 años, con tumor completamente resecado y márgenes negativos, y tamaño del tumor $<3 \mathrm{~cm}$. Nivel de evidencia 1++, grado de recomendación A.

Revisión de la literatura médica y análisis. En una RS con metaanálisis ${ }^{48}$ de tres ensayos aleatorios $(n=1,140$ pacientes), la RPA no dio lugar a ninguna diferencia en la supervivencia general o el riesgo de metástasis a distancia en comparación con la radioterapia externa a toda la mama. Sin embargo, se observó un mayor riesgo tanto local (OR = 2.15; IC 95\%: 1.4-3.3) como de recurrencia axilar (OR combinado $=3.43$; IC 95\%: 2.06-5.72).

En una RS de Cochrane ${ }^{49}$ se evaluaron 7,586 pacientes incluidas en estudios controlados que compararon directamente el tratamiento adyuvante a toda la mama versus RPA. Uno de los puntos más destacados encontrado por los autores es que la RPA de mama se relacionó con un mayor porcentaje de RL, con un HR de 1.62 (IC 95\%: 1.11-2.35), sin que esto se viera reflejado en los demás puntos oncológicos a evaluar, como la SG, sobrevida causa específica, sobrevida libre de metástasis a distancia, sobrevida libre de recurrencia y sobrevida libre de recurrencia locorregional. Sí se encontró, en cambio, diferencia versus la RPA en los siguientes parámetros: fibrosis subcutánea (HR: 3.0814.06), telangiectasias (HR: 26.56; IC 95\%: 3.56-196.51) y necrosis grasa (HR: 1.58; IC 95\%: 1.02-2.43), sin encontrarse diferencia en toxicidad tardía cutánea o dolor.

Estudios retrospectivos han permitido definir los factores clínicos y patológicos de los pacientes que parecen beneficiarse mayormente de la terapia acelera$\mathrm{da}^{29,48}$. A día de hoy se están llevando a cabo estudios prospectivos para validar estos datos, por lo que el nivel de evidencia no puede ser mayor (Tabla 2 B).

\section{Pregunta clínica 15. ¿Cuál es el beneficio de AGREGAR SOBREIMPRESIÓN DE RADIACIÓN (BOOST) AL LECHO QUIRÚRGICO EN PACIENTES CON CÁNCER DE MAMA EN ESTADIO TEMPRANO?}

Recomendación. Se sugiere el uso de sobreimpresión (boost) al lecho quirúrgico en pacientes con cáncer de mama invasor en estadio temprano debido a que mejora el control local; sin embargo, la evidencia actual no ha demostrado un aumento en la SG. Nivel de evidencia 1+, grado de recomendación $B$.

El mayor beneficio se encuentra en pacientes menores de 50 años. Nivel de evidencia 1+, grado de recomendación $B$.

Revisión de la literatura médica y análisis. En un estudio ${ }^{50}$ se evaluó a 5,318 pacientes con cáncer de mama completamente resecado, llevadas a radioterapia adyuvante de 50 Gy en 25 fracciones y posteriormente se aleatorizaron a recibir boost o sobreimpresión de 16 Gy versus no recibirlo; el seguimiento fue de 10.8 años. Se reportaron 278 pacientes con $R L$ en el grupo que no recibió boost versus 165 pacientes en el grupo que sí lo recibió. La incidencia de RL fue de 10.2 versus $6.2 \%$ a favor de las pacientes que recibieron boost (HR: 0.59; IC 95\%: 0.46-0.76; $p \leq 0.0001$ ). La reducción absoluta del riesgo fue mayor en el grupo de pacientes menores de 40 años, pasando del 23.9 al $13.5 \%$ ( $p=0.0014)$, que resultó en una disminución del porcentaje de mastectomías de salvamento en un $41 \%$. La fibrosis severa a 10 años fue mayor en el grupo que recibió boost, reportándose un 4.4 versus $1.6 \%$ ( $p \leq 0.0001$ ). La supervivencia a 10 años para los dos grupos fue del $82 \%$. 
Pregunta clínica 16. ¿Qué herRamientas (FIRMAS GENÓMICAS Y PLATAFORMAS ELECTRÓNICAS) DE ESTRATIFICACIÓN DE RIESGO PUEDEN USARSE PARA DETERMINAR LA UTILIDAD DE DETERMINADAS TERAPIAS SISTÉMICAS EN PACIENTES CON CÁNCER DE MAMA EN ESTADIO TEMPRANO?

Recomendación. En pacientes con cáncer de mama ER/PgR+, HER2- (ganglios negativos) se sugiere el uso de pruebas validadas, como, por ejemplo, Oncotype DX, EndoPredict, PAM-50, Breast Cancer Index, para guiar las decisiones de la QT adyuvante. Nivel de evidencia $2++$, grado de recomendación B.

En pacientes con cáncer de mama triple negativo (CMTN) o HER2+ no está indicado usar estas herramientas para guiar las decisiones de la QT adyuvante. Nivel de evidencia $2++$, grado de recomendación $\mathrm{B}$.

En pacientes con cáncer de mama ER/PgR+, HER2- (ganglios positivos) aún no existe evidencia suficiente para usar estas herramientas para guiar las decisiones de la QT adyuvante. Nivel de evidencia 2++, grado de recomendación B.

Revisión de la literatura médica y análisis. Existe una $\mathrm{RS}^{51}$ en la que se busca la efectividad clínica de Oncotype, MammaPrint y Mammostrat, y cuyos resultados fueron consistentes con otras guías publicadas. En cuanto al Oncotype, se encontró que la puntuación de recurrencia (RS) del Oncotype DX se correlaciona con beneficio de la $Q T$, definida en términos de recurrencia a 10 años (SLR), con un beneficio significativamente mayor del uso de QT en el grupo de alto riesgo de Oncotype DX comparado con el grupo de bajo riesgo, siendo receptor de estrógeno positivo $(\mathrm{ER}+)$, ganglios negativos. En cuanto al uso de MammaPrint, los autores comentan que los estudios clínicos encontrados en esta revisión, junto con los datos clínico-patológicos, cambiaron las recomendaciones de tratamiento en el $18-40 \%$ de todos los pacientes evaluados, y en el 2-32\% de todos los pacientes de dar o no QT. Del Mammostrat sólo mencionan que no encontraron estudios prospectivos del impacto a largo plazo en los desenlaces. Los autores de esta RS mencionan que el análisis de datos se dificultó debido a la heterogeneidad de los estudios, por lo que no podemos tomar esta revisión para emitir una recomendación. En consecuencia, se resumirá la evidencia de manera individual para cada plataforma de los ECA:

- Oncotype cuenta con RS con metaanálisis con estudios previos a 2013. El estudio TAILORx, que no se considera en al análisis previo, evaluó los resultados en 1,626 mujeres con cáncer de mama, ganglios negativos con receptores hormonales positivos, HER2- y una puntuación de recurrencia (RS) baja $(\leq 10)^{52}$. A los cinco años, se observaron altas tasas de SLE invasiva (93.8\%; IC 95\%: 92.4-94.9), SLE metastásica a distancia (99.3\%; IC 95\%: 98.799.6) y SG (98.0\%; IC 95\%: 97.1-98.6) en este subconjunto de RS bajo. Está pendiente la notificación de pacientes con puntuaciones intermedias y altas de RS.

- EndoPredict fue validado al utilizar datos de dos ensayos clínicos (ABCSG-6 y ABCSG-8), y su valor pronóstico fue independiente de los factores pronósticos convencionales. EndoPredict parece ser útil en la identificación de un subgrupo de pacientes con tumores ER+, HER2- que tienen un riesgo muy bajo de recurrencia sin QT adyuvante (ABSCG-6: HR: 1.19; IC 95\%: 1.06-1.32; y ABSCG-8: HR: 1.27; IC 95\%: $1.18-1.37)^{53}$ y parece identificar a los pacientes de bajo riesgo de recurrencia tardía (seguimiento de 5 a 10 años: HR: 3.28; IC 95\%: 1.48-7.24) $)^{54}$.

- PAM-50 se diseñó originalmente para determinar el subtipo intrínseco de las pacientes con cáncer de mama, pero se logró ensamblar una puntuación de riesgo de recurrencia (PRR) a partir de los datos del estudio en pacientes ER+, encontrándose la PRR como un predictor pronóstico en pacientes con ganglios negativos ${ }^{55}$. En análisis retrospectivos la PRR de PAM-50 ha demostrado tener significancia pronóstica independientemente del estatus ganglionar ${ }^{56}$; sin embargo, consideramos que se requieren estudios prospectivos para considerarlo dentro de la recomendación.

- Breast Cancer Index ha sido validado como predictor de respuesta a tamoxifeno (OR $=0.16$; IC 95\%: 0.060.45 ) en pacientes con cáncer de mama ER+/ganglios negativos ${ }^{57}$. Otro estudio asoció a las pacientes que presentan expresión de HOXB13-IL17BR alta a una disminución absoluta en la recurrencia a cinco años del $16.5 \%$ y a largo plazo (OR $=0.35$; IC 95\%: $0.16-0.75$ ) en las que recibieron terapia extendida con letrozol ${ }^{58}$.

Estudios prospectivos recientes han contribuido a la información, pero no se ha analizado en un metaanálisis que nos permita determinar el beneficio concreto de MammaPrint. El estudio MINDACT ${ }^{59}$, cuyo desenlace primario era la sobrevida libre de metástasis a distancia, sugirió que entre los pacientes de la población con intención de tratar que presentaban un riesgo clínico alto de recurrencia, pero un bajo riesgo 
según el perfil genético de Ámsterdam, la tasa de supervivencia libre de metástasis fue del $95.9 \%$ con QT y del $94.4 \%$ sin QT (HR: 0.78; IC 95\%: 0.50-1.21). Sin embargo, cabe señalar que el estudio MINDACT no fue diseñado para excluir un beneficio de la QT, por lo que su recomendación en este contexto no es válida.

\section{Pregunta clínica 17. ¿Cuáles son las opciones DE TERAPIA ENDOCRINA Y SU DURACIÓN EN PACIENTES POSMENOPÁUSICAS CON CÁNCER DE MAMA CON RECEPTORES HORMONALES POSITIVOS EN ESTADIO TEMPRANO?}

Recomendación. Se recomienda el uso de IA sobre el tamoxifeno en pacientes T1 y T2 consideradas de bajo riesgo de recaída durante cinco años. Nivel de evidencia 1++, grado de recomendación A.

Revisión de la literatura médica y análisis. En una RS con metaanálisis del grupo EBCTCG ${ }^{60}$, en la que se incluyeron 31,920 pacientes posmenopáusicas con $\mathrm{ER}+$ llevadas a cinco años de tratamiento adyuvante con terapia endocrina, se comparó en un subanálisis a 9,885 pacientes el uso de IA versus tamoxifeno, existiendo una disminución en la recurrencia particularmente durante los años posteriores a la cirugía: años 0-1 (RR = 0.64; IC 95\%: 0.52-0.78) y años 2-4 $(R R=0.80 ;$ IC 95\%: 0.68-0.93). Además, mostró una disminución del riesgo de muerte por cáncer de mama a 10 años (RR $=0.85 \%$; IC 95\%: 0.75-0.96).

Los IA aparentan tener eficacia similar en el contexto adyuvante, pero no se tienen RS que determinen preferencia de algún IA sobre otro.

Pregunta clínica 18. ¿Cuál es la subpoblación DE PACIENTES PREMENOPÁUSICAS CON CÁNCER DE MAMA EN ESTADIO TEMPRANO Y RECEPTORES HORMONALES POSITIVOS QUE SE BENEFICIA DE RECIBIR SUPRESIÓN OVÁRICA ADYUVANTE SUMADA A LA TERAPIA ENDOCRINA ESTÁNDAR?

Recomendación. Se considera que el uso de terapia endocrina, con un IA más supresión ovárica con agonistas de LHRH reduce significativamente el riesgo de recurrencia en pacientes premenopáusicas consideradas de alto riesgo de recurrencia. Nivel de evidencia 1++, grado de recomendación A.

Revisión de la literatura médica y análisis. En una RS con metaanálisis del grupo EBCTCG ${ }^{61}$, en la que se analizaron 16 ensayos clínicos, para un total de 11,906 pacientes premenopáusicas consideradas con riesgo promedio para recurrencia, la comparación de usar tamoxifeno más un agonista de LHRH versus tamoxifeno solo no dio lugar a diferencias significativas en el riesgo de recurrencia (HR: 0.85; IC 95\%: 0.671.09) o mortalidad (HR: 0.84; IC 95\%: 0.59-1.19).

El metaanálisis del grupo de Cochrane ${ }^{62}$ concluyó que la información es insuficiente para recomendar el uso de tamoxifeno con agonista de LHRH.

Estudios más recientes han buscado contestar esta pregunta. Dos estudios independientes de análisis conjunto de los estudios SOFT y TEXT ${ }^{63,64}$, que analizaron a pacientes premenopáusicas con diagnóstico de cáncer de mama receptores hormonales positivos, buscaban responder cuáles eran las mejores terapias endocrinas con o sin supresión ovárica, y demostraron que en las pacientes con riesgo alto (más de cuatro ganglios patológicos positivos, tamaño tumoral $>2 \mathrm{~cm}$, alto grado tumoral, invasión linfovascular, menores de 40 años) el intervalo libre de enfermedad invasiva (Iocorregional, distante o contralateral) era menor en las pacientes con terapia de supresión ovárica con exemestano, en comparación con la población de terapia de supresión ovárica y tamoxifeno (92.8 vs. $88.8 \%$ ) y también con tamoxifeno solo.

Pregunta Clínica 19. Si la terapia de supresión OVÁRICA ES RECOMENDADA, ¿CON QUÉ TERAPIA ENDOCRINA DEBE SER COMBINADA EN PACIENTES PREMENOPÁUSICAS CON CÁNCER DE MAMA RECEPTORES HORMONALES POSITIVOS EN ESTADIO TEMPRANO?

Recomendación. Se recomienda la combinación con exemestano (IA) en pacientes que tienen indicada supresión ovárica. Nivel de evidencia 1++, grado de recomendación $\mathrm{A}$.

Revisión de la literatura médica y análisis. En dos estudios de análisis conjunto de los estudios SOFT y TEXT $^{64,65}$, se analizó a pacientes premenopáusicas con diagnóstico de cáncer de mama receptores hormonales positivos en busca de responder cuáles eran las mejores terapias endocrinas con o sin supresión ovárica. Se demostró que en las pacientes con riesgo alto (más de cuatro ganglios patológicos positivos, tamaño tumoral $>2 \mathrm{~cm}$, alto grado tumoral, invasión linfovascular, edad temprana) el intervalo libre de enfermedad invasiva (locorregional, distante o contralateral) es menor en las pacientes con terapia de supresión ovárica con exemestano, en comparación con la población de terapia de supresión ovárica y tamoxifeno (92.8 vs. $88.8 \%)$ y también sólo con tamoxifeno. 
Además del estudio previo, la combinación de la supresión ovárica más tamoxifeno 0 un IA se evaluó en el estudio ABCSG-12 ${ }^{66}$, en el que 1,803 mujeres premenopáusicas con CMT (la mayoría de las cuales no recibieron QT) fueron tratadas durante tres años con goserelín y tamoxifeno 0 anastrazol. El seguimiento fue de 48 meses, y demostró que el uso de goserelín más anastrazol tiene una SLE similar en comparación con goserelín más tamoxifeno (HR: 1.10; IC 95\%: 0.781.53), aunque en este estudio se pretendió asociar el uso de ácido zoledrónico a los desenlaces.

\section{Pregunta clínica 20. ¿EN QUé Pacientes con CÁNCER DE MAMA RECEPTORES HORMONALES POSITIVOS SE PUEDE CONSIDERAR EL TRATAMIENTO ENDOCRINO EXTENDIDO?}

Recomendación. Se recomienda usar tratamiento endocrino extendido en pacientes con alto riesgo: $>$ T3 y/o ganglios positivos. Nivel de evidencia 1++, grado de recomendación $A$.

Se sugiere tomar en cuenta la administración de tratamiento sintomático para mejorar la sintomatología de los posibles eventos adversos del tratamiento endocrino extendido. Nivel de evidencia 4, grado de recomendación $\mathrm{D}$.

Revisión de la literatura médica y análisis. En una RS con metaanálisis de cinco estudios clínicos que incluyó 21,554 pacientes $^{67}$, el uso de tamoxifeno adyuvante extendido (10 años) no se asoció con una reducción del riesgo de recurrencia $(O R=0.89$; IC $95 \%$ : 0.71-1.05). Un análisis de subgrupos mostró beneficio sólo en aquellas pacientes con enfermedad ganglionar positiva (OR: 0.76; IC 95\%: 0.63-0.92), pero sin diferencia significativa en comparación con las de ganglios positivos ( $p=0.16$ ), entre las pacientes con alto riesgo (considerando $\geq \mathrm{T} 3 \mathrm{y} / \mathrm{o}$ ganglios positivos).

Otra RS con metaanálisis más reciente que incluyó estudios con terapia extendida con IA, de 29,000 pacientes $^{68}$, clasificó los estudios en tres grupos: grupo I, tamoxifeno por 5 versus 10 años; grupo II, cinco años de tamoxifeno versus tamoxifeno durante cinco años seguido de IA por cinco años, y grupo III (más heterogéneo), después de cuatro o más años de terapia adyuvante fueron aleatorizados a recibir anastrozol por tres años o letrozol por cinco años. Se encontró mejoría del $13 \%$ en la SLE (OR = 0.87; IC 95\%: 0.75-0.99) en los grupos II y III, y un beneficio en el riesgo de recurrencia (OR = 0.76; IC 95\%: 0.64-0.90) en el grupo II. El análisis de metarregresión demostró que el beneficio es mayor en pacientes con ganglios positivos $(\mathrm{OR}=0.70$; IC 95\%: 0.58-0.84).

Pregunta clínica 21. ¿Cuál es el beneficio de LOS BISFOSFONATOS EN LAS PACIENTES QUE RECIBEN INHIBIDORES DE AROMATASA ADYUVANTE?

Recomendación. Existe beneficio en la SLE y SG en las pacientes posmenopáusicas en terapia adyuvante con IA y bisfosfonatos. Nivel de evidencia 1++, grado de recomendación A.

Los bisfosfonatos no reducen el riesgo de fracturas; sin embargo, se recomienda su uso en las pacientes que durante la vigilancia ósea presentan pérdida de la densidad o tienen diagnóstico de osteoporosis al inicio del tratamiento. Nivel de evidencia 1++, grado de recomendación A.

Otra opción es el uso de denosumab en pacientes posmenopáusicas en manejo con IA por su reducción en el riesgo de eventos óseos. Nivel de evidencia 1++, grado de recomendación A.

Se recomienda la administración de calcio y calcitriol coadyuvante a la terapia con bisfosfonatos. Nivel de evidencia 1++, grado de recomendación A.

Se sugiere tomar en cuenta la administración de tratamiento sintomático para mejorar la sintomatología de los posibles eventos adversos del tratamiento con bisfosfonatos. Nivel de evidencia 4, grado de recomendación $\mathrm{D}$.

Revisión de la literatura médica y análisis. En una RS con metaanálisis ${ }^{69}$ que evaluó los beneficios del tratamiento con bisfosfonatos de manera adyuvante en 18,766 pacientes, se observa una reducción en la recurrencia ósea (RR = 0.83; IC 95\%: 0.73-0.94), recurrencia global (RR =0.9; IC 95\%: 0.87-1.01), recurrencia a distancia ( $R R=0.92 ; 0.85-0.99)$ y mortalidad relacionada con cáncer $(0.91 ; 0.83-0.99)$, con significancia limítrofe y sólo observada en pacientes posmenopáusicas.

En otro metaanálisis de Cochrane ${ }^{70}$ de pacientes con etapa temprana (11 ensayos que incluían 15,005 pacientes), los bisfosfonatos se asociaron con reducción del riesgo de metástasis óseas ( $R R=0.86$; IC $95 \%$ : 0.75-0.99), beneficio en la SG y SLE, corroborando que el beneficio sólo se produce en pacientes posmenopáusicas, y no en premenopáusicas. Los bisfosfonatos no redujeron la incidencia de fracturas $(R R=0.77$; IC 95\%: 0.54-1.08).

Una RS con metaanálisis ${ }^{71}$ demostró que el uso de bisfosfonatos y denosumab disminuía la incidencia de eventos óseos (OR = 0.61; IC 95\%: 0.51-0.72). El estudio ABCSG-18 ${ }^{72}$ aleatorizó denosumab versus placebo 
en pacientes posmenopáusicas que recibían tratamiento con IA, encontrando una reducción en el tiempo de fractura clínica (HR: 0.50; IC 95\%: 0.39-0.65) (Tabla 2 C).

\section{Pregunta clínica 22. ¿Cuál es la Quimioterapia SISTÉMICA ADYUVANTE ÓPTIMA EN PACIENTES CON CÁNCER DE MAMA EN ESTADIO TEMPRANO HER2-?}

Recomendación. Se recomienda en pacientes con alto riesgo antraciclinas y taxanos secuencial. Nivel de evidencia 1++, grado de recomendación A.

En pacientes de bajo riesgo o con contraindicación a las antraciclinas, se puede usar alguno de los siguientes esquemas:

- Docetaxel con ciclofosfamida (4c). Nivel de evidencia 1+, grado de recomendación A.

- Paclitaxel en monoterapia semanal. Nivel de evidencia 1+, grado de recomendación A.

- CMF. Nivel de evidencia 1++, grado de recomendación A.

Revisión de la literatura médica y análisis. Una RS con metaanálisis, EBCTCG ${ }^{73}$, comparó en 5,120 pacientes el uso de antraciclinas administradas a dosis «estándar» versus CMF. El análisis encontró riesgo de recurrencia (41\% de AC vs. 42.1\%; RR = 0.99; IC 95\%: 0.90-1.08), mortalidad por cáncer de mama (31.6 vs. $32.5 \%$; RR = 0.98; IC 95\%: 0.89-1.08) y mortalidad general (34.6 vs. 33.4\%; RR = 0.97; IC 95\%: 0.89-1.07) similares a los 10 años. Los pacientes que recibieron mayores dosis acumuladas de antraciclinas tuvieron mejoras marginales en estos datos en comparación con el esquema CMF.

En un seguimiento a siete años ${ }^{74}$ docetaxel/ciclofosfamida mostró diferencias en la SLE versus doxorubicina/ciclofosfamida (HR: 0.74; IC 95\%: 0.56-0.98), así como en la SG (HR: 0.69; IC 95\%: 0.50-0.97).

El estudio CALGB $40101^{75}$ no alcanzó a demostrar la no inferioridad de paclitaxel semanal monofármaco contra doxorubicina/ciclofosfamida, por lo que puede considerarse una alternativa en el contexto adyuvante.

\section{Pregunta clínica 23. ¿Qué esquema de QUIMIOTERAPIA CON RESPECTO A ANTRACICLINAS VERSUS NO ANTRACICLINAS DEBE SER USADO EN EL MANEJO DE PACIENTES CON CÁNCER DE MAMA EN ESTADIO TEMPRANO CON ALTO RIESGO?}

Recomendación. Los tratamientos que se recomiendan como manejo adyuvante en pacientes con cáncer de mama en estadio temprano con alto riesgo son: fluorouracilo-epirubicina-ciclofosfamida (3c) seguido de docetaxel (3c), doxorubicina-ciclofosfamida (4c) seguido de docetaxel (4c), docetaxel-doxorubicina-ciclofosfamida (6c), doxorubicina-ciclofosfamida (4c) seguido de paclitaxel semanal (12c) y dosis densas de doxorubicina-ciclofosfamida (4c) con manejo secuencial de paclitaxel cada dos semanas (4c). Nivel de evidencia 1++, grado de recomendación $\mathrm{A}$.

En pacientes con contraindicación a las antraciclinas, se recomienda el tratamiento de docetaxel-ciclofosfamida (6c). Nivel de evidencia 1+, grado de recomendación A.

En pacientes HER2+ debe administrarse trastuzumab por un año iniciando en la secuencia de taxanos. No se recomienda la combinación en la secuencia de antraciclinas. Nivel de evidencia 1++, grado de recomendación A.

En pacientes con tumores $<3 \mathrm{~cm}$ y ganglios negativos se sugiere el esquema de paclitaxel semanal junto con trastuzumab por un año. Nivel de evidencia 2+, grado de recomendación $\mathrm{C}$.

Revisión de la literatura médica y análisis. Una RS de la literatura con metaanálisis del grupo $\mathrm{EBCTCG}^{73} \mathrm{com}$ paró en 5,120 pacientes el uso de antraciclinas administradas a dosis «estándar» versus CMF. El análisis encontró riesgo de recurrencia ( $41 \%$ de $A C$ vs. $42.1 \%$; RR = 0.99; IC 95\%: 0.90-1.08), mortalidad por cáncer de mama (31.6 vs. $32.5 \%$; RR = 0.98; IC 95\%: 0.89-1.08) y mortalidad general ( 34.6 vs. $33.4 \%$; RR $=0.97$; IC $95 \%$ : 0.89-1.07) similares a los 10 años. Los pacientes que recibieron mayores dosis acumuladas de antraciclinas tuvieron mejoras marginales en estos desenlaces en comparación con el tratamiento con CMF.

En el análisis conjunto de los estudios de antraciclinas en CMT (The ABC Trials: USOR 06-090, NSABP B-46-I/USOR 07132 y NSABP B-49) ${ }^{76}$ se comparó el uso de docetaxel con ciclofosfamida contra doxorubicina y ciclofosfamida en 4,242 pacientes. El estudio concluye que, aunque el tratamiento TC fue inferior al tratamiento basado en antraciclina y taxano en cuanto a la SLE invasiva a cuatro años (88.2 vs. $90.7 \%$; HR: 1.23; IC 95\%: 1.01-1.50), los datos del estudio sugieren que la terapia basada en antraciclina no mejora significativamente los resultados en el cáncer de mama ER+ de bajo riesgo. En el caso de cáncer de alto riesgo, ER+ y CMTN parece haber un papel para las antraciclinas.

Un metaanálisis de Cochrane ${ }^{77}$ que valoró el beneficio de adicionar trastuzumab a la QT adyuvante en 11,991 pacientes HER2+ de ocho estudios demostró incremento en la SLE (HR: 0.60; IC 95\%: 0.50-0.70), así como mejoría en la SG (HR: 0.66; IC 95\%: 0.570.77 ), encontrando asociación en la mejoría en el esquema temporal de 12 meses y la mejoría en la SG 
(HR: 0.67; IC 95\%: 0.57-0.80); aunque el esquema temporal de seis meses demostró una tendencia a la mejoría en la SG, no alcanzó significancia estadística (HR: 0.55; IC 95\%: 0.27-1.11).

\section{Cáncer de mama localmente avanzado}

\section{Pregunta clínica 24. ¿EN QUé Pacientes con CÁNCER DE MAMA LOCALMENTE AVANZADO ESTÁ RECOMENDADO REALIZAR CIRUGÍA CONSERVADORA DE MAMA POSTERIOR A NEOADYUVANCIA?}

Recomendación. En pacientes que presentaron buena respuesta (parcial o completa) a la QT se sugiere llevar a cabo la CCM posterior a neoadyuvancia. Nivel de evidencia 4 , grado de recomendación $\mathrm{D}$.

No se sugiere llevar a cabo el procedimiento cuando se encuentra presente: enfermedad multicéntrica, microcalcificaciones extensas, cáncer de mama inflamatorio o cambios en la piel (ganglios subdérmicos tomados). Nivel de evidencia 4 , grado de recomendación D.

Revisión de la literatura médica y análisis. No existen RS o ECA que permitan establecer una recomendación basada en evidencia. Sin embargo, las GPC y los consensos de expertos nos dan una sugerencia para pacientes con buena respuesta al tratamiento de $\mathrm{QT}^{78,79}$. El panel de expertos consideró estas recomendaciones (Tabla $3 \mathrm{~A}$ ).

Pregunta clínica 25. ¿Cuál es el manejo axilar EN PACIENTES CON CÁNCER DE MAMA LOCALMENTE AVANZADO?

Recomendación. Se sugiere en pacientes con cáncer de mama localmente avanzado y con axila positiva previo al tratamiento:

- En pacientes con evidencia clínica de ganglios linfáticos positivos cN2 o cN3, se sugiere llevar a cabo la DRA después de la terapia neoadyuvante, independientemente de la respuesta clínica. Nivel de evidencia $2+$, grado de recomendación $\mathrm{C}$.

- En pacientes con cN1 o NO con axilar positiva por biopsia por aguja fina o ganglio centinela previo al tratamiento, el manejo dependerá de la respuesta al tratamiento neoadyuvante. En aquéllos que continúen clínicamente positivos (ycN1) después del tratamiento, se sugiere la realización de la DRA. Nivel de evidencia 2+, grado de recomendación C. Después del tratamiento:
- En pacientes con ultrasonido axilar anormal posterior al tratamiento se sugiere realizar la DRA en el momento de la cirugía. Nivel de evidencia 2+, grado de recomendación $\mathrm{C}$.

- En pacientes con ultrasonido negativo o incierto, si uno o más ganglios centinelas tienen patología positiva (ypN+) o si un ganglio no centinela está tomado o si no se identifican ganglios centinelas, se sugiere que se lleve a cabo la DRA. Nivel de evidencia 2+, grado de recomendación $\mathrm{C}$.

Revisión de la literatura médica y análisis. El estudio clínico ACOSOG Z1071 ${ }^{80}$ evaluó la precisión de los ultrasonidos axilares en 611 pacientes con cáncer de mama T0-4, N1-2, M0 llevadas a ultrasonido, ganglio centinela y disección axilar posterior al tratamiento neoadyuvante (QTNeo), observando que las pacientes con ganglios sospechosos en el ultrasonido posterior a QTNeo eran propensas a tener ganglios positivos durante la cirugía (71.8\%) y un mayor número de ganglios positivos y metástasis ganglionares más grandes que las pacientes con nódulos de apariencia normal (56.5\%). El estudio clínico sugiere que limitar la toma de ganglios centinela a los pacientes con ultrasonido normal y la disección axilar en pacientes con ultrasonido anormal reduce los falsos negativos del resultado de ganglio centinela (cuando se toman al menos dos ganglios) de un 12.6 a un $9.8 \%$.

En una RS con metaanálisis ${ }^{81}$ en la que se valora la BGC como alternativa a la disección axilar completa posterior a QTNeo en pacientes con clínica de mama ganglio positivo (clínico o por ultrasonido), el estudio concluye que la BGC puede sustituir a la disección ganglionar en pacientes con ganglios negativos (al menos dos muestrados) después de QTNeo (ypNo).

Las recomendaciones actuales comentan que todas las pacientes con enfermedad ganglionar probada por biopsia antes de QTNeo deben ser llevadas a disección ganglionar ${ }^{78}$.

\section{Pregunta clínica 26. ¿Qué Resulta mejor en CUANTO A LA SOBREVIDA Y LAS TASAS DE RECURRENCIA EN EL MANEJO DE RADIOTERAPIA - RADIACIÓN LOCORREGIONAL O RADIACIÓN COMPLETA A MAMA- EN PACIENTES CON CÁNCER DE MAMA LOCALMENTE AVANZADO?}

Recomendación. En pacientes con cáncer de mama localmente avanzado, se recomienda radiación a pared torácica y áreas ganglionares ipsilaterales, ya que disminuye la recurrencia locorregional 
con aumento en la SLE y SG. Nivel de evidencia $1++$, grado de recomendación $A$.

La radioterapia a pared torácica y áreas ganglionares ipsilaterales se recomienda en pacientes con tumores $>5 \mathrm{~cm}$ y cuatro o más ganglios positivos. Nivel de evidencia 1++, grado de recomendación A.

La radioterapia a pared torácica y áreas ganglionares ipsilaterales se puede dar en pacientes con 1-3 ganglios positivos. Nivel de evidencia 1++, grado de recomendación $\mathrm{A}$.

Revisión de la literatura médica y análisis. Una RS con metaanálisis que examinó el papel de la radioterapia a ganglios regionales incluyó tres ensayos (dos resúmenes y una publicación completa) en pacientes con CMT o CMLA ${ }^{82}$, y concluyó que la radioterapia regional a mamarios internos y supraclavicular medios mejora la SLE, la SG y la sobrevida libre de metástasis a distancia en las fases I-III del cáncer de mama. Este análisis en particular no cumplió con los criterios de inclusión porque sólo aproximadamente el $36 \%$ de los pacientes tuvieron CMLA, por lo que los resultados deben ser confirmados con análisis de datos de subgrupos.

Una RS con metaanálisis más reciente ${ }^{83}$ de 8,135 mujeres en 22 ensayos aleatorios mostró este beneficio de la radiación adyuvante incluso en el establecimiento de 1-3 ganglios positivos. Para las 1,314 mujeres con disección axilar y 1-3 ganglios positivos, la radioterapia redujo la recurrencia locorregional (3.8 vs. 20.3\%), la recurrencia general $(\mathrm{RR}=0.68$; IC 95\%: 0.57-0.82) y la mortalidad por cáncer de mama (RR = 0.80; IC 95\%: 0.67-0.95); sin embargo, estos datos deben ponderarse, ya que en muchos casos no se dio terapia sistémica o se usaron tratamientos de QT menos eficaces, siendo el resultado influenciado por los resultados de los ensayos daneses.

La recomendación de incluir las áreas locales (región infraclavicular y área supraclavicular) de los ganglios en la radioterapia posmastectomía (RTPM) en pacientes con cáncer de mama T1-2 con 1-3 ganglios axilares positivos es consistente con la práctica actual y otras $\mathrm{GPC}^{78}$, aunque en subgrupos de pacientes con cáncer T1-2N1 y T3N0 (especialmente si la evaluación axilar es insuficiente 0 hay presente invasión linfovascular extensa) esta recomendación es controvertida y debe ser individualizada.

Pregunta clínica 27. ¿Está Indicada la RADIOTERAPIA EN PACIENTES CON CÁNCER DE MAMA
LOCALMENTE AVANZADO QUE PRESENTARON RESPUESTA PATOLÓGICA COMPLETA A LA TERAPIA NEOADYUVANTE?

Recomendación. En pacientes que recibieron terapia neoadyuvante y fueron llevadas a tratamiento quirúrgico se sugiere radiación a mama o pared torácica y áreas ganglionares ipsilaterales, independientemente de la respuesta al tratamiento, aunque es necesario contar con estudios controlados de alta calidad. Nivel de evidencia 3, grado de recomendación $D$.

Revisión de la literatura médica y análisis. Hasta la fecha no existen RS de la literatura médica que permitan determinar el beneficio de la radioterapia posterior a tratamiento neoadyuvante en pacientes que presentaron respuesta patológica completa (pCR). En general, los datos ${ }^{84}$ sugieren que para los pacientes con enfermedad en estadio II que logran pCR es improbable que la RTPM proporcione un beneficio significativo de recurrencia locorregional. En pacientes con enfermedad en estadio II o III que logran una pCR ganglionar, presencia de enfermedad mamaria residual o jóvenes, puede predecir tasas de LRR más altas, con evidencia contradictoria en cuanto a la necesidad de RTPM, particularmente en pacientes con enfermedad en estadio III.

Pregunta clínica 28. ¿EXISTe beneficio de la QUIMIOTERAPIA ADYUVANTE EN PACIENTES CON ENFERMEDAD RESIDUAL PATOLÓGICA POSTERIOR A QUIMIOTERAPIA NEOADYUVANTE CON ANTRACICLINAS Y TAXANOS?

Recomendación. No se sugiere el uso de QT adyuvante después del manejo con neoadyuvancia (tratamiento con antraciclinas y taxanos). Nivel de evidencia 4, grado de recomendación $D$.

Revisión de la literatura médica y análisis. Hasta el momento no existe evidencia de alta calidad que permita desarrollar una recomendación basada en evidencia.

El grupo de expertos clínicos está de acuerdo en no sugerir el uso de QT adyuvante posterior al manejo con neoadyuvancia. El pronóstico de los pacientes que no logran una PCR con QT neoadyuvante es peor comparado con quienes sí lo hacen, especialmente en pacientes con triple negativo o HER2+ tipos. Sin embargo, se desconoce si el uso de QT adyuvante en pacientes que ya han recibido tratamiento neoadyuvante completo es suficiente como para justificar su toxicidad ${ }^{85,86}$.

En el estudio CREATE-X, en población oriental, con capecitabina adyuvante por ocho ciclos en pacientes con enfermedad residual después de tratamiento 
neoadyuvante con taxanos 0 antraciclinas, se obtuvo beneficio en la SLE a cinco años (74 vs. $68 \%$; HR: 0.70; IC $95 \%$ : 0.53-0.92) y la SG (89 vs. $84 \%$; HR para muerte: 0.59; IC 95\%: 0.39-0.90). El análisis de subgrupos indicó mejoría en la SLE con capecitabina especialmente en triple negativo (70 vs. $56 \%$; HR: 0.58; IC $95 \%$ : 0.39-0.87). Sin embargo, la toxicidad fue más alta entre los pacientes que recibieron capecitabina, con eventos adversos como diarrea, neutropenia y síndrome mano-pie ${ }^{87}$. Estudios adicionales están evaluando otros agentes, incluyendo QT con platinos e inmunoterapia.

\section{Pregunta clínica 29. ¿Cuál es la eficacia y la SEGURIDAD DE LA CIRUGÍA CONSERVADORA DE MAMA EN COMPARACIÓN CON LA MASTECTOMÍA, EN PACIENTES CON CÁNCER DE MAMA LOCALMENTE AVANZADO CON BUENA RESPUESTA AL TRATAMIENTO NEOADYUVANTE, INCLUYENDO TERAPIA ENDOCRINA?}

Recomendación. Se sugiere el manejo con CCM llevada a cabo por un cirujano con adiestramiento y experiencia en pacientes bien seleccionadas y con vigilancia clínica estrecha de la respuesta clínica después del tratamiento neoadyuvante, ya que ha demostrado ser segura y eficiente en términos de SG, RL y sobrevida libre de RL. Nivel de evidencia 2+, grado de recomendación $\mathrm{C}$.

Revisión de la literatura médica y análisis. Una RS con metaanálisis ${ }^{88}$ incluyó 3,215 pacientes y comparó las tasas de recurrencia de pacientes llevadas a CCM versus mastectomía posterior al tratamiento de QT neoadyuvante. La prevalencia de la $\mathrm{RL}$ fue del $9.2 \%$ en el grupo de CCM versus el $8.3 \%$ en el grupo de mastectomía, sin diferencia significativa (OR = 1.07; IC 95\%: 0.28-1.48; $p=0.66$ ). La sobrevida libre de $R L$ a cinco años fue menor en el grupo de mastectomía que en el de CCM, pero no hubo diferencias significativas entre los dos grupos (OR = 1.11; IC 95\%: 0.61-1.99; $p$ $=0.74)$. La $S G$ a cinco años fue mejor para el grupo de CCM en comparación con el grupo de mastectomía $(\mathrm{OR}=0.32$; IC 95\%: 0.14-0.72; $\mathrm{p}=0.006$ ) (Tabla $3 \mathrm{~B}$ ).

Pregunta clínica 30. ¿Cuál es el beneficio de AÑADIR TERAPIA ANTI-HER2 EN EL TRATAMIENTO NEOADYUVANTE EN PACIENTES CON CÁNCER DE MAMA LOCALMENTE AVANZADO CON SOBREEXPRESIÓN DE HER2?

Recomendación. La terapia anti-HER2 incrementa la tasa de PCR en pacientes con cáncer de mama HER2+. Los tratamientos recomendados son: trastuzumab con QT (nivel de evidencia 1++, grado de recomendación A) y pertuzumab con trastuzumab con QT (nivel de evidencia 1+, grado de recomendación A).

No se recomienda el uso de lapatinib (nivel de evidencia 1++, grado de recomendación A) ni la terapia de anti-HER2 con antraciclinas (nivel de evidencia 1++, grado de recomendación A).

Revisión de la literatura médica y análisis. En la RS con metaanálisis de Houssami ${ }^{89}$, un análisis de subgrupos basado en tumores HER2+ considerando el efecto de la inclusión de terapia HER2-dirigida (trastuzumab) se asoció con un porcentaje de pCR estimado del 46.4\% (IC 95\%: 32.5-61.0\%).

Otra RS con metaanálisis del grupo internacional de Ensayos Colaborativos en Neoadyuvancia en Cáncer de Mama (CTNEoBC) ${ }^{90}$, en 1,989 pacientes con enfermedad HER2+ tratados con neoadyuvancia, encontró que añadir trastuzumab incrementó la tasa de respuesta completa (RpC) del 23 al 40\%. La RpC se asoció con una mejoría en la sobrevida libre de eventos (enfermedad invasiva) en los pacientes con HER2+, independientemente del estatus de receptores (HR: 0.39; IC 95\%: 0.31-0.50).

Pertuzumab ha sido evaluado en suma con trastuzumab y QT neoadyuvante. NeoSphere ${ }^{91}$ es un ensayo clínico en fase II de cuatro brazos y aleatorizado que incluyó a 417 pacientes con cáncer de mama HER2 + BC en estadio II-III para evaluar la eficacia de la combinación de trastuzumab y pertuzumab. Los pacientes fueron asignados a uno de los cuatro brazos de tratamiento: 1) trastuzumab sólo con docetaxel; 2) pertuzumab sólo con docetaxel; 3) trastuzumab y pertuzumab con docetaxel, o 4) trastuzumab y pertuzumab sin QT antes de la cirugía de mama. Aquéllos que fueron asignados al brazo 3 tuvieron mayor tasa de pCR (45.8\%), en comparación con los del brazo $1(29 \%)$ o el brazo $2(24 \%)$. El análisis a cinco años no demostró beneficio en la sobrevida libre de progresión (SLP) (HR: 0.69; IC 95\%: 0.34-1.40) de forma global; sin embargo, hizo evidente que las pacientes que tuvieron pCR obtuvieron mejores desenlaces clínicos en términos de SLE, aunque el estudio no fue diseñado inicialmente para detectar diferencias en este desenlace ${ }^{92}$.

El estudio TRYPHAENA ${ }^{93}$ fue diseñado para investigar la tolerabilidad de los tratamientos neoadyuvantes combinando pertuzumab con trastuzumab y una antraciclina estándar o QT basada en platino para cáncer de mama HER2+. Las pacientes fueron asignados al azar a: a) docetaxel, carboplatino, trastuzumab y pertuzumab (6c) (DCTP); b) FEC (3c) seguidos docetaxel (3c) más 
trastuzumab o pertuzumab (FEC/DTP), o c) FEC (3c) seguidos de docetaxel (3c), todos simultáneamente con trastuzumab o pertuzumab (FEC-TP/DTP), resultando en una $\mathrm{RpC}$ del $61.6,57.3$ y $66.2 \%$, respectivamente.

\section{Pregunta clínica 31. ¿Cuál es el subgrupo de PACIENTES CON CÁNCER DE MAMA LOCALMENTE AVANZADO QUE SE BENEFICIA DE LA NEOADYUVANCIA SISTÉMICA CON QUIMIOTERAPIA?}

Recomendación. La neoadyuvancia sistémica se recomienda en pacientes con cáncer de mama localmente avanzado (estadios clínicos IIB-IIIC), sin importar el subtipo. Nivel de evidencia 1+, grado de recomendación A.

Revisión de la literatura médica y análisis. En una RS con metaanálisis ${ }^{89}$ se midió la RpC especificando dos modelos de metarregresión, siendo el segundo modelo el que permitió determinar las respuestas por subtipo, encontrando tasas de RpC del 8.3\% (6.7-10.2\%) en HR+/HER2- (OR = 1/referente), $18.7 \%$ (15.0-23.1\%) en HER2+/HR+ (OR = 2.6), 38.9\% (33.2-44.9\%) en HER2+/ HR- $(\mathrm{OR}=7.1)$ y $31.1 \%(26.5-36.1 \%)$ en triple negativo $(\mathrm{OR}=5.0)$. El tanto por ciento de $\mathrm{pCR}$ fue significativamente mayor para tumores HER2+/HR- en comparación con el subtipo triple negativo; sin embargo, la pCR fue muy similar para estos subtipos (OR $=5.0$ en ambos subtipos). Las mayores tasas de respuesta se alcanzaron basándose en antraciclinas con taxanos, determinado por 15 estudios, con tasas del $50 \%$.

En otro estudio, en el que se seleccionaron siete ensayos de los grupos GBG $^{77}$ y AGO-B ${ }^{94}$, se demostró que la RpC se asoció con la SLE en los tumores de mama subtipos luminal B/HER2- $(p=0.005)$, HER2+/no luminal $(p<0.001)$ y triples negativos $(p<0.001)$, pero no así en el cáncer de mama luminal $A(p=0.39)$ o luminal $B / H E R 2+(p=0.45)$. Así mismo, la $R p C$ se asoció con excelente pronóstico en tumores HER2+ (no luminal) (SLE, HR: 8.7; IC 95\%: 3.17-24.12) (SG, HR: 13.8; IC 95\%: 1.87-102) y triples negativos (SLE, HR: 6.0; IC 95\%: 3.929.25) (SG, HR: 12.41; IC 95\%: 5.82-26.49).

Un estudio de un solo centro ${ }^{95}$ que tomó los datos clínicos de siete estudios prospectivos, incluyendo 1,118 pacientes que recibieron neoadyuvancia con estadio I-III, mostró que los pacientes con CMTN, en comparación con los que no tenían CMTN, tuvieron tasas significativamente más altas de RpC (22 vs. $11 \%$; $p=0.034$ ), pero disminuyeron las tasas de SLP a los tres años $(p<0.0001)$ y la $S G$ a tres años $(p<0.0001)$. EI CMTN se asoció con un mayor riesgo de metástasis viscerales $(p=0.0005)$, menor riesgo de recurrencia ósea $(p=0.027)$ y menor supervivencia posrecurrencia $(p<0.0001)$. Las tasas de recidiva y muerte fueron más altas para TNBC sólo en los primeros tres años. Si se lograba pCR, los pacientes con TNBC y no TNBC tenían similar supervivencia $(p=0.24)$. Por el contrario, los pacientes con enfermedad residual tenían peor SG si padecían TNBC, en comparación con aquéllos no TNBC $(p<0.0001)$.

Pregunta clínica 32. En el Grupo de pacientes CON CÁNCER DE MAMA LOCALMENTE AVANZADO RH+, HER2-, ¿CUÁL ES EL BENEFICIO DE LA NEOADYUVANCIA SISTÉMICA CON TERAPIA ENDOCRINA?

Recomendación. Se sugiere el uso de IA sobre tamoxifeno; sin embargo, la evidencia científica que ha evaluado el beneficio de la neoadyuvancia sistémica con terapia endocrina es escasa. Los análisis benefician mayormente a las pacientes posmenopáusicas bien seleccionadas y con vigilancia estrecha a la respuesta clínica con expresión de ER. Nivel de evidencia 1+, grado de recomendación A.

Revisión de la literatura y análisis. Una RS con metaanálisis ${ }^{96}$ realizó la comparación entre dos ensayos clínicos aleatorizados probando el tratamiento preoperatorio endocrino versus QT neoadyuvante. En un subanálisis de mujeres posmenopáusicas, la tendencia hacia el beneficio de la QT desaparece, sugiriendo que este subgrupo específico podría beneficiarse de la terapia preoperatoria endocrina y del tratamiento citotóxico; aunque los autores concluyen que esto debe ser demostrado en estudios clínicos prospectivos. Lo que este metaanálisis logra demostrar es un beneficio no significativo de la QT en las tasas de respuesta (OR = 0.75; IC 95\%: 0.35-1.6) y la superioridad de los IA, en comparación con tamoxifeno, en las tasas de respuesta global medida con tumorímetro (OR = 1.9; IC 95\%: 1.173.08) o ultrasonido (OR = 1.54; IC 95\%: 1.18-2.00).

\section{Pregunta clínica 33. ¿Cuál es la mejor} ESTRATEGIA QUIRÚRGICA DE MANEJO DESPUÉS DE RECURRENCIA LOCAL IPSILATERAL EN PACIENTES CON ADENOCARCINOMA DE MAMA CON CIRUGÍA CONSERVADORA PREVIA?

Recomendación. Se sugiere realizar la mastectomía al presentarse la recurrencia ipsilateral en pacientes que fueron llevadas inicialmente a CCM. Nivel de evidencia 3 , grado de recomendación C.

Revisión de la literatura médica y análisis. A día de hoy no existen MA O RS que comparen estas 
intervenciones o definan un subgrupo que se beneficie de alguna de ellas.

Existen estudios que buscan dar lugar a la cirugía conservadora posterior a la recurrencia ${ }^{97}$, encontrando que la incidencia acumulada a los cinco años de una nueva $R L$ del tumor después de CCM fue del $15.2 \%$ en los pacientes con tamaño de la tumoral a la recurrencia (TTR) $\leq 2 \mathrm{~cm}$ y tiempo para la recurrencia (TRLI) de $>48$ meses, del $31.2 \%$ en los pacientes con TTR $\leq 2 \mathrm{~cm}$ y TRLI $\leq 48$ meses, y del $71.2 \%$ en pacientes con TTR $>2 \mathrm{~cm}(p<0.001)$.

Otro estudio retrospectivo ${ }^{98}$ demostró que la $S G$ a 10 años en las pacientes llevadas a mastectomía de rescate posterior a recurrencia locorregional fue del $60.2 \%$ para aquéllas que alcanzaron márgenes negativos y del $26.3 \%$ para quienes tenían márgenes cercanos o positivos. En las pacientes llevadas a CCM, la SG a 10 años fue del $67.2 \%$ para aquéllas con márgenes negativos y del $19.2 \%$ para aquéllas con márgenes cercanos o positivos. En la comparación entre mastectomía y biopsia o excisión local, la sobrevida específica por cáncer de mama fue superior (HR: $0.66 ; p=0.212$ ), pero sin significancia estadística, lo mismo que para la SG (HR: $0.77 ; p=0.38$ ).

\section{Pregunta clínica 34. ¿Cuál es el tratamiento SISTÉMICO RECOMENDADO EN PACIENTES CON CÁNCER DE MAMA CON RECURRENCIA LOCORREGIONAL POSTERIOR A TRATAMIENTO CON CIRUGÍA Y/O RADIOTERAPIA?}

Recomendación. La evidencia es de baja calidad y escasa. Debido a ello, se sugiere individualizar el caso de acuerdo al intervalo libre de enfermedad, subtipo biológico, comorbilidades y tratamientos previos, para aquellas pacientes con cáncer de mama recurrente (enfermedad limitada) que recibieron tratamiento local con éxito, sin evidencia de enfermedad. Nivel de evidencia 1-, grado de recomendación A.

Revisión de la literatura médica y análisis. Se llevó a cabo un análisis del ensayo clínico BIG 1-02/IBCSG 2702/NSABP B-37 $7^{99}$ en 162 pacientes a quienes se les realizó resección por cáncer de mama con $\mathrm{RL}$ y aleatorizadas a recibir QT posterior a la excisión (con tratamiento determinado por el oncólogo tratante) o sin tratamiento; todas las pacientes, especialmente las que presentaron márgenes positivos, fueron sometidas a radioterapia. La SLE en aquéllas que recibieron QT versus las que no la recibieron fue del 69 versus 57\% (HR: 0.59; IC 95\%: 0.35 0.99). Sin embargo, la población es pequeña con sesgo en los eventos entre las pacientes con receptores hormonales positivos (que recibieron hormonoterapia).
No existen otros estudios o MA que discutan este escenario, por lo que no es posible emitir una recomendación al respecto (Tabla $3 \mathrm{C}$ ).

\section{Pregunta clínica 35. En pacientes con cáncer DE MAMA RECURRENTE REGIONAL Y/O LOCORREGIONAL, ¿QUÉ TIPO DE RADIOTERAPIA ES EL MEJOR TRATAMIENTO?}

Recomendación. En los pacientes que presentan recurrencia regional y/o locorregional y que no han recibido previamente irradiación se sugiere la administración de radioterapia. Nivel de evidencia 4, grado de recomendación $\mathrm{D}$.

En pacientes con recurrencia regional y/o locorregional que han recibido previamente irradiación se sugiere la evaluación por parte de un equipo multidisciplinario, ya que la reirradiación debe ser un tratamiento individualizado. Nivel de evidencia 4 , grado de recomendación $D$.

Revisión de la literatura médica y análisis. No hay evidencia de alta calidad que haya evaluado el beneficio de la irradiación de pared torácica o nodal regional después de la mastectomía posrecurrencia. Sin embargo, existen revisiones ${ }^{100}$ que comentan que la irradiación de los ganglios regionales es una opción en el escenario infrecuente de un paciente que inicialmente no se sometió a irradiación nodal regional en el momento del BCT y en el que se encuentran cuatro o más ganglios positivos, tamaño tumoral $\geq 5 \mathrm{~cm}$ o extensión de grasa perinodal en el momento de la mastectomía posrecurrencia. La reirradiación de la pared torácica después de RT total puede ser ofrecida a pacientes con recurrencias de muy alto riesgo, particularmente con un largo intervalo de tiempo desde la radiación previa. En un estudio multiinstitucional se alcanzaron buenas Rpc con la segunda reirradiación $(57 \%)^{101}$.

La braquiterapia intersticial basada en catéter y la RT estándar de haz externo pueden administrarse a la mama radiada previamente, sin efectos secundarios significativos en la mayoría de los pacientes y con resultados cosméticos aceptables en algunos de ellos.

Pregunta clínICa 36. ¿EN QuÉ Situaciones SE RECOMIENDA INICIAR QUIMIOTERAPIA EN PACIENTES CON CÁNCER DE MAMA RECEPTORES HORMONALES POSITIVOS (HER2-) Y RECURRENCIA SISTÉMICA?

Recomendación. Se recomienda inicialmente el uso de QT en pacientes con recurrencia sistémica y enfermedad sintomática rápidamente progresiva 
o crisis visceral sistémica, por el incremento en las tasas de respuesta. Nivel de evidencia 1+, grado de recomendación $\mathbf{A}$.

Revisión de la literatura y análisis. Una RS con metaanálisis ${ }^{102}$ que incluyó ocho ensayos clínicos (publicados antes de 1995) comparó las tasas de respuesta de la QT versus la endocrinoterapia, demostrando una ventaja de la QT (RR: 1.25; IC 95\%: 1.01-1.54), pero no una significancia en la SG (HR: 0.94; IC 95\%: 0.79-1.12).

\section{Cáncer de mama metastásico}

\section{Pregunta clínica 37. ¿Cuál es el beneficio de REALIZAR RESECCIÓN DEL TUMOR PRIMARIO EN PACIENTES CON CÁNCER DE MAMA METASTÁSICO?}

Recomendación. Se sugiere en pacientes con tumores primarios pequeños y enfermedad oligometastásica. La resección del tumor primario en pacientes con cáncer de mama metastásico parece tener beneficio en la $S G$ a tres años, pero el beneficio se limita a las pacientes con buena respuesta al tratamiento previo con QT. Nivel de evidencia 1-, grado de recomendación $\mathrm{A}$.

La evidencia es de baja calidad y en algunos estudios los resultados son contradictorios. Se requieren estudios controlados para mejorar la calidad de la evidencia.

Revisión de la literatura médica y análisis. En una RS con metaanálisis de 10 estudios retrospectivos ${ }^{103}$, que incluyeron 28,693 pacientes con cáncer de mama en estadio IV, las mujeres sometidas a una resección del cáncer de mama primario tenían mejores tasas de sobrevida a tres años en comparación con aquéllas que no fueron llevadas a una resección primaria del cáncer (40 vs. $22 \%$ ) (OR = 2.32; IC 95\%: 2.08-2.60). El análisis de subgrupos favoreció a los tumores primarios pequeños, menos comorbilidades y oligometastásicas $(p<0.01)$. Una revisión previa ${ }^{104}$ demostró que el beneficio en la sobrevida en pacientes llevados a cirugía de primario en cáncer de mama en estadio IV se limitaba a aquéllos que recibieron QT inicialmente y obtuvieron buena respuesta (del $90 \%$ a dos años) versus a los que se les realizó cirugía y luego recibieron QT, aunque estos análisis cuentan con sesgo de selección por su carácter retrospectivo.

Al menos dos estudios prospectivos cuentan con resultados en la comparación de resección de primario en contexto de enfermedad metastásica. En un estudio ${ }^{105}, 350$ mujeres con cáncer de mama metastásico de novo que lograron una respuesta parcial o completa a la QT basada en antraciclinas fueron asignadas aleatoriamente a cirugía (mastectomía o CCM) y radiación postoperatoria estándar versus ningún tratamiento locorregional. No hubo diferencia entre los dos grupos en cuanto a la SG (19.2 vs. 20.5 meses, respectivamente) (HR: 1.04; IC 95\%: 0.81-1.34). Se observó que el tratamiento locorregional resultó en una mejoría en la SLP locorregional (mediana no alcanzada vs. 18.2 meses) (HR: 0.16; IC 95\%: 0.10-0.26), pero empeoró la SLP a distancia (11.3 vs. 19.8 meses) (IC 95\%: 1.08-1.85), teniendo como sesgo que no se seleccionaron las QT de acuerdo a los subtipos tumorales y no se usó trastuzumab en los pacientes HER2+. Otro estudio ${ }^{106}$, que usó terapias sistémicas más actuales y acordes al subtipo tumoral, incluyó a 274 mujeres con cáncer de mama metastásico de novo que se asignaron aleatoriamente a tratamiento quirúrgico (mastectomía o BCS con radiación) seguido por la terapia sistémica versus terapia sistémica sola. Aunque no hubo diferencias en la supervivencia a los tres años (60 y $51 \%$, respectivamente; $p=0.5$ ), los pacientes tratados con manejo local experimentaron una mejoría en la supervivencia a cinco años con tratamiento locorregional (46.4 vs. $26.4 \%$ ) (HR: 0.66; IC 95\%: 0.49-0.88) (Tabla 4 A).

Pregunta clínica 38. ¿Cuáles son las INDICACIONES PARA METASTASECTOMÍA (HEPÁtICA, PULMONAR Y OTROS SITIOS) EN PACIENTES CON CÁNCER DE MAMA METASTÁSICO?

Recomendación. Se sugiere la metastasectomía hepática en aquellos pacientes con afección hepática limitada, particularmente en aquéllos con enfermedad hormonal positiva, función hepática normal, buen estado funcional y largo periodo de intervalo libre de enfermedad. Nivel de evidencia 2++, grado de recomendación $\mathrm{B}$.

Se sugiere la metastasectomía pulmonar en el caso de metástasis solitarias, un periodo de intervalo libre de enfermedad de 36 meses y enfermedad hormonal positiva. Se benefician los pacientes que pueden someterse a escisión completa. Nivel de evidencia 2++, grado de recomendación B.

Todo lo anterior en la consideración de tumor primario controlado y resección completa de la enfermedad metastásica.

Revisión de la literatura médica y análisis. Una RS ${ }^{107}$, en la cual no pudo realizarse metaanálisis por la heterogeneidad de los grupos de los estudios, reportó en dos variables: el estado de los márgenes y el uso de la modalidad ablativa. En las pacientes con enfermedad 
Tabla 4A. Recomendaciones clínicas, síntesis y niveles de evidencia para el cáncer de mama metastásico.

\begin{tabular}{|c|c|}
\hline $\begin{array}{l}37 \text { - Resección del tumor } \\
\text { primario }\end{array}$ & $\begin{array}{l}\text { - Se sugiere en pacientes con tumores } \\
\text { primarios pequeños y enfermedad } \\
\text { oligometastásica. } \\
\text { - (nivel de evidencia 1-, grado de } \\
\text { recomendación A) }\end{array}$ \\
\hline $\begin{array}{l}\text { 38.- Metastasectomía } \\
\text { (hepática, pulmonar y } \\
\text { otros sitios) }\end{array}$ & $\begin{array}{l}\text { - Se sugiere la metastasectomía hepática en } \\
\text { aquellos pacientes con afección hepática } \\
\text { limitada } \\
\text { - (nivel de evidencia } 2++, \text { grado de } \\
\text { recomendación B). }\end{array}$ \\
\hline $\begin{array}{l}\text { 39.- Tratamiento } \\
\text { endocrino en pacientes } \\
\text { premenopáusicas con } \\
\text { receptores hormonales } \\
\text { positivos, HER2- }\end{array}$ & $\begin{array}{l}\text { - Se recomienda la supresión ovárica o } \\
\text { ablación en combinación con tamoxifeno } \\
\text { (nivel de evidencia } 1++, \text { grado de } \\
\text { recomendación } A \text { ). }\end{array}$ \\
\hline $\begin{array}{l}\text { 40.- Tratamiento endocrino } \\
\text { recomendado en pacientes } \\
\text { premenopáusicas con cáncer } \\
\text { de mama receptores } \\
\text { hormonales positivos, } \\
\text { HER2- en segunda línea }\end{array}$ & $\begin{array}{l}\text { - Se sugiere tratar a estas pacientes como } \\
\text { posmenopáusicas en caso de progresión de } \\
\text { primera línea } \\
\text { - (nivel de evidencia } 4, \text { grado de } \\
\text { recomendación D). }\end{array}$ \\
\hline $\begin{array}{l}\text { 41.- Tratamiento endocrino } \\
\text { recomendado en pacientes } \\
\text { posmenopáusicas, } \\
\text { receptores hormonales } \\
\text { positivos, HER2 - }\end{array}$ & $\begin{array}{l}\text { - El régimen recomendado son los inhibidores de } \\
\text { aromatasa con un inhibidor CDK } 4 / 6 \\
\text {-(nivel de evidencia } 1++, \text { grado de recomendación B) } \\
\text { - Fulvestrant monofármaco (nivel de evidencia } 1+, \text { grado } \\
\text { de recomendación A) o un inhibidor de aromatasa } \\
\text { monofármaco (nivel de evidencia } 1+, \text { grado de } \\
\text { recomendación A). }\end{array}$ \\
\hline
\end{tabular}

metastásica a un solo órgano, sólo los estudios con enfermedad hepática limitada (no difusa) encontraron una mejora en la sobrevida, no observándose en las metástasis a sistema nervioso central o pulmonares.

Un estudio ${ }^{108}$ en el que se valoró la metastasectomía pulmonar de manera retrospectiva encontró que el factor pronóstico asociado a mejor sobrevida era un intervalo libre de enfermedad $\geq 36$ meses, con una sobrevida a cinco años del $45 \%$ y una sobrevida a los 10 años del $26 \%$. La metástasis pulmonar solitaria también está asociada con una tasa de sobrevida a cinco años del $44 \%$, y del $23 \%$ después de 10 y 15 años, pero esto no fue estadísticamente significativo en comparación con las metástasis múltiples. 
Pregunta clínica 39. ¿Cuál es el tratamiento ENDOCRINO RECOMENDADO EN PACIENTES

PREMENOPÁUSICAS CON CÁNCER DE MAMA

RECEPTORES HORMONALES POSITIVOS, HER2-, METASTÁSICO QUE NO HAN RECIBIDO TRATAMIENTO ENDOCRINO EN EL AÑO ANTERIOR?

Recomendación. Se recomienda la supresión ovárica o ablación en combinación con tamoxifeno como tratamiento de elección en pacientes premenopáusicas con cáncer de mama receptores hormonales positivos metastásico que no han recibido tratamiento endocrino en el año anterior. Nivel de evidencia 1++, grado de recomendación A.

Se sugiere como alternativa el uso de IA con supresión ovárica o ablación.

Revisión de la literatura médica y análisis. Un análisis conjunto de estudios en fase II antes de $1991^{109}$ demostró una tasa de respuesta del $45 \%$ para el tamoxifeno en pacientes premenopáusicas. Una RS con metaanálisis ${ }^{110}$ que incluía cuatro ensayos clínicos, con un total de 506 mujeres premenopáusicas, comparó el uso de agonistas de la hormona liberadora de gonadotropina versus el uso combinado de agonistas de GnRH con tamoxifeno, y encontró un beneficio en la SLP (HR: 0.70; IC 95\%: 0.58-0.85) y la SG (HR: 0.78; IC 95\%: 0.63-0.96) a favor del grupo en combinación.

Otro estudio ${ }^{111}$ usó agonistas de GnRH con IA y mostró resultados comparables con pacientes posmenopáusicas; sin embargo, la muestra de pacientes fue pequeña, por lo que no cambia la recomendación.

\section{Pregunta clínica 40. ¿Cuál es el tratamiento ENDOCRINO RECOMENDADO EN PACIENTES PREMENOPÁUSICAS CON CÁNCER DE MAMA RECEPTORES HORMONALES POSITIVOS, HER2-, METASTÁSICO QUE RECIBIERON TRATAMIENTO ENDOCRINO EN EL AÑO ANTERIOR O DE SEGUNDA LÍNEA?}

Recomendación. La literatura médica no permite emitir una recomendación basada en evidencia; sin embargo, se sugiere tratar a estas pacientes como posmenopáusicas en caso de progresión de primera línea. Nivel de evidencia 4, grado de recomendación $\mathrm{D}$.

Revisión de la literatura médica y análisis. En el estudio que valoraba el uso de palbociclib con fulvestrant versus fulvestrant solo ${ }^{112}$, posterior a la progresión de primera línea de terapia endocrina o dentro de los 12 meses previos, se permitió la inclusión de pacientes premenopáusicas o perimenopáusicas $(21 \%$ de la población del estudio), demostrando en ellas un beneficio de la terapia combinada (HR: 0.44; IC 95\%: 0.23-0.83). El grupo de expertos clínicos está de acuerdo en tratar a estas pacientes como posmenopáusicas en caso de progresión a primera línea.

\section{Pregunta clínica 41. ¿Cuál es el tratamiento ENDOCRINO RECOMENDADO EN PACIENTES POSMENOPÁUSICAS CON CÁNCER DE MAMA METASTÁSICO, RECEPTORES HORMONALES POSITIVOS, HER2-, QUE NO HAN RECIBIDO TRATAMIENTO ENDOCRINO EN EL AÑO ANTERIOR?}

Recomendación. El tratamiento recomendado son los IA con un inhibidor CDK 4/6 (nivel de evidencia 1++, grado de recomendación A). Otras opciones son fulvestrant monofármaco (nivel de evidencia 1+, grado de recomendación A) O un IA monofármaco (nivel de evidencia 1+, grado de recomendación A).

Revisión de la literatura médica y análisis. En una RS de la literatura con metaanálisis de 23 estudios aleatorizados, con un total de 8,504 pacientes $^{113}$, se comparó el uso de IA versus tamoxifeno en pacientes posmenopáusicas con cáncer de mama metastásico o avanzado, y se reportó mejoría en la SG con los inhibidores de tercera generación (HR: 0.89; IC 95\%: 0.800.99), lo cual fue corroborado por el grupo Cochrane más adelante ${ }^{114}$ (HR: 0.90; IC 95\%: 0.84-0.97). En 2011, otro metaanálisis con la misma comparación ${ }^{115}$ determinó que existe beneficio a favor de los IA en cuanto a las tasas de respuesta (OR = 1.56; IC 95\%: 1.17-2.07) y en el beneficio clínico (OR = 1.70; IC 95\%: 1.24-2.33); sin embargo, la tendencia a la mejoría en la sobrevida es considerada no significativa (OR $=1.95$; IC 95\%: 0.88-4.30; $p=0.10$ ). Otro metaanálisis más reciente ${ }^{60}$, cuyo desenlace primario fue la recurrencia, comparó el uso durante cinco años de IA o tamoxifeno y mostró una mejoría con los IA durante los años 2-4 de uso (RR = 0.80; IC 95\%: 0.68-0.93), con una mortalidad a 10 años menor con el uso de los IA (12.1 vs. $14.2 \%$; $R R=0.85$; IC 95\%: 0.75-0.96). Los datos son limitados para determinar qué IA es mejor sobre los otros ${ }^{114}$.

El papel de fulvestrant en la enfermedad metastásica quedó plasmado en un metaanálisis reciente tomando nueve estudios, sumando un total de 4,514 pacientes ${ }^{116}$. Respecto a la SLP, las pacientes con fulvestrant tuvieron la misma respuesta que los grupos de control 
Tabla 4B. Recomendaciones clínicas, síntesis y niveles de evidencia para el cáncer de mama metastásico.

\begin{tabular}{|c|c|}
\hline $\begin{array}{l}42 \text { - Tratamiento } \\
\text { endocrino en pacientes } \\
\text { receptores hormonales } \\
\text { positivos, segunda línea }\end{array}$ & $\begin{array}{l}\text { - Inhibidor CDK } 4 / 6 \text { con fulvestrant (nivel de evidencia 1+, grado de } \\
\text { recomendación A) } \\
\text { - Inhibidor CDK } 4 / 6 \text { con inhibidor de aromatasa (nivel de evidencia 1+, } \\
\text { grado de recomendación IA) } \\
\text { - Everolimus con exemestano (nivel de evidencia 1+, grado de } \\
\text { recomendación A) } \\
\text { - Fulvestrant monofármaco (nivel de evidencia 1+, grado de recomendación } \\
\text { A) }\end{array}$ \\
\hline $\begin{array}{l}\text { 43. - Everolimus } 0 \\
\text { Inhibidores Cdk4/6 a la } \\
\text { terapia hormonal en } \\
\text { paciente con cáncer de } \\
\text { mama metastásico HER2- }\end{array}$ & $\begin{array}{l}\text { - Se recomienda en primera línea añadir inhibidores } \\
\text { CDK con IA } \\
\text { - (nivel de evidencia 1++, grado de recomendación A) } \\
\text { - En segunda línea añadir everolimus a la terapia } \\
\text { endocrina } \\
\text { - (nivel de evidencia } 1++, \text { grado de recomendación A). }\end{array}$ \\
\hline $\begin{array}{l}\text { 44.- Terapia endocrina en } \\
\text { combinación con } \\
\text { quimioterapia }\end{array}$ & $\begin{array}{l}\text { - Se sugiere no utilizar este esquema en } \\
\text { pacientes con enfermedad metastásica } \\
\text { - (nivel de evidencia } 1+, \text { grado de } \\
\text { recomendación A). }\end{array}$ \\
\hline $\begin{array}{l}\text { 45. - Tratamiento sistémico } \\
\text { en pacientes con cáncer de } \\
\text { mama metastásico HER2+ }\end{array}$ & $\begin{array}{l}\text { - Se recomienda la administración de trastuzumab más } \\
\text { pertuzumab en combinación con un taxano (docetaxel } \\
\text { o paclitaxel) en pacientes HER2+ no tratado que no } \\
\text { recibieron terapia adyuvante en el momento del } \\
\text { diagnóstico inicial como primera línea de tratamiento } \\
\text {-(nivel de evidencia 1+, grado de recomendación A) }\end{array}$ \\
\hline $\begin{array}{l}\text { 46.- Tratamiento sistémico en } \\
\text { combinación vs monoterapia en } \\
\text { pacientes receptores hormonales } \\
\text { positivos con crisis visceral o } \\
\text { receptores hormonales negativos y } \\
\text { HER2- }\end{array}$ & $\begin{array}{l}\text { - Se recomienda el uso del manejo sistémico } \\
\text { como monofármaco y en casos en que se } \\
\text { buscan tasas de respuesta rápida se sugiere } \\
\text { usar combinación. } \\
\text { - (nivel de evidencia } 1+, \text { grado de } \\
\text { recomendación B) }\end{array}$ \\
\hline
\end{tabular}

(HR: 0.95; IC 95\%: 0.89-1.02), y también se demostró la no diferencia con fulvestrant en la tasa de beneficio clínico (RR = 1.03; IC 95\%: 0.97-1.10) o la SG (HR: 0.97; IC 95\%: 0.87-1.09), sin mejoría en monofármaco versus combinar con otros IA. Este estudio no considera la combinación con inhibidores de CDK 4/6.

Los inhibidores de ciclinas CDK 4/6 demuestran eficacia y beneficio en pacientes posmenopáusicas en la
SLP. Actualmente su uso está autorizado junto con IA. Los estudios que validan esto se encuentran en una RS reciente ${ }^{117}$, la cual plasma los beneficios en los estudios en fase I y II, lo cual llevó a la autorización del uso en estudios en fase III. El uso conjunto de inhibidores CDK 4/6 con IA se analizó en los siguientes estudios: 
- El estudio PALOMA-2 ${ }^{118}$ evaluó el uso de letrozol con o sin palbociclib en 666 pacientes $\mathrm{RH}+$, HER2-, demostrando mejoría en la SLP (HR: 0.58; IC 95\%: $0.46-0.72)$, con tasas de respuesta del 42.1 versus $34.7 \%(p=0.031)$, estando pendiente los resultados en cuanto a la SG.

- MONALEESA-2 ${ }^{119}$ analizó el uso de ribociclib con o sin letrozol en 668 pacientes, en primera línea, mostrando igualmente beneficio en la SLP (HR: 0.56; IC 95\%: 0.43-0.72), con tasas de respuesta del 40.7 versus $27.5 \%(p<0.001)$. La tolerancia a la toxicidad de estos inhibidores quedó demostrada en una RS con metaanálisis publicada recientemente ${ }^{120}$.

\section{Pregunta clínica 42. ¿Cuál es el tratamiento} ENDOCRINO RECOMENDADO EN PACIENTES

POSMENOPÁUSICAS CON CÁNCER DE MAMA RECEPTORES HORMONALES POSITIVOS METASTÁSICO QUE RECIBIERON TRATAMIENTO ENDOCRINO EN EL AÑO ANTERIOR O DE SEGUNDA LÍNEA?

Recomendación. Se recomiendan por su beneficio en la SLP:

- Inhibidor CDK 4/6 con fulvestrant. Nivel de evidencia 1+, grado de recomendación $A$.

- Inhibidor CDK 4/6 con IA. Nivel de evidencia 1+, grado de recomendación $A$.

- Everolimus con exemestano. Nivel de evidencia 1+, grado de recomendación A.

- Fulvestrant monofármaco. Nivel de evidencia 1+, grado de recomendación $\mathrm{A}$.

- Inhibidores de aromatasa monofármaco. Nivel de evidencia 1+, grado de recomendación A.

- Tamoxifeno. Nivel de evidencia 1+, grado de recomendación A.

Revisión de la literatura médica y análisis. El uso de inhibidores CDK $4 / 6$ ha demostrado su beneficio en diferentes estudios. El uso de fulvestrant con palbociclib en segunda línea en pacientes que progresaron a primera línea de tratamiento se basa en los resultados del ensayo clínico PALOMA-3, en el que se comparó el uso de fulvestrant con palbociclib versus fulvestrant con placebo, encontrando un beneficio en la SLP (HR: 0.46; IC 95\%: 0.36-0.59) ${ }^{112}$; sin embargo, está pendiente el beneficio en la SG. El estudio MONARCH-2121 asignó a las pacientes a fulvestrant con o sin amebaciclib, mostrando mejoría en la SLP (HR: 0.55; IC 95\%: 0.45-0.68).

El uso de everolimus, un inhibidor de la vía PI3K/ AKT/mTOR, ha mostrado beneficio en pacientes con cáncer de mama metastásico, receptores hormonales positivos, HER2-, en segunda línea posterior a progresión de la enfermedad sobre primera línea metastásica o sobre adyuvancia. El uso con exemestano se evaluó en el estudio BOLERO-2 $2^{122}$, el cual enroló a pacientes que progresaron a anastrozol aleatorizándolos a dos brazos de manejo: exemestano con everolimus o exemestano monofármaco, demostrando un beneficio de la combinación en la SLP (HR: 0.45; IC 95\%: 0.35$0.54)$ y en la respuesta global (9.5 vs. $0.4 \%$, respectivamente), aunque sin diferencia en la SG (HR: 0.89 ; IC 95\%: 0.73-1.10). El uso combinado con tamoxifeno quedó plasmado en el estudio GINECO ${ }^{123}$, que demostró mejoría en el tiempo a la progresión (HR: 0.54; IC 95\%: 0.36-0.81) (Tabla 4 B).

Pregunta clínica 43. ¿Cuál es el beneficio de AÑADIR EVEROLIMUS O INHIBIDORES CDK 4/6 A LA TERAPIA HORMONAL EN PACIENTES CON CÁNCER DE MAMA METASTÁSICO HER2-?

Recomendación. Se recomienda en primera línea añadir inhibidores CDK con IA por el beneficio en la SLP. Nivel de evidencia 1++, grado de recomendación A.

Se recomienda en segunda línea añadir everolimus a la terapia endocrina debido al beneficio en la SLP. Nivel de evidencia 1++, grado de recomendación A.

Se recomienda el uso de inhibidores CDK con fulvestrant como segunda línea por el beneficio en la SLP. Nivel de evidencia $1++$, grado de recomendación B.

Revisión de la literatura médica y análisis. Los inhibidores de ciclinas CDK 4/6 han demostrado eficacia y beneficio en pacientes posmenopáusicas en la SLP. En el momento actual su uso está autorizado junto con IA. Los estudios que lo validan se encuentran en una RS reciente ${ }^{117}$, la cual muestra los beneficios en los estudios en fase I y II, los cuales fueron confirmados, lo cual llevó a la autorización del uso en estudios en fase III. El uso conjunto de inhibidores CDK 4/6 con IA se analizó en los siguientes estudios:

- El estudio PALOMA-2 ${ }^{118}$ evaluó el uso de letrozol con o sin palbociclib en 666 pacientes $\mathrm{RH}+$, HER2-, demostrando mejoría en la SLP (HR: 0.58; IC 95\%: $0.46-0.72)$ con tasas de respuesta del 42.1 versus $34.7 \%(p=0.031)$, estando pendiente los resultados en cuanto a la SG.

- MONALEESA-2 ${ }^{119}$ analizó el uso de ribociclib con 0 sin letrozol en 668 pacientes en primera línea, mostrando igualmente beneficio en la SLP (HR: 0.56; 
IC 95\%: 0.43-0.72), con tasas de respuesta del 40.7 versus $27.5 \%(p<0.001)$. La tolerancia a la toxicidad de estos inhibidores quedó demostrada en una RS con metaanálisis reciente ${ }^{120}$.

El uso de fulvestrant con palbociclib en segunda línea de pacientes que progresaron a primera línea de tratamiento se soporta en los resultados del ensayo clínico PALOMA-3, en el que se comparó el uso de fulvestrant con palbociclib versus fulvestrant con placebo, encontrando un beneficio en la SLP (HR: 0.46; IC 95\%: 0.36$0.59)^{112}$; sin embargo, está pendiente el beneficio en la SG. El estudio MONARCH-2 asignó a las pacientes a fulvestrant con o sin abemaciclib, mostrando mejoría en SLP (HR: 0.55; IC 95\%: 0.45-0.68) ${ }^{121}$.

El uso de everolimus, un inhibidor de la vía PI3K/ AKT/mTOR, ha mostrado beneficio en pacientes con cáncer de mama metastásico, receptores hormonales positivos, HER2-, en segunda línea posterior a progresión de la enfermedad sobre primera línea metastásica o sobre adyuvancia. El uso con exemestano se evaluó en el estudio BOLERO-2 ${ }^{122}$, el cual enroló a pacientes que progresaron a anastrozol aleatorizándolos a dos brazos de manejo: exemestano con everolimus o exemestano monofármaco, demostrando un beneficio con la combinación en la SLP (HR: 0.45; IC 95\%: 0.35 $0.54)$ y en la respuesta global (9.5 vs. $0.4 \%$, respectivamente), pero sin encontrar diferencia en la SG (HR: 0.89; IC 95\%: 0.73-1.10). El uso combinado con tamoxifeno quedó plasmado en el estudio GINECO ${ }^{123}$, que demostró mejoría en el tiempo a la progresión (HR: 0.54; IC 95\%: 0.36-0.81).

\section{Pregunta clínica 44. ¿EXIste beneficio al ADMINISTRAR LA TERAPIA ENDOCRINA EN COMBINACIÓN CON QUIMIOTERAPIA?}

Recomendación. La evidencia científica de alta calidad es escasa para recomendar el uso de la combinación de QT con terapia endocrina en enfermedad metastásica de manera rutinaria, por lo que se sugiere no utilizar este esquema en pacientes con enfermedad metastásica. Nivel de evidencia 1+, grado de recomendación A.

Revisión de la literatura médica y análisis. Existe poca evidencia y ninguna RS que compare el uso de QT con QT con hormonoterapia en enfermedad metastásica. El estudio ECOG E3186 ${ }^{124}$ y un estudio del grupo cooperativo australiano ${ }^{125}$ son los únicos ensayos aleatorizados encontrados que hacen esta comparación, demostrando tasas de respuesta similares, sin significancia en el tiempo a falla al tratamiento y sin beneficio en la SG, y con aumento en la toxicidad.

\section{Pregunta clínica 45. ¿Cuál es la mejor PRIMERA LÍNEA DE TRATAMIENTO SISTÉMICO EN PACIENTES CON CÁNCER DE MAMA METASTÁSICO HER2+?}

Recomendación. Se recomienda la administración de trastuzumab más pertuzumab en combinación con un taxano (docetaxel o paclitaxel) en pacientes con cáncer de mama metastásico HER2+ no tratado que no recibieron terapia adyuvante en el momento del diagnóstico inicial como primera línea de tratamiento. Nivel de evidencia 1+, grado de recomendación $A$.

Se sugiere el uso de trastuzumab más un taxano más pertuzumab en pacientes que recibieron trastuzumab adyuvante con un intervalo sin tratamiento de 12 meses o más. Nivel de evidencia 1+, grado de recomendación $A$.

En los centros en los que no estén disponibles las terapias previas se sugiere utilizar trastuzumab con tratamiento de QT basada en taxanos. Nivel de evidencia 1++, grado de recomendación $A$.

Para los pacientes que recaen dentro de los 12 meses de completar el tratamiento con trastuzumab adyuvante, se sugiere administrar ado-trastuzumab emtansina (T-DM1). Nivel de evidencia 1+, grado de recomendación $\mathrm{A}$.

Revisión de la literatura médica y análisis. La evidencia se basa en el ensayo CLEOPATRA, un estudio en fase III de 808 mujeres con cáncer de mama metastásico HER2+ que fueron tratadas con trastuzumab (dosis de carga de $8 \mathrm{mg} / \mathrm{kg}$ y luego $6 \mathrm{mg} / \mathrm{kg}$ intravenoso) y docetaxel ( $75 \mathrm{mg} / \mathrm{m}^{2}$ intravenoso) y luego asignadas al tratamiento con pertuzumab (840 mg dosis de carga y luego $420 \mathrm{mg}$ ) o placebo. Aproximadamente el 10\% de estas pacientes habían recibido previamente trastuzumab en el contexto de adyuvante o neoadyuvante. Con una mediana de seguimiento de 19 meses, la adición de pertuzumab a docetaxel más trastuzumab resultó en mejora en la tasa de respuesta global del 80 versus $69 \%$, encontrando mejoría en la SLP, en comparación con placebo (mediana de 19 vs. 12 meses) (HR: 0.62; IC 95\%: $0.51-0.75)^{126}$, y la SG, en comparación con placebo (mediana de 56.5 vs. 40.8 meses sin pertuzu-

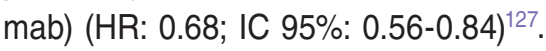

Para la recomendación dependiente del tiempo de intervalo libre de tratamiento adyuvante, la evidencia se basa en los siguientes estudios: 
- En el CLEOPATRA, si los pacientes habían recibido trastuzumab anteriormente, se requirió un tratamiento de 12 meses de intervalo entre el trastuzumab neoadyuvante 0 adyuvante y el diagnóstico de enfermedad metastásica. En un análisis de subgrupos preespecificado entre los pacientes que habían recibido previamente trastuzumab, la mediana de la SLP fue de 16.9 versus 10.4 meses para los pacientes tratados con pertuzumab, trastuzumab y docetaxel versus trastuzumab más docetaxel, respectivamente ${ }^{128}$.

- El metaanálisis de Cochrane ${ }^{129}$ para el uso de terapia anti-HER2 en pacientes con cáncer de mama metastásico HER2+ arrojó resultados en la SG y SLP a favor del grupo con trastuzumab (HR: 0.82; IC 95\%: 0.71-0.94 y HR: 0.61; IC 95\%: 0.54-0.70, respectivamente), y en las tasas de respuesta global ( $R R=1.70$; IC 95\%: 1.16-2.49). Este mismo estudio mostró un beneficio en la tasa de respuesta global para el subgrupo de pacientes en manejo combinado con taxanos ( $R R=1.71$; IC 95\%: 1.23-2.38), por lo que consideramos que continúa siendo una opción para los pacientes que no pueden acceder a las nuevas terapias anti-HER2.

- El estudio EMILIA ${ }^{130}$ evaluó el uso de TDM-1 versus lapatinib y capecitabina. Dentro de los criterios de inclusión se requería que los participantes hubieran recibido trastuzumab con taxano durante el tratamiento metastásico o dentro de los seis meses de tratamiento adyuvante. Los participantes potenciales fueron excluidos si habían recibido T-DM1 anteriormente. El 16\% de los participantes en ambos brazos cumplían con ese criterio. En un análisis de subgrupos de PFS por tratamiento previo con trastuzumab para metastásico, ambos subgrupos se beneficiaron de T-DM1 ${ }^{128,131 .}$

\section{Pregunta clínica 46. ¿Cuál es el beneficio de MANEJO SISTÉMICO EN COMBINACIÓN VERSUS MONOTERAPIA EN PACIENTES CON CÁNCER DE MAMA METASTÁSICO, RECEPTORES HORMONALES POSITIVOS CON CRISIS VISCERAL O RECEPTORES HORMONALES NEGATIVOS Y HER2-?}

Recomendación. Se recomienda el uso del manejo sistémico como monofármaco. En los casos en los que se buscan tasas de respuesta rápida, se sugiere usar combinación. Nivel de evidencia 1+, grado de recomendación $A$.

Revisión de la literatura médica y análisis. Aunque un metaanálisis ${ }^{132}$ que incluyó 43 ensayos ( $n=9,742$ mujeres, $55 \%$ de las cuales fueron tratadas en la primera línea de ajuste) mostró que la terapia de combinación podría mejorar la SG (HR: 0.82; IC 95\%: 0.750.89), el resultado se considera incompleto por no comparar la terapia secuencial.

Una RS de Cochrane ${ }^{133}$ buscó aclarar la eficacia de la QT monofármaco versus combinación en pacientes con enfermedad metastásica. Incluyó 12 ensayos clínicos con nueve comparaciones de tratamiento, sin encontrar diferencia en la SG (HR: 1.04; IC 95\%: 0.931.16) independientemente del tipo de esquema de QT. En cuanto a la SLP, este estudio mostró una evidencia débil, con mayor riesgo de progresión para la terapia de combinación versus la terapia de monofármaco (HR: 1.1; IC 95\%: 0.99-1.25). Respecto a la tasa de respuesta, la combinación presentó mejoría con significancia estadística (RR = 1.16; IC 95\%: 1.06-1.28).

En una RS más reciente ${ }^{134}$ de pacientes con CMM previamente tratadas con antraciclinas o taxanos, el beneficio fue demostrado con los tratamientos con dos agentes versus monofármacos en la SG (HR: 0.90; IC 95\%: 0.84-0.96) y la SLP (HR: 0.81; IC 95\%: 0.76-0.88).

Pregunta clínica 47. ¿Cuál es el mejor ESQUEMA DE PRIMERA LÍNEA EN EL MANEJO SISTÉMICO EN PACIENTES CON CÁNCER DE MAMA METASTÁSICO, RECEPTORES HORMONALES POSITIVOS CON CRISIS VISCERAL O RECEPTORES HORMONALES NEGATIVOS Y HER2-?

Recomendación. Se recomienda el manejo de acuerdo a las características individuales de los pacientes y al momento de la indicación:

- Diagnóstico de novo (sin tratamiento previo):

- Antraciclina o taxano monofármaco. Nivel de evidencia 1++, grado de recomendación A.

- Paclitaxel o docetaxel + capecitabina. Nivel de evidencia 1++, grado de recomendación A.

- Posterior a terapia con antraciclinas (adyuvancia/ neoadyuvancia):

- Paclitaxel semanal. Nivel de evidencia 1++, grado de recomendación $A$.

- Docetaxel trisemanal. Nivel de evidencia 1++, grado de recomendación $A$.

- Capecitabina. Nivel de evidencia 1++, grado de recomendación $\mathrm{A}$.

- Nab-paclitaxel. Nivel de evidencia 1++, grado de recomendación $A$.

- Posterior a terapia (adyuvante/neoadyuvante) con antraciclinas y taxanos: 
TABLA 4C. Recomendaciones clínicas, síntesis y niveles de evidencia para el cáncer de mama metastásico.

\begin{tabular}{|c|c|}
\hline $\begin{array}{l}\text { 47. - Tratamiento } \\
\text { sistémico en pacientes } \\
\text { receptores hormonales } \\
\text { positivos con crisis } \\
\text { visceral o receptores } \\
\text { hormonales negativos y } \\
\text { HER2- }\end{array}$ & $\begin{array}{l}\text { - Diagnóstico de novo(sin tratamiento } \\
\text { previo): } \\
\text { - Antraciclina o taxano monofármaco (nivel } \\
\text { de evidencia } 1++, \text { grado de } \\
\text { recomendación A). } \\
\text { - Paclitaxel ó docetaxel + capecitabine } \\
\text { (nivel de evidencia 1++, grado de } \\
\text { recomendación A). } \\
\text { - Posterior a terapia con antraciclinas } \\
\text { (adyuvancia/Neoadyuvancia): } \\
\text { - Paclitaxel semanal (nivel de evidencia } \\
\text { 1++, grado de recomendación A). } \\
\text { - Docetaxel trisemanal (nivel de evidencia } \\
\text { 1++, grado de recomendación A). } \\
\text { - Capecitabina (nivel de evidencia 1++, } \\
\text { grado de recomendación A). } \\
\text { - Nab-paclitaxel (nivel de evidencia 1++, } \\
\text { grado de recomendación A). } \\
\text { - Posterior a terapia } \\
\text { (adyuvante/neoadyuvante) con } \\
\text { antraciclinas y taxanos: } \\
\text { - Capecitabina (nivel de evidencia 1++, } \\
\text { grado de recomendación A). } \\
\text { - Eribulina (nivel de evidencia 1++, grado } \\
\text { de recomendación A). } \\
\text { - Vinorelbina (nivel de evidencia 1++, grado } \\
\text { de recomendación A). } \\
\text { Doxorubicina liposomal pegilada (nivel } \\
\text { de evidencia 1++, grado de } \\
\text { recomendación A). } \\
\text { evidencia 1++, grado de recomendación } \\
\text { A). }\end{array}$ \\
\hline
\end{tabular}

- Capecitabina. Nivel de evidencia 1++, grado de recomendación A.

- Eribulina. Nivel de evidencia 1++, grado de recomendación A.

- Vinorelbina. Nivel de evidencia $1++$, grado de recomendación A.

- Doxorubicina liposomal pegilada. Nivel de evidencia 1++, grado de recomendación A.

- Retratamiento con taxano. Nivel de evidencia $1++$, grado de recomendación A.

Revisión de la literatura médica y análisis. En primera línea se prefiere la combinación, como lo define un metaanálisis ${ }^{132}$ que incluyó 43 ensayos ( $n=9,742$ mujeres, el $55 \%$ de las cuales fueron tratadas en la primera línea de ajuste) y que mostró que la terapia de combinación podría mejorar la SG (HR: 0.82; IC 95\%: 0.75-0.89). Basándose en diferentes estudios, existen guías y consensos internacionales que realizan recomendaciones según el contexto del paciente ${ }^{131}$.
En una RS con metaanálisis ${ }^{134}$ de pacientes con CMM previamente tratadas con antraciclinas o taxanos, el beneficio fue demostrado con los tratamientos con dos agentes versus monofármacos en la SG (HR: 0.90; IC 95\%: 0.84-0.96) y la SLP (HR: 0.81; IC 95\%: 0.76-0.88). Una RS con metaanálisis ${ }^{135}$ logró calcular la relación de los desenlaces con la eficacia de los tratamientos en la primera línea.

Eribulina se probó en un estudio en fase $1 \mathrm{II}^{136}$ con 762 pacientes pretratadas, aleatorizadas al tratamiento con eribulina u otra QT (según la elección del médico y paciente). La eribulina mejoró significativamente la SG (mediana de 13.1 vs. 10.6 meses). Sin embargo, en otro estudio ${ }^{137}$, en el que se aleatorizaron a las pacientes con CMM previamente tratadas con antraciclinas y taxanos a dos brazos, eribulina versus capecitabina, la media de SG no mostró superioridad para el brazo de eribulina (15.9 vs. 14.5 meses, respectivamente; HR: 0.88; IC 95\%: 0.77-1.00) (Tabla 4C). 
TABLA 4D. Recomendaciones clínicas, síntesis y niveles de evidencia para el cáncer de mama metastásico.

48 - Segunda línea de manejo sistémico en pacientes con cáncer de mama metastásico HER2+
- Se recomienda como segunda línea de manejo T-DM1 debido al beneficio en sobrevida libre de progresión y sobrevida global

- (nivel de evidencia 1+, grado de recomendación A).

- Para los pacientes sin acceso a T-DM1, se sugiere la terapia

basada en lapatinib combinada con capecitabina

- (nivel de evidencia 1+, grado de recomendación A)

- En pacientes que inicialmente recibieron trastuzumab con quimioterapia, se sugiere cambiar de régimen de quimioterapia y continuar trastuzumab más allá de la progresión

- (nivel de evidencia 1++, grado de recomendación A).
49.- Platinos a la quimioterapia de primera línea en pacientes con cáncer de mama metastásico subtipo triple negativo
- Se sugiere el uso de platinos en las mujeres con mutación BRCA1 o BRCA2

- (nivel de evidencia 1+, grado de recomendación $\mathrm{A}$ ).
50.- Bevacizumab en el manejo de quimioterapia sistémica en pacientes con cáncer de mama metastásico
- No se sugiere el uso de bBevacizumab en combinación a la quimioterapia de manera rutinaria.

- (nivel de evidencia 1+, grado de recomendación $\mathrm{A}$ ).
51.- Tratamiento de soporte en salud ósea del cáncer de mama metastásico
- Se recomienda el uso de denosumab, acido zoledronico y bisfosfonatos como alternativas de tratamiento de soporte de salud ósea.

- (nivel de evidencia 1+, grado de recomendación $A$ ).
Pregunta clínica 48. ¿Cuál es la mejor SEGUNDA LÍNEA DE MANEJO SISTÉMICO EN PACIENTES CON CÁNCER DE MAMA METASTÁSICO HER2+?

Recomendación. Se recomienda como segunda línea de manejo T-DM1 debido al beneficio en la SLP y SG. Nivel de evidencia 1+, grado de recomendación $\mathrm{A}$.
Para los pacientes sin acceso a T-DM1, se sugiere la terapia basada en lapatinib combinada con capecitabina. Nivel de evidencia 1+, grado de recomendación A.

En pacientes que inicialmente recibieron trastuzumab con QT, se sugiere cambiar de tratamiento de QT y continuar trastuzumab más allá de la progresión. Nivel de evidencia 1++, grado de recomendación A. 
Revisión de la literatura médica y análisis. El ensayo EMILIA ${ }^{130}$ incluyó a 978 pacientes con cáncer de mama HER2+ previamente tratados con trastuzumab y un taxano, y asignados aleatoriamente al tratamiento con T-DM1 o la combinación de capecitabina más lapatinib cada tres semanas. Con una duración mediana de seguimiento de 19 meses, T-DM1 resultó en una mejora en la SLP en comparación con lapatinib más capecitabina (mediana de 10 vs. 6 meses, respectivamente) (HR: 0.65; IC 95\%: 0.55-0.77), y también demostró mejoría en la mediana de la SG, con 31 versus 25 meses (HR: 0.68; IC 95\%: 0.55-0.85). Un informe posterior de seguimiento más prolongado (> 40 meses) ${ }^{138}$ también mostró una supervivencia mejorada con TDM-1 (29.9 vs. 25.9 meses en el grupo de control) (HR: 0.75; IC 95\%: 0.64-0.88), incluso en presencia de un tratamiento cruzado (HR: 0.69; IC 95\%: 0.59-0.82), y una mejora clínicamente significativa de la tasa de respuesta global (44 vs. $31 \%$ ).

El ensayo MA. $31^{139}$ incluyó a 652 pacientes tratados con un taxano semanal (paclitaxel o docetaxel) y asignados al azar a tratamiento concomitante con lapatinib o trastuzumab, y mostró un PFS significativamente más corto en comparación con trastuzumab más paclitaxel (mediana de 8.8 vs. 11.4 meses; HR: 1.33; IC 95\%: 1.06-1.67), que fue más pronunciado cuando el análisis se restringió a pacientes en los que la positividad de HER2 fue confirmada por un laboratorio central, con 9 versus 13.7 meses, respectivamente (HR: 1.48; IC 95\%: 1.15-1.92). No hubo diferencia en la SG (HR: 1.11; IC 95\%: 0.75-1.61). El tratamiento con lapatinib se asoció con una mayor tasa de toxicidad, lo que provocó una mayor tasa de interrupción (17.8 vs. $10.6 \%)^{140}$. Una RS con metaanálisis de Cochrane ${ }^{129}$ mostró que trastuzumab más allá de la progresión mejoraba la SLP (HR: 0.72; IC 95\%: 0.59-0.88) (Tabla 4 D).

\section{Pregunta clínica 49. ¿Cuál es el beneficio de AÑADIR PLATINOS A LA QUIMIOTERAPIA DE PRIMERA LÍNEA EN PACIENTES CON CÁNCER DE MAMA METASTÁSICO SUBTIPO TRIPLE NEGATIVO?}

Recomendación. La evidencia científica de alta calidad es escasa. Se sugiere el uso de platinos en las mujeres con mutación BRCA1 o BRCA2 debido a que se observó un incremento en la tasa de respuesta y la SLP. Nivel de evidencia $1+$, grado de recomendación $\mathbf{A}$.
No se sugiere el uso de platinos en pacientes con cáncer de mama metastásico triple negativo sin mutación BRCA debido a que los estudios retrospectivos no han encontrado beneficio a 1-2 años en la SLP. Nivel de evidencia 1+, grado de recomendación $\mathrm{A}$.

Se requieren más estudios prospectivos controlados de alta calidad para definir el papel de los platinos en esta población de pacientes.

Revisión de la literatura médica y análisis. Una RS con metaanálisis ${ }^{141}$, que incluyó pacientes con cáncer de mama metastásico triple negativo con manejo basado en platinos, pudo analizar en 234 pacientes en tres de siete estudios retrospectivos la $S G$ y la SLP, encontrando que la tasa de SLP de seis meses fue mayor en las pacientes triple negativo en comparación con el grupo no triple negativo $(\mathrm{OR}=1.81$; IC 95\%: 1.11-2.96; $p=0.02$ ); sin embargo, la tasa de SLP a un año no fue significativamente diferente entre los dos grupos (OR = 1.42; IC 95\%: 0.69-2.92; $p=0.35)$.

A pesar del resultado previo, los estudios prospectivos que han buscado esta respuesta han sido positivos. Un estudio ${ }^{142}$ comparó docetaxel combinado con cisplatino versus docetaxel-capecitabina, y mostró que la SLP fue más del doble (10.9 vs. 4.8 meses; $p<0.001$ ) y la mediana de $S G$ también mejoró en gran medida (32.8 vs. 21.5 meses; $p=0.027$ ) a favor del tratamiento con platino.

Otro ensayo comparó directamente docetaxel con carboplatino en el tratamiento de primera línea para las mujeres con cáncer de mama triple-negativo metastásico, y se presentó en el San Antonio Breast Cancer Symposium 2014 ${ }^{143}$. Las tasas de respuesta global fueron similares (31.4 vs. $35.6 \%$ ), excepto en las mujeres con mutación BRCA1 o BRCA2, en las que había una tasa de respuesta significativamente mayor (68 vs. $33.3 \%$ ) y la SLP (6.8 vs. 3.1 meses) versus en las pacientes del brazo con carboplatino.

Otro estudio ${ }^{144}$ demostró el beneficio del doblete cisplatino con gemcitabina comparando paclitaxel con gemcitabina, encontrando una no inferioridad en la SLP (HR: 0.69; IC 95\%: 0.52-0.91).

Pregunta clínica 50. ¿Cuál es el beneficio de AÑADIR BEVACIZUMAB EN EL MANEJO DE QUIMIOTERAPIA SISTÉMICA EN PACIENTES CON CÁNCER DE MAMA METASTÁSICO?

Recomendación. No se sugiere el uso de bevacizumab (BEV) en combinación a la QT de manera 
rutinaria. Aunque en los estudios se encontró beneficio en la SLP, no existe mejoría en la SG. Nivel de evidencia 1+, grado de recomendación $A$.

Revisión de la literatura médica y análisis. En una RS con metaanálisis ${ }^{145}$ que valoró la adición de BEV a la terapia sistémica no se encontró mejoría significativa en la $S G$ en el grupo de QT + BEV en comparación con el grupo de QT sola (HR: 0.95; IC 95\%: 0.86-1.05), encontrando heterogeneidad significativa en el PFS entre los grupos de QT + BEV y QT $(p<0.10)$. El análisis global y HER2- análisis de subgrupos indicaron una mejora significativa del PFS en el grupo de QT + BEV en comparación con el de QT (HR: 0.75; IC 95\%: 0.68-0.84; $p<0.001$; HR: 0.75; IC 95\%: 0.69-0.82; $p<0.001$, respectivamente). Los análisis de subgrupos no HER2- no produjeron resultados similares (HR: 0.78; IC 95\%: 0.57-1.05; $p>0.05$ ), observando beneficio en los pacientes con cáncer triple negativo (HR: 0.61; IC 95\%: 0.47-0.80; $p<0.001$ ). En el análisis de subgrupos se encontró mejoría significativa en los grupos de DOC + BEV versus DOC, y en el de PAC + BEV frente a PAC (HR: 0.81; IC 95\%: 0.73-0.90 y HR: 0.62; IC 95\%: 0.54-0.71, respectivamente). Resultados similares no se obtuvieron en los grupos de CAP + BEV versus CAP (HR: 0.79; IC 95\%: 0.62-1.01).

\section{Pregunta clínica 51. ¿Cuáles son las ALTERNATIVAS DE TRATAMIENTO DE SOPORTE EN SALUD ÓSEA DEL CÁNCER DE MAMA METASTÁSICO?}

Recomendación. Se recomienda el uso de denosumab, ácido zoledrónico y bisfosfonatos como alternativas de tratamiento de soporte de salud ósea. Nivel de evidencia 1+, grado de recomendación A.

Revisión de la literatura médica y análisis. Una RS con metaanálisis ${ }^{146}$ de tres ensayos en fase III comparó el ácido zoledrónico versus denosumab para la enfermedad ósea metastásica, y concluyó que el denosumab era superior al ácido zoledrónico en la reducción del riesgo de un evento esquelético relacionado (EER) (HR: 0.83; IC 95\%: 0.76-0.90) y en retrasar el tiempo a un primer EER (27.66 vs. 19.45 meses) (HR: 0.82; IC 95\%: 0.75-0.89) o a hipercalcemia de malignidad. La SG (HR: 0.99; IC 95\%: 0.91-1.07) y las tasas de progresión de enfermedad (HR: 1.02; IC 95\%: 0.95-1.08) fueron similares en ambos tratamientos.

En otro estudio ${ }^{147}$ que comparó los bisfosfonatos, el ácido zoledrónico está asociado con la tasa más baja de incidencia de EER (1.60), seguido del ibandronato oral (1.67) e intravenoso (1.70).

\section{Investigación futura}

Existen temas dentro de la guía que no tienen respuestas o que la evidencia no ha alcanzado la cobertura adecuada para poder dar ciertas recomendaciones, por lo que a nivel mundial existen grupos de trabajo que se encargan de crear protocolos dirigidos a responderlas. Un ejemplo de ello es el papel de la inmunoterapia en el cáncer de mama en las diferentes modalidades; para buscar una mejor respuesta ya existen intentos en la literatura médica que dan una buena aproximación a lo que pudiéramos esperar, sobre todo en tumores de difícil tratamiento como los triple negativo. Esta misma estrategia podría darnos respuesta a los retratamientos o los tratamientos sistémicos posteriores a las recurrencias en las pacientes que ya recibieron QT. Aún existe mucho por explorar y para definir el tratamiento óptimo del cáncer de mama, por ello en México debemos continuar en la suma de esfuerzos para establecer grupos cooperativos y concretar protocolos que apoyen el entendimiento y contribuyan a la evidencia en la literatura médica global de la enfermedad.

\section{Actualización}

Se planea un periodo de actualización de la GPC para incorporar nueva evidencia científica a las recomendaciones en 2-3 años.

\section{Declaración de conflictos de interés}

SRR, AMA, BCS, JAGO, JEBR, MLGT, CHAS, NGO, CFV, MHM, FJLR, LARR, DRS, BHH, JATT, YLBA, MAP y FJOC declaran no tener ningún conflicto de interés. RCGA ha participado como speaker y ha formado parte de Advisory Boards de Pfizer y Roche. RVV ha participado como speaker y ha formado parte de Advisory Boards de Amgen, Merck y Roche. Y JLMB, LVH, AGG, JAGO, BMV, MAFM, MZT, MAO y GMR recibieron honorarios como parte del grupo metodológico independiente.

\section{Información importante}

Esta GPC y los documentos que sean publicados basados en ella representan herramientas originadas por el consenso de expertos clínicos acerca de las terapias y toma de decisiones vigentes para el manejo del cáncer de mama. Este documento ha sido publicado para que los especialistas consideren las 
recomendaciones clínicas y las incorporen a su toma de decisiones de su práctica clínica cotidiana. Sin embargo, estas recomendaciones no se encuentran por encima del criterio clínico independiente de cada médico y de las condiciones individuales de cada paciente.

\section{Bibliografía}

1. Stewart B, Wild CP, editores. International Agency for Research on Cancer W. World Cancer Report 2014. [Internet]. 2014. Disponible en http://publications.iarc.fr/Non-Series-Publications/World-Cancer-Reports/ World-Cancer-Report-2014

2. Ferlay J, Soerjomataram I, Ervik M, Dikshit R, Eser S, Mathers C, et al GLOBOCAN 2012 v1.0, Cancer Incidence and Mortality Worldwide: IARC CancerBase N. ${ }^{\circ} 11$ [Internet]. Lyon, France: International Agency for Research on Cancer; 2013. Disponible en: http://globocan.iarc.fr, accessed on day/month/year. 2012.

3. INEGI. Estadísticas a propósito del día mundial de la lucha contra el cáncer de mama (19 de octubre) [Internet]. 2013. Disponible en: http:// www.beta.inegi.org.mx/app/saladeprensa/noticia.html?id=2958

4. Sackett DL, Rosenberg WMC, Gray JAM, Haynes RB, Richardson WS. Evidence based medicine: what it is and what it isn't. BMJ. 1996; 312(7023):71-2.

5. Hunink MGM, Weinstein MC, Wittenberg E, Drummond MF, Pliskin JS, Wong JB, et al. Decision Making in Health and Medicine: Integrating Evidence and Values [Internet]. 2. ${ }^{a}$ ed. Cambridge: Cambridge University Press; 2014. Disponible en: https://www.cambridge.org/core/books/ decision-making-in-health-and-medicine/31FD197195DAE2A6321409568BEFA2DD

6. Bate L, Hutchinson A, Underhill J, Maskrey N. How clinical decisions are made. Br J Clin Pharmacol. 2012;74(4):614-20.

7. Higgins JPT, Altman DG, Gøtzsche PC, Jüni $P$, Moher D, Oxman AD, et al. The Cochrane Collaboration's tool for assessing risk of bias in randomised trials. BMJ. 2011;343:5928.

8. Shekelle PG, Woolf SH, Eccles M, Grimshaw J. Clinical guidelines: developing guidelines. BMJ. 1999;318(7183):593-6.

9. Grimshaw J, Russell I. Achieving health gain through clinical guidelines. I: Developing scientifically valid guidelines. Qual Health Care. 1993;2(4):243-8.

10. Hayward RS. Clinical practice guidelines on trial. C Can Med Assoc J. 1997;156(12):1725-7.

11. Medicine I of Guidelines for Clinical Practice: From Development to Use [Internet]. Field MJ, Lohr KN, editores. Washington, DC: The National Academies Press; 1992. Disponible en: https://www.nap.edu/catalog/1863/guidelines-for-clinical-practice-from-development-to-use

12. Medicine I of Clinical Practice Guidelines We Can Trust [Internet]. Graham R, Mancher M, Wolman DM, Greenfield S, Steinberg E, editores. Washington, DC: The National Academies Press; 2011. Disponible en: https://www.nap.edu/catalog/13058/clinical-practice-guidelines-we-can-trust

13. National Institute for Health and Care Excellence. The guidelines manual: Process and methods [PMG ${ }^{6}$. Natl Inst Heal Care Excell [Internet]. 2012. Disponible en: https://www.nice.org.uk/guidance/pmg6/resources/the-guidelines-manual-pdf-2007970804933\%0Ahttps://www.nice.org.uk/process/pmg6/chapter/reviewing-the-evidence

14. National Institutes of Health. Retirement of the National Institutes of Health Consensus Development Program. [Internet]. Disponible en: http://consensus.nih.gov

15. Guideline International Network. Guideline International Network Homepage.

16. Harbour R, Miller J. A new system for grading recommendations in evidence based guidelines. BMJ. 2001;323(7308):334-6.

17. Fisher B, Anderson S, Redmond CK, Wolmark N, Wickerham DL, Cronin WM. Reanalysis and Results after 12 Years of Follow-up in a Randomized Clinical Trial Comparing Total Mastectomy with Lumpectomy with or without Irradiation in the Treatment of Breast Cancer. N Engl J Med. Massachusetts Medical Society. 1995;333(22):1456-61.

18. Narod SA, Iqbal J, Giannakeas V, Sopik V, Sun P. Breast Cancer Mortality After a Diagnosis of Ductal Carcinoma In Situ. JAMA Oncol. 2015;1(7):888.

19. Marinovich ML, Azizi L, Macaskill P, Irwig L, Morrow M, Solin LJ, et al. The Association of Surgical Margins and Local Recurrence in Women with Ductal Carcinoma In Situ Treated with Breast-Conserving Therapy: A Meta-Analysis. Ann Surg Oncol. 2016;23(12):3811-21.

20. McCormick B, Winter K, Hudis C, Kuerer HM, Rakovitch E, Smith BL, et al. RTOG 9804: A Prospective Randomized Trial for Good-Risk Ductal Carcinoma In Situ Comparing Radiotherapy With Observation. J Clin Oncol. J Clin Oncol. 2015;33(7):709-15.

21. Leidenius M, Salmenkivi K, von Smitten K, Heikkilä P. Tumour-positive sentinel node findings in patients with ductal carcinoma in situ. J Surg Oncol. 2006;94(5):380-4.
22. Virnig BA, Tuttle TM, Shamliyan T, Kane RL. Ductal carcinoma in Situ of the breast: A systematic review of incidence, treatment, and outcomes. J Natl Cancer Inst. 2010;102(3):170-8.

23. Bruening W, Fontanarosa J, Tipton K, JR T, Launders J, Schoelles K. Systematic review: Comparative effectiveness of core-needle and open surgical biopsy to diagnose breast lesions. Ann Intern Med. 2010; 152(4):238-46.

24. Ansari B, Ogston SA, Purdie CA, Adamson DJ, Brown DC, Thompson AM Meta-analysis of sentinel node biopsy in ductal carcinoma in situ of the breast. Br J Surg. 2008;95(5):547-54.

25. El Hage Chehade $\mathrm{H}$, Headon $\mathrm{H}$, Wazir U, Abtar H, Kasem A, Mokbel K Is sentinel lymph node biopsy indicated in patients with a diagnosis of ductal carcinoma in situ? A systematic literature review and meta-analysis. Am J Surg. 2017;213(1):171-80.

26. Goodwin A, Parker S, Ghersi D, Wilcken N. Post-operative radiotherapy for ductal carcinoma in situ of the breast. Cochrane Database Syst Rev. 2013;(11):CD000563.

27. Sagara Y, Freedman RA, Vaz-Luis I, Mallory MA, Wong SM, Aydogan F et al. Patient Prognostic Score and Associations With Survival Improvement Offered by Radiotherapy After Breast-Conserving Surgery for Ductal Carcinoma In Situ: A Population-Based Longitudinal Cohort Study. J Clin Oncol. 2016;34(11):1190-6.

28. Hathout L, Hijal T, Théberge V, Fortin B, Vulpe H, Hogue JC, et al. Hypofractionated Radiation Therapy for Breast Ductal Carcinoma In Situ. Int J Radiat Oncol Biol Phys. 2017;87(5):1058-63.

29. Shah C, Vicini F, Wazer DE, Arthur D, Patel RR. The American Brachytherapy Society consensus statement for accelerated partial breast irradiation. Brachytherapy. 2017;12(4):267-77.

30. Strnad V, Ott OJ, Hildebrandt G, Kauer-Dorner D, Knauerhase H, Major T, et al. 5-year results of accelerated partial breast irradiation using sole interstitial multicatheter brachytherapy versus whole-breast irradiation with boost after breast-conserving surgery for low-risk invasive and in-situ carcinoma of the female breast: a ran. Lancet. 2016;387(10015):229-38.

31. Staley H, McCallum I, Bruce J. Postoperative Tamoxifen for ductal carcinoma in situ: Cochrane systematic review and meta-analysis. Breast. 2014;23(5):546-51.

32. Margolese R, Cecchini RS, Julian TB, Ganz PA, Costantino JP, Vallow LA, et al. Primary results, NSABP B-35/NRG Oncology: A clinical trial of anastrozole vs tamoxifen in postmenopausal patients with DCIS undergoing lumpectomy plus radiotherapy $\mathrm{A}$ randomized clinical trial. Lancet. 2016;387(10021):849-56.

33. Chen $Y$, Jiang $L$, Gao B, Cheng $Z Y$, Jin J, Yang KH. Survival and disease-free benefits with mastectomy versus breast conservation therapy for early breast cancer: a meta-analysis. Breast Cancer Res Treat. 2016; 157(3):517-25.

34. Hwang ES, Lichtensztajn DY, Gómez SL, Fowble B, Clarke CA. Survival after lumpectomy and mastectomy for early stage invasive breast cancer. Cancer. 2013;119(7):1402-11.

35. Hwang ES, Lichtensztajn DY, Gómez SL, Fowble B, Clarke CA. Survival after lumpectomy and mastectomy for early stage invasive breast cancer. Cancer. 2013;119(7):1402-11.

36. Agarwal S, Pappas L, Neumayer L, Kokeny K, Agarwal J. Effect of Breast Conservation Therapy vs Mastectomy on Disease-Specific Survival for Early-Stage Breast Cancer. JAMA Surg. 2014;149(3):267.

37. Hartmann-Johnsen OJ, Kåresen R, Schlichting E, Nygård JF. Survival is Better After Breast Conserving Therapy than Mastectomy for Early Stage Breast Cancer: A Registry-Based Follow-up Study of Norwegian Women Primary Operated Between 1998 and 2008. Ann Surg Oncol. 2015; 22(12):3836-45.

38. Houssami N, Macaskill $P$, Luke Marinovich M, Morrow M. The Association of Surgical Margins and Local Recurrence in Women with Early-Stage Invasive Breast Cancer Treated with Breast-Conserving Therapy: A Meta-Analysis. Ann Surg Oncol. 2014;21(3):717-30.

39. Bromham N, Astin M, Hasler E, Mw R. Axillary treatment for operable primary breast cancer (Review) SUMMARY OF FINDINGS FOR THE MAIN COMPARISON. Cochrane Database Syst Rev. 2017;(1):1-243.

40. Lyman GH, Temin S, Edge SB, Newman LA, Turner RR, Weaver DL, et al. Sentinel lymph node biopsy for patients with early-stage breast cancer: American Society of Clinical Oncology clinical practice guideline update. J Clin Oncol. 2014;32(13):1365-83.

41. Rao R, Euhus D, Mayo HG, Balch C. Axillary Node Interventions in Breast Cancer. JAMA. 2013;310(13):1385.

42. Giuliano AE, McCall L, Beitsch $P$, Whitworth $P W$, Blumencranz $P$ Leitch AM, et al. Locoregional Recurrence After Sentinel Lymph Node Dissection With or Without Axillary Dissection in Patients With Sentinel Lymph Node Metastases. Trans Meet Am Surg Assoc. 2010; 128(3):12-21.

43. Galimberti V, Cole B, Zurrida S. IBCSG 23-01 randomised controlled trial comparing axillary dissection versus no axillary dissection in patients with sentinel node micrometastases. Lancet. 2013;14(4):297-305.

44. Fayanju OM, Stoll CRT, Fowler S, Colditz GA, Margenthaler JA. Contralateral Prophylactic Mastectomy after Unilateral Breast Cancer: A Systematic Review \& Meta-Analysis. Ann Surg. 2014;260(6):1000-10. 
45. Wong SM, Freedman RA, Sagara Y, Aydogan F, Barry WT, Golshan M. Growing Use of Contralateral Prophylactic Mastectomy Despite no Improvement in Long-term Survival for Invasive Breast Cancer. Ann Surg. 2017:265(3):581-9.

46. Li X, You R, Wang X, Liu C, Xu Z, Zhou J, et al. Effectiveness of prophylactic surgeries in BRCA1 or BRCA2 mutation carriers: A meta-analysis and systematic review. Clin Cancer Res. 2016;22:3971-81.

47. Ludwig KK, Neuner J, Butler A, Geurts JL, Kong AL. Risk reduction and survival benefit of prophylactic surgery in BRCA mutation carriers, a systematic review. Am J Surg. 2016;212(4):660-9.

48. Smith BD, Arthur DW, Buchholz TA, Haffty BG, Hahn CA, Hardenbergh PH, et al. Accelerated Partial Breast Irradiation Consensus Statement From the American Society for Radiation Oncology (ASTRO). Int J Radiat Oncol. 2009;74(4):987-1001.

49. Hickey B, Lehman M, Francis D, See A. Partial breast irradiation for early breast cancer. Cochrane database Syst Rev. 2016;(7):CD007077.

50. Bartelink $\mathrm{H}$, Maingon $\mathrm{P}$, Poortmans $\mathrm{P}$, Weltens $\mathrm{C}$, Fourquet $\mathrm{A}$, Jager $\mathrm{J}$ et al. Whole-breast irradiation with or without a boost for patients treated with breast-conserving surgery for early breast cancer: 20-year follow-up of a randomised phase 3 trial. Lancet Oncol. 2015;16(1):47-56.

51. Scope A, Essat M, Pandor A, Rafia R, Ward SE, Wyld L, et al. GENE EXPRESSION PROFILING AND EXPANDED IMMUNOHISTOCHEMISTRY TESTS TO GUIDE SELECTION OF CHEMOTHERAPY REGIMENS IN BREAST CANCER MANAGEMENT: A SYSTEMATIC REVIEW. Int $J$ Technol Assess Health Care. 2017:33(1):32-45.

52. Sparano JA, Gray RJ, Makower DF, Pritchard KI, Albain KS, Hayes DF et al. Prospective Validation of a 21-Gene Expression Assay in Breast Cancer. N Engl J Med. 2015;373(21):2005-14.

53. Filipits M, Rudas M, Jakesz R, Dubsky P, Fitzal F, Singer CF, et al. A New Molecular Predictor of Distant Recurrence in ER-Positive, HER2-Negative Breast Cancer Adds Independent Information to Conventional Clinical Risk Factors. Clin Cancer Res. 2011:17(18):6012-20.

54. Dubsky P, Brase JC, Jakesz R, Rudas M, Singer CF, Greil R, et al. The EndoPredict score provides prognostic information on late distant metastases in ER+/HER2- breast cancer patients. Br J Cancer. 2013; 109:2959-64.

55. Parker JS, Mullins M, Cheang MCU, Leung S, Voduc D, Vickery T, et al Supervised Risk Predictor of Breast Cancer Based on Intrinsic Subtypes. J Clin Oncol. 2009;27(8):1160-7.

56. Dowsett M, Sestak I, López-Knowles E, Sidhu K, Dunbier AK, Cowens JW et al. Comparison of PAM50 Risk of Recurrence Score With Oncotype DX and IHC4 for Predicting Risk of Distant Recurrence After Endocrine Therapy. J Clin Oncol. 2013;31(22):2783-90.

57. Jansen MPHM, Sieuwerts AM, Look MP, Ritstier K, Meijer-van Gelder ME, van Staveren IL, et al. HOXB13-to-IL17BR Expression Ratio Is Related With Tumor Aggressiveness and Response to Tamoxifen of Recurrent Breast Cancer: A Retrospective Study. J Clin Oncol. 2007;25(6):662-8.

58. Sgroi DC, Carney E, Zarrella E, Steffel L, Binns SN, Finkelstein DM, et al. Prediction of Late Disease Recurrence and Extended Adjuvant Letrozole Benefit by the HOXB13/LL17BR Biomarker. J Natl Cancer Inst. 2013 105(14):1036-42.

59. Cardoso F, van't Veer LJ, Bogaerts J, Slaets L, Viale G, Delaloge S, et al. 70-Gene Signature as an Aid to Treatment Decisions in Early-Stage Breast Cancer. N Engl J Med. 2016;375(8):717-29.

60. Bradley R, Burrett J, Clarke M, Davies C, Duane F, Evans V, et al. Aromatase inhibitors versus tamoxifen in early breast cancer: Patient-level meta-analysis of the randomised trials. Lancet. 2015;386(10001): 1341-52.

61. Cuzick J, Ambroisine L, Davidson N, Jakesz R, Kaufmann M, Regan M. Use of luteinizing-hormone-releasing hormone agonists as adjuvant treatment in premenopausal patients with hormone-receptor- positive breast cancer: a meta-analysis of individual patient data from randomized adjuvant trials. Lancet. 2007:369(9574):1711-23.

62. Goel S, Sharma R, Hamilton A, Beith J. LHRH agonists for adjuvan therapy of early breast cancer in premenopausal women. Cochrane Database Syst Rev. 2009:(4):CD004562.

63. Pagani O, Regan MM, Walley BA, Fleming GF, Colleoni M, Láng I, et al. Adjuvant Exemestane with Ovarian Suppression in Premenopausa Breast Cancer. N Engl J Med. 2014;371(2):107-18.

64. Regan MM, Francis PA, Pagani O, Fleming GF, Walley BA, Viale G, et al. Absolute benefit of adjuvant endocrine therapies for premenopausal women with hormone receptor-positive, Human epidermal growth factor receptor 2-Negative early breast cancer: TEXT and SOFT Trials. J Clin Oncol. 2016;34(19):2221-30.

65. Pagani O, Regan MM, Walley BA, Fleming GF, Colleoni M, Láng I, et al. Adjuvant Exemestane with Ovarian Suppression in Premenopausal Breast Cancer. N Engl J Med. 2014:371(2):107-18.

66. Gnant M, Mlineritsch B, Schippinger W, Luschin-Ebengreuth G, Pöstlberger S, Menzel C, et al. Endocrine therapy plus zoledronic acid in premenopausal breast cancer. N Engl J Med. 2009;360(7):679-91.

67. Al-Mubarak M, Tibau A, Templeton AJ, Cescon DW, Ocana A, Seruga B, et al. Extended adjuvant tamoxifen for early breast cancer: A meta-analysis. PLoS One. 2014;9(2):1-9.
68. Ibrahim EM, Al-Hajeili MR, Bayer AM, Abulkhair OA, Refae AA. Extended adjuvant endocrine therapy in early breast cancer: a meta-analysis of published randomized trials. Med Oncol. 2017;34(7):1-13.

69. (EBCTCG) EBCTCG. Adjuvant bisphosphonate treatment in early breast cancer: meta-analyses of individual patient data from randomised trials. Lancet. 2017;386(10001):1353-61.

70. O'Carrigan B, Wong MH, Willson ML, Stockler MR, Pavlakis N, Goodwin A. Bisphosphonates and other bone agents for breast cancer. Cochrane Database Syst Rev. 2017;10:CD003474

71. Wang $\mathrm{X}$, Yang K, Wanyan $\mathrm{P}$, Tian J. Comparison of the efficacy and safety of denosumab versus bisphosphonates in breast cancer and bone metastases treatment: A meta-analysis of randomized controlled trials. Oncol Lett. 2014;7(6):1997-2002.

72. Gnant M, Pfeiler G, Dubsky PC, Hubalek M, Greil R, Jakesz R, et al. Adjuvant denosumab in breast cancer (ABCSG-18): a multicentre, randomised, double-blind, placebo-controlled trial. Lancet. 2015;386(9992): 433-43.

73. Peto R, Davies C, Godwin J, Gray R, Pan HC, Clarke M, et al. Comparisons between different polychemotherapy regimens for early breast cancer: meta-analyses of long-term outcome among 100,000 women in 123 randomised trials. Lancet. 2012;379(9814):432-44. t

74. Jones S, Holmes FA, O'Shaughnessy J, Blum JL, Vukelja SJ, McIntyre KJ, et al. Docetaxel With Cyclophosphamide Is Associated With an Overall Survival Benefit Compared With Doxorubicin and Cyclophosphamide: 7-Year Follow-Up of US Oncology Research Trial 9735. J Clin Oncol. 2009;27(8):1177-83

75. Shulman LN, Berry DA, Cirrincione CT, Becker HP, Pérez EA, O'Regan R, et al. Comparison of doxorubicin and cyclophosphamide versus single-agent paclitaxel as adjuvant therapy for breast cancer in women with 0 to 3 positive axillary nodes: CALGB 40101 (alliance). J Clin Oncol. 2014;32(22):2311-7.

76. Blum JL, Flynn PJ, Yothers G. Asmar L, Geyer CE, Jacobs SA, et al. Anthracyclines in Early Breast Cancer: The ABC Trials-USOR 06-090, NSABP B-46-I/USOR 07132, and NSABP B-49 (NRG Oncology). J Clin Oncol. 2017:35(23):2647-55.

77. Moja L, Tagliabue L, Balduzzi S, Parmelli E, Pistotti V, Guarneri V, et al. Trastuzumab containing regimens for early breast cancer. Cochrane Database Syst Rev. 2012;(4):CD006243.

78. Network NCC. Breast Cancer. NCCN Clin Pract Guidel Oncol. 2017:Version 2. Disponible en: http://www.cancer.org.au/about-cancer/types-ofcancer/breast-cancer/\#note_1

79. Teshome M, Kuerer HM. Breast conserving surgery and locoregional control after neoadjuvant chemotherapy. Eur J Surg Oncol. 2017;43(5): 865-74

80. Boughey JC, Ballman KV, Hunt KK, McCall LM, Mittendorf EA, Ahrendt GM, et al. Axillary ultrasound after neoadjuvant chemotherapy and its impact on sentinel lymph node surgery: Results from the American college of surgeons oncology group Z1071 Trial (Alliance). J Clin Oncol. 2015;33(30):3386-93.

81. El Hage Chehade H, Headon H, El Tokhy O, Heeney J, Kasem A, Mokbel $\mathrm{K}$. Is sentinel lymph node biopsy a viable alternative to complete axillary dissection following neoadjuvant chemotherapy in women with node-positive breast cancer at diagnosis? An updated meta-analysis involving 3,398 patients. Am J Surg. 2016;212(5):969-81.

82. Budach W, Kammers K, Boelke E, Matuschek C. Adjuvant radiotherapy of regional lymph nodes in breast cancer - a meta-analysis of randomized trials. Radiat Oncol. 2013;8:267.

83. EBCTCG (Early Breast Cancer Trialists' Collaborative Group), McGale P, Taylor C, Correa C, Cutter D, Duane F, et al. Effect of radiotherapy after mastectomy and axillary surgery on 10-year recurrence and 20-year breast cancer mortality: meta-analysis of individual patient data for 8135 women in 22 randomised trials. Lancet. 2014;383(9935):2127-35.

84. Kishan AU, McCloskey SA. Postmastectomy radiation therapy after neoadjuvant chemotherapy: review and interpretation of available data. Ther Adv Med Oncol. 2015;8(1):85-97.

85. Kimmick GG, Cirrincione C, Duggan DB, Bhalla K, Robert N, Berry D, et al. Fifteen-year median follow-up results after neoadjuvant doxorubicin, followed by mastectomy, followed by adjuvant cyclophosphamide, methotrexate, and fluorouracil (CMF) followed by radiation for stage II breast cancer: a phase II trial (CALGB 8944). Breast Cancer Res Treat. 2009;113(3):479-90

86. Thomas E, Holmes FA, Smith TL, Buzdar AU, Frye DK, Fraschini G, et al. The Use of Alternate, Non-Cross-Resistant Adjuvant Chemotherapy on the Basis of Pathologic Response to a Neoadjuvant Doxorubicin-Based Regimen in Women With Operable Breast Cancer: Long-Term Results From a Prospective Randomized Trial. J Clin Oncol. 2004:22(12):2294-302.

87. Masuda N, Lee SJ, Ohtani S, Im YH, Lee ES, Yokota I, et al. Adjuvant Capecitabine for Breast Cancer after Preoperative Chemotherapy. N Engl J Med. 2017:376(22):2147-59

88. Zhou X, Li Y. Local Recurrence after Breast-Conserving Surgery and Mastectomy Following Neoadjuvant Chemotherapy for Locally Advanced Breast Cancer - a Meta-Analysis. Breast Care (Basel). 2016;11(5):345-51. 
89. Houssami N, MacAskill P, Von Minckwitz G, Marinovich ML, Mamounas E. Meta-analysis of the association of breast cancer subtype and pathologic complete response to neoadjuvant chemotherapy. Eur $\mathrm{J}$ Cancer. 2012:48(18):3342-54.

90. Cortazar P, Zhang L, Untch M, Mehta K, Costantino JP, Wolmark N, et al. Pathological complete response and long-term clinical benefit in breast cancer: The CTNeoBC pooled analysis. Lancet. 2014;384(9938):164-72.

91. Gianni L, Pienkowski T, Im YH, Roman L, Tseng LM, Liu MC, et al. Efficacy and safety of neoadjuvant pertuzumab and trastuzumab in women with locally advanced, inflammatory, or early HER2-positive breast cancer (NeoSphere): A randomised multicentre, open-label, phase 2 trial. Lancet Oncol. 2012;13(1):25-32.

92. Gianni L, Pienkowski T, Im YH, Tseng LM, Liu MC, Lluch A, et al. 5-year analysis of neoadjuvant pertuzumab and trastuzumab in patients with locally advanced, inflammatory, or early-stage HER2-positive breast cancer (NeoSphere): a multicentre, open-label, phase 2 randomised trial. Lancet Oncol. 2016;17(6):791-800.

93. Schneeweiss A, Chia S, Hickish T, Harvey V, Eniu A, Hegg R, et al. Pertuzumab plus trastuzumab in combination with standard neoadjuvant anthracycline-containing and anthracycline-free chemotherapy regimens in patients with HER2-positive early breast cancer: A randomized phase II cardiac safety study (TRYPHAENA). Ann Oncol. 2013;24(9):2278-84.

94. Von Minckwitz G, Untch M, Blohmer JU, Costa SD, Eidtmann H, Fasching $\mathrm{P}$ a, et al. Definition and impact of pathologic complete response on prognosis after neoadjuvant chemotherapy in various intrinsic breast cancer subtypes. J Clin Oncol. 2012;30(15):1796-804.

95. Liedtke C, Mazouni C, Hess KR, Andre F, Symmans WF, Gonáalez-Angulo $\mathrm{AM}$, et al. Response to neoadjuvant therapy and long-term survival in patients with triple-negative breast cancer. J Clin Oncol. 2008;26(8):1275-81.

96. Leal F, Liutti VT, Antunes dos Santos VC, Novis de Figueiredo MA, Macedo LT, Rinck Junior JA, et al. Neoadjuvant endocrine therapy for resectable breast cancer: A systematic review and meta-analysis. Breast. 2017;24(4):406-12.

97. Gentilini O, Botteri E, Veronesi P, Sangalli C, Del Castillo A, Ballardini B, et al. Repeating Conservative Surgery after Ipsilateral Breast Tumor Reappearance: Criteria for Selecting the Best Candidates. Ann Surg Oncol. 2012;19(12):3771-6. 5

98. Panet-Raymond V, Truong PT, Alexander C, Lesperance M, McDonald RE, Watson PH. Clinicopathologic factors of the recurrent tumor predict outcome in patients with ipsilateral breast tumor recurrence. Cancer. 2011;117(10):2035-43.

99. Aebi S, Gelber S, Láng I, Anderson SJ, Robidoux A, Martín M, et al. Chemotherapy prolongs survival for isolated local or regional recurrence of breast cancer: The CALOR trial (Chemotherapy as Adjuvant for Locally Recurrent breast cancer; IBCSG 27-02, NSABP B-37, BIG 1-02). Cancer Res. 2012;72(24 Suppl):S3-2-S3-2 [Abstract S3-2]

100. Siglin J, Champ CE, Vakhnenko Y, Anne PR, Simone NL. Radiation Therapyfor Locally RecurrentBreast Cancer. IntJ Breast Cancer. 2012;2012:571946.

101. Wahl AO, Rademaker A, Kiel KD, Jones EL, Marks LB, Croog V, et al. Multi-Institutional Review of Repeat Irradiation of Chest Wall and Breas for Recurrent Breast Cancer. Int $J$ Radiat Oncol Biol Phys. 2017;70(2):477-84.

102. Wilcken N, Hornbuckle J, Ghersi D. Chemotherapy alone versus endocrine therapy alone for metastatic breast cancer. Cochrane Database Syst Rev. 2003;(2):CD002747.

103. Harris E, Barry M, Kell MR. Meta-Analysis to Determine if Surgical Resection of the Primary Tumour in the Setting of Stage IV Breast Cancer Impacts on Survival. Ann Surg Oncol. 2013;20(9):2828-34.

104. Cady B, Nathan NR, Michaelson JS, Golshan M, Smith BL. Matched pair analyses of stage IV breast cancer with or without resection of primary breast site. Ann Surg Oncol. 2008;15(12):3384-95

105. Badwe R, Hawaldar R, Nair N, Kaushik R, Parmar V, Siddique S, et al. Locoregional treatment versus no treatment of the primary tumour in metastatic breast cancer: An open-label randomised controlled trial. Lancet Oncol. 2015;16(13):1380-8.

106. Soran A, Ozmen V, Ozbas S, Karanlik H, Muslumanoglu M, Igci A, et al. A randomized controlled trial evaluating resection of the primary breast tumor in women presenting with de novo stage IV breast cancer: Turkish Study (Protocol MF07-01). En: ASCO Annual Meeting. 2016. [Abstract 1005]

107. Kucharczyk MJ, Parpia S, Walker-Dilks C, Banfield L, Swaminath A. Ablative Therapies in Metastatic Breast Cancer: A Systematic Review. Breast Cancer Res Treat. 2017;164(1):13-25.

108. Friedel G, Pastorino U, Ginsberg RJ, Goldstraw P, Johnston M, Pass H, et al. Results of lung metastasectomy from breast cancer: Prognostic criteria on the basis of 467 cases of the international registry of lung metastases. Eur J Cardio-thoracic Surg. 2002;22(3):335-44.

109. Sunderland $M$, Osborne $C$. Tamoxifen in premenopausal patients with metastatic breast cancer: a review. J Clin Oncol. 1991;9(7):1283-97.

110. Klijn BJGM, Blamey RW, Boccardo F, Tominaga T, Duchateau L, Sylvester R, et al. Hormone (LHRH) Agonist Versus LHRH Agonist Alone in Premenopausal Advanced Breast Cancer: A Meta-Analysis of Four Randomized Trials. 2015;19(2):343-53.
111. Carlson RW, Theriault R, Schurman CM, Rivera E, Chung CT, Phan S-C, et al. Phase II Trial of Anastrozole Plus Goserelin in the Treatment of Hormone Receptor-Positive, Metastatic Carcinoma of the Breast in Premenopausal Women. J Clin Oncol. 2010;28(25):3917-21.

112. Cristofanilli M, Turner NC, Bondarenko I, Ro J, Im SA, Masuda N, et al. Fulvestrant plus palbociclib versus fulvestrant plus placebo for treatment of hormone-receptor-positive, HER2-negative metastatic breast cancer that progressed on previous endocrine therapy (PALOMA-3): final analysis of the multicentre, double-blind, phas. Lancet Oncol. 2017;17(4):425-39.

113. Mauri D, Pavlidis N, Polyzos NP, loannidis JPA. Survival with aromatase inhibitors and inactivators versus standard hormonal therapy in advanced breast cancer: Meta-analysis. J Natl Cancer Inst. 2006;98(18):1285-91.

114. Lorna G, David L, Claire D, Judith B. Aromatase inhibitors for treatment of advanced breast cancer in postmenopausal women. Cochrane Database Syst Rev. 2009;(4).

115. Xu H Bin, Liu YJ, Li L. Aromatase inhibitor versus tamoxifen in postmenopausal woman with advanced breast cancer: A literature-based meta-analysis. Clin Breast Cancer. 2011;11(4):246-51.

116. Lee Cl, Goodwin A, Wilcken N. Fulvestrant for hormone-sensitive metastatic breast cancer. Cochrane Database Syst Rev. 2017;1:CD011093.

117. Polk A, Kolmos IL, Kümler I, Nielsen DL. Specific CDK4/6 inhibition in breast cancer: a systematic review of current clinical evidence. ESMO Open. 2017;1(6):e000093.

118. Finn RS, Martin M, Rugo HS, Jones S, Im SA, Gelmon K, et al. Palbociclib and Letrozole in Advanced Breast Cancer. N Engl J Med. 2016;375(20):1925-36

119. Hortobagyi GN, Stemmer SM, Burris HA, Yap YS, Sonke GS, Paluch-Shimon S, et al. Ribociclib as First-Line Therapy for HR-Positive, Advanced Breast Cancer. N Engl J Med. 2016;375(18):1738-48.

120. Costa R, Costa RB, Talamantes SM, Helenowski I, Peterson J, Kaplan J, et al. Meta-analysis of selected toxicity endpoints of CDK4/6 inhibitors: Palbociclib and ribociclib. Breast. 2017:35:1-7.

121. Sledge GW, Toi M, Neven P, Sohn J, Inoue K, Pivot X, et al. MONARCH 2: Abemaciclib in combination with fulvestrant in women with $\mathrm{HR}+$ / HER2-advanced breast cancer who had progressed while receiving endocrine therapy. J Clin Oncol. 2017;35(25):2875-84.

122. Piccart M, Hortobagyi GN, Campone M, Pritchard KI, Lebrun F, Ito Y, et al. Everolimus plus exemestane for hormone-receptor-positive, human epidermal growth factor receptor-2-negative advanced breast cancer: overall survival results from BOLERO-2†. Ann Oncol. 2014;25(12):2357-62.

123. Bachelot T, Bourgier C, Cropet C, Ray-Coquard I, Ferrero JM, Freyer G, et al. Randomized phase II trial of everolimus in combination with tamoxifen in patients with hormone receptor-positive, human epidermal growth factor receptor 2-negative metastatic breast cancer with prior exposure to aromatase inhibitors: A GINECO study. J Clin Oncol. 2012; 30(22):2718-24.

124. Sledge GW, Hu P, Falkson G, Tormey D, Abeloff M. Comparison of Chemotherapy With Chemohormonal Therapy as First-Line Therapy for Metastatic, Hormone-Sensitive Breast Cancer: An Eastern Cooperative Oncology Group Study. J Clin Oncol. 2000;18(2):262

125. Perry MC, Kardinal CG, Korzun AH, Ginsberg SJ, Raich PC, Holland JF, et al. Chemohormonal therapy in advanced carcinoma of the breast: Cancer and Leukemia Group B protocol 8081. J Clin Oncol. 1987;5(10):1534-45

126. Baselga J, Cortés J, Kim S-B, Im SA, Hegg R, Im YH, et al. Pertuzumab plus Trastuzumab plus Docetaxel for Metastatic Breast Cancer. N Engl J Med. 2011;366(2):109-19.

127. Swain SM, Baselga J, Kim SB, Ro J, Semiglazov V, Campone M, et al. Pertuzumab, Trastuzumab, and Docetaxel in HER2-Positive Metastatic Breast Cancer. N Engl J Med. 2015;372(8):724-34

128. Ramakrishna N, Temin S, Chandarlapaty S, Crews JR, Davidson NE, Esteva FJ, et al. Recommendations on disease management for patients with advanced human epidermal growth factor receptor 2-positive breast cancer and brain metastases: American Society of Clinical Oncology clinical practice guideline. J Clin Oncol. 2014;32(19):2100-8.

129. Balduzzi S, Mantarro S, Guarneri V, Tagliabue L, Pistotti V, Moja L, et al. Trastuzumab-containing regimens for metastatic breast cancer. [Review]. Cochrane Database Syst Rev. 2014;6:CD006242.

130. Verma S, Miles D, Gianni L, Krop IE, Welslau M, Baselga J, et al. Trastuzumab Emtansine for HER2-Positive Advanced Breast Cancer. N Engl J Med. 2012;367(19):1783-91.

131. Cardoso F, Costa A, Senkus E, Aapro M, André F, Barrios $\mathrm{CH}$, et al. $3^{\text {rd }}$ ESO-ESMO International Consensus Guidelines for Advanced Breast Cancer (ABC 3). Ann Oncol. 2017;28(1):16-33.

132. Carrick S, Parker S, Ce T, Ghersi D, Simes J, Wilcken N. Single agent versus combination chemotherapy for metastatic breast cancer (Review). 2009;(2):CD003372

133. Dear R, McGeechan K, Jenkins M, Barratt A, Tattersall M, Nicholas W. Combination versus sequential single agent chemotherapy for metastatic breast cancer. Cochrane Database Syst Rev. 2013;(12):1-98

134. Liang X, Xiaobo W, Chun H, Zhiying Z, Le Z, Shujing L, et al. A meta-analysis of combination therapy versus single-agent therapy in anthra- 
cycline- and taxane-pretreated metastatic breast cancer: results from nine randomized Phase III trials. Onco Targets Ther. 2016;9:4061-74.

135. Petrelli F, Barni S. Surrogate endpoints in metastatic breast cance treated with targeted therapies: An analysis of the first-line phase III trials. Med Oncol. 2014;31(1).

136. Cortes J, O'Shaughnessy J, Loesch D, Blum JL, Vahdat LT, Petrakova K et al. Eribulin monotherapy versus treatment of physician's choice in patients with metastatic breast cancer (EMBRACE): a phase 3 open-label randomised study. Lancet. 2011;377(9769):914-23.

137. Kaufman PA, Awada A, Twelves C, Yelle L, Pérez EA, Velikova G, et al. Phase III open-label randomized study of eribulin mesylate versus capecitabine in patients with locally advanced or metastatic breast cance previously treated with an anthracycline and a taxane. J Clin Oncol. 2015;33(6):594-601.

138. Diéras V, Miles D, Verma S, Pegram M, Welslau M, Baselga J, et al. Trastuzumab emtansine versus capecitabine plus lapatinib in patients with previously treated HER2-positive advanced breast cancer (EMILIA): a descriptive analysis of final overall survival results from a randomised, open-label, phase 3 trial. Lancet Oncol. 2017;18(6):732-42.

139. Gelmon KA, Boyle FM, Kaufman B, Huntsman DG, Manikhas A Di Leo A, et al. Lapatinib or Trastuzumab Plus Taxane Therapy for Human Epidermal Growth Factor Receptor 2-Positive Advanced Breast Cancer: Final Results of NCIC CTG MA.31. J Clin Oncol. 2015; 33(14):1574-83.

140. Mendes D, Alves C, Afonso N, Cardoso F, Passos-Coelho JL, Costa L, et al. The benefit of HER2-targeted therapies on overall survival of pa- tients with metastatic HER2-positive breast cancer - a systematic review. Breast Cancer Res. Breast Cancer Research. 2015;17(1):140.

141. Liu M, Mo Q, Wei C, Qin Q, Huang Z, He J. Platinum-based chemotherapy in triple-negative breast cancer: A meta-analysis. Oncol Lett 2013.5.983-91.

142. Fan Y, Xu BH, Yuan P, Ma F, Wang JY, Ding XY, et al. Docetaxel-cisplatin might be superior to docetaxel-capecitabine in the first-line treatment of metastatic triple-negative breast cancer. Ann Oncol. 2013; 24(5):1219-25.

143. Tutt $A$, Ellis $P$, Kilburn $L$, Gilett $C$, Pinder $S$, Abraham J, et al. TNT: A randomized phase III trial of carboplatin compared with docetaxel for patients with metastatic or recurrent locally advanced triple negative or BRCA 1/2 breast cancer. En: San Antonio Breast Cancer Symposium. 2014.

144. Hu XC, Zhang J, Xu BH, Cai L, Ragaz J, Wang ZH, et al. Cisplatin plus gemcitabine versus paclitaxel plus gemcitabine as first-line therapy for metastatic triple-negative breast cancer (CBCSG006): a randomised, open-label, multicentre, phase 3 trial. Lancet Oncol. 2015;16(4):436-46.

145. Li Q, Yan H, Zhao P, Yang Y, Cao B. Efficacy and safety of bevacizumab combined with chemotherapy for managing metastatic breast cancer: A meta-analysis of randomized controlled trials. Sci Rep. 2015;5:1-11.

146. Lipton A, Fizazi K, Stopeck AT, Henry DH, Brown JE, Yardley DA, et al. Superiority of denosumab to zoledronic acid for prevention of skeletal-related events: A combined analysis of 3 pivotal, randomised, phase 3 trials. Eur J Cancer. 2012;48(16):3082-92.

147. Palmieri C, Fullarton JR, Brown J. Comparative efficacy of bisphosphonates in metastatic breast and prostate cancer and multiple myeloma: A mixed-treatment meta-analysis. Clin Cancer Res. 2013;19(24):6863-72. 


\section{Anexos}

\section{Anexo A. Documento de alcances de la GPC}

\section{Título de la GPC}

Guía de práctica clínica nacional para el manejo del cáncer de mama en estadios tempranos, localmente avanzados y metastásicos.

\section{Título abreviado}

Guía de práctica clínica nacional en cáncer de mama.

\section{Antecedentes}

- La Sociedad Mexicana de Oncología, en colaboración con el Consejo Mexicano de Oncología y el Centro Nacional de Excelencia Tecnológica, apoyados metodológicamente por la agencia Ibero American Agency for Development and Assessment of Health Technologies, llevarán a cabo el desarrollo de una GPC que cumple con los más altos estándares internacionales sobre el tratamiento del cáncer de mama, tanto en estadio temprano, localmente avanzado como metastásico, para apoyar a los especialistas en la toma de decisiones clínicas y brindar recomendaciones puntuales sobre los distintos tópicos a este respecto.

- Esta GPC cumple con estándares bien validados publicados por distintas instituciones a nivel internacional, como el IOM, el NICE, la SIGN y la GIN.

- Se realizará también una estrategia de promoción, diseminación e implementación de las recomendaciones contenidas en esta GPC para apoyar a los distintos tomadores de decisión, tanto elaboradores de políticas en salud, administrativos, médicos especialistas, así como otros profesionales de la salud, pacientes y sus cuidadores para lograr elevar la calidad en la atención clínica en estos pacientes.

\section{Justificación para el desarrollo de la GPC}

Aquí se trata el tema desde el punto de vista epidemiológico y de relevancia en nuestro medio, por lo que está justificada la elaboración de la GPC. Las distintas áreas de investigación se encuentran en constante desarrollo y es preciso incorporar la evidencia científica a la práctica clínica cotidiana a través de recomendaciones clínicas basadas en evidencia que asistan a los distintos tomadores de decisión y que ayuden a mejorar la calidad de la atención clínica.

\section{Población}

\section{Población incluida}

Mujeres de 18 años o más con diagnóstico histopatológico de cáncer de mama en estadios tempranos (incluido el carcinoma in situ), localmente avanzado o metastásico (incluido el recurrente).

\section{Población excluida}

- Tumor de Paget.

- Cáncer de mama en pacientes de género masculino.

- Mujeres y hombres con tumores de mama poco frecuentes (p. ej., angiosarcomas, linfomas).

- Mujeres y hombres con metástasis a mama de otros tumores primarios.

- Mujeres y hombres con tumores de mama benignos (p. ej., fibroadenomas, tumores filodes benignos).

\section{Tópicos clínicos que no serán considerados}

- Diagnóstico del cáncer de mama.

- Diagnóstico de tamizaje del cáncer de mama.

- Reconstrucción mamaria.

- Tratamiento psicológico.

- Tratamiento paliativo.

- Manejo de linfedema.

- Tratamiento en pacientes embarazadas.

- Fertilidad en pacientes premenopáusicas. 
- Consejo genético en cáncer de mama.

- Información para el paciente.

- Células circulantes como marcador de progresión.

\section{Escenarios clínicos en los que se} aplicarán las recomendaciones de la GPC

- Segundo y tercer nivel de atención.

- Oncólogos clínicos y quirúrgicos en instituciones públicas y privadas.

- Radiooncólogos en instituciones públicas y privadas.

\section{Procesos clínicos que serán considerados en la GPC}

\section{Estadios clínicos}

- CDIS y CLIS.

- Adenocarcinoma en estadio temprano.

- Localmente avanzado operable y localmente avanzado inoperable.

- Cáncer de mama recurrente.

- Cáncer de mama metastásico.

\section{Manejo}

- Tratamiento hormonal.

- Tratamiento quirúrgico.

- Tratamiento con QT.

- Perfiles de expresión génica.

- Agentes biológicos y terapias blanco.

- Tratamiento con radioterapia.

- Bisfosfonatos.

\section{Intervenciones y tratamientos que serán} considerados

- Cirugía:

- Cirugía con conservación del seno (escisión/lumpectomia/cuadrantectomía).

- Mastectomía.

- Cirugía de ganglios linfáticos para el cáncer de seno (disección axilar).

- Ganglio centinela.

- Radioterapia:

- Radioterapia en etapa temprana.

- Radioterapia localmente avanzado.

- RT 1-3 ganglios.

- RPBI radiación parcial.
- Radiación hipofraccionada.

- SBRT oligometastásica.

- Terapia endocrina:

- Tamoxifeno.

- IA.

- Antagonista de ER (fulvestrant).

- Ablación ovárica.

- QT:

- Taxanos (nab-paclitaxel).

- Antraciclinas.

- Antimetabolitos.

- Platinos.

- Vinorelbina.

- Capecitabina.

- Eribulina.

- Terapia biológica:

- Trastuzumab.

- Pertuzumab.

- T-DM1.

- Lapatinib.

- Palbociclib.

- Everolimus.

- Bisfosfonatos.

- Inhibidor de RANK (Xgeva).

\section{Desenlaces clínicos a ser evaluados}

- SG (overall survival).

- SLE (disease-free survival).

- SLP (progression-free survival).

- Calidad de vida.

- Tasa de respuesta global.

- Incidencia de eventos adversos.

- Mortalidad relacionada con el tratamiento.

- Tiempo a la progresión.

- Recurrencia locorregional.

- Recurrencia a distancia.

\section{Aportaciones clínicas que consideramos de relevancia en la GPC}

El objetivo de esta GPC es cerrar la brecha entre el conocimiento científico que se genera continuamente en el tratamiento de las distintas etapas del cáncer de mama y la práctica clínica cotidiana, para mejorar la calidad y los desenlaces en los pacientes con cáncer de mama.

CLIS: carcinoma lobular in situ;SBRT: radioterapia estereotáctica del Cuerpo; RANK: receptor activador del Factor Nuclear Kappa-B. 


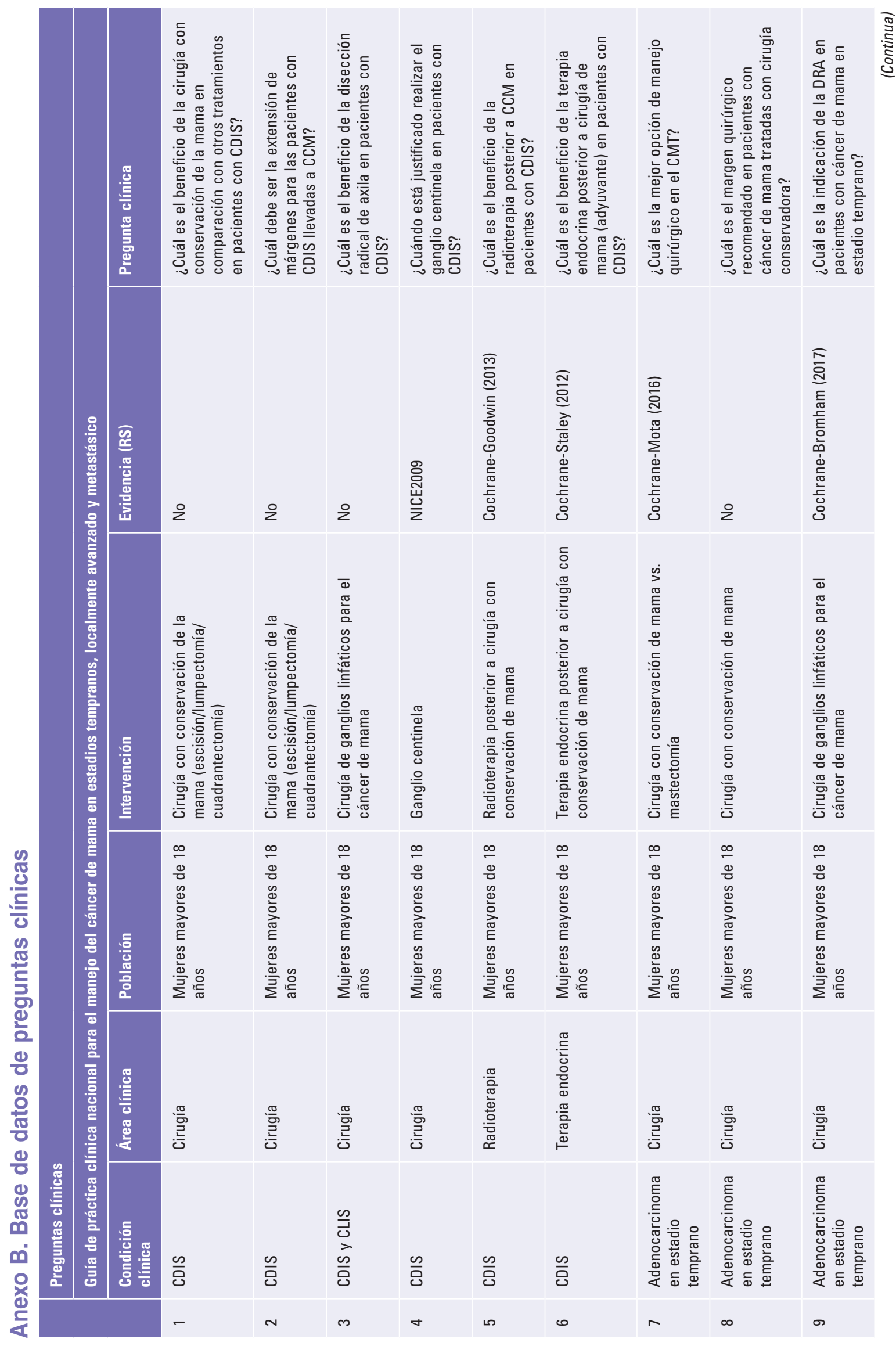




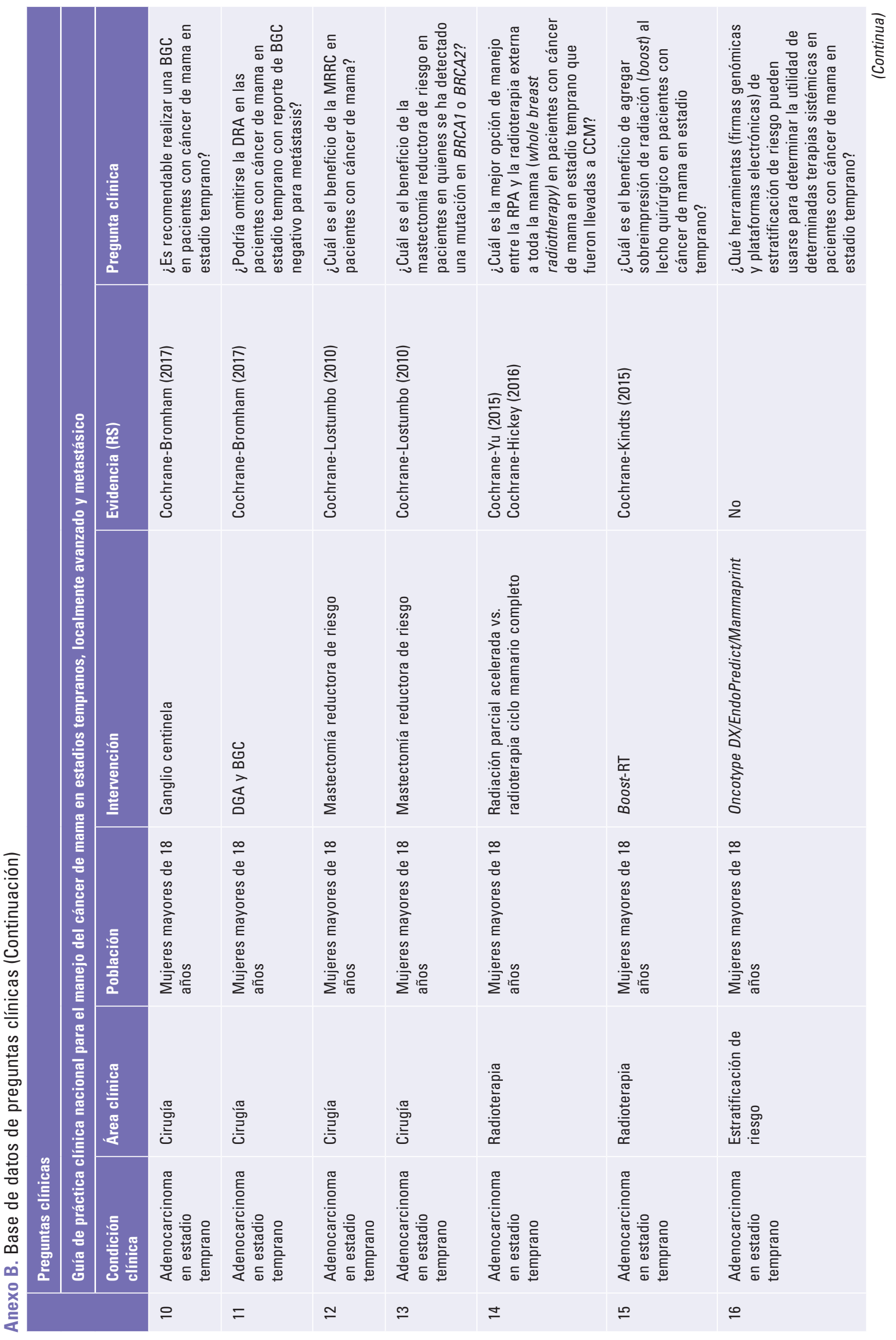




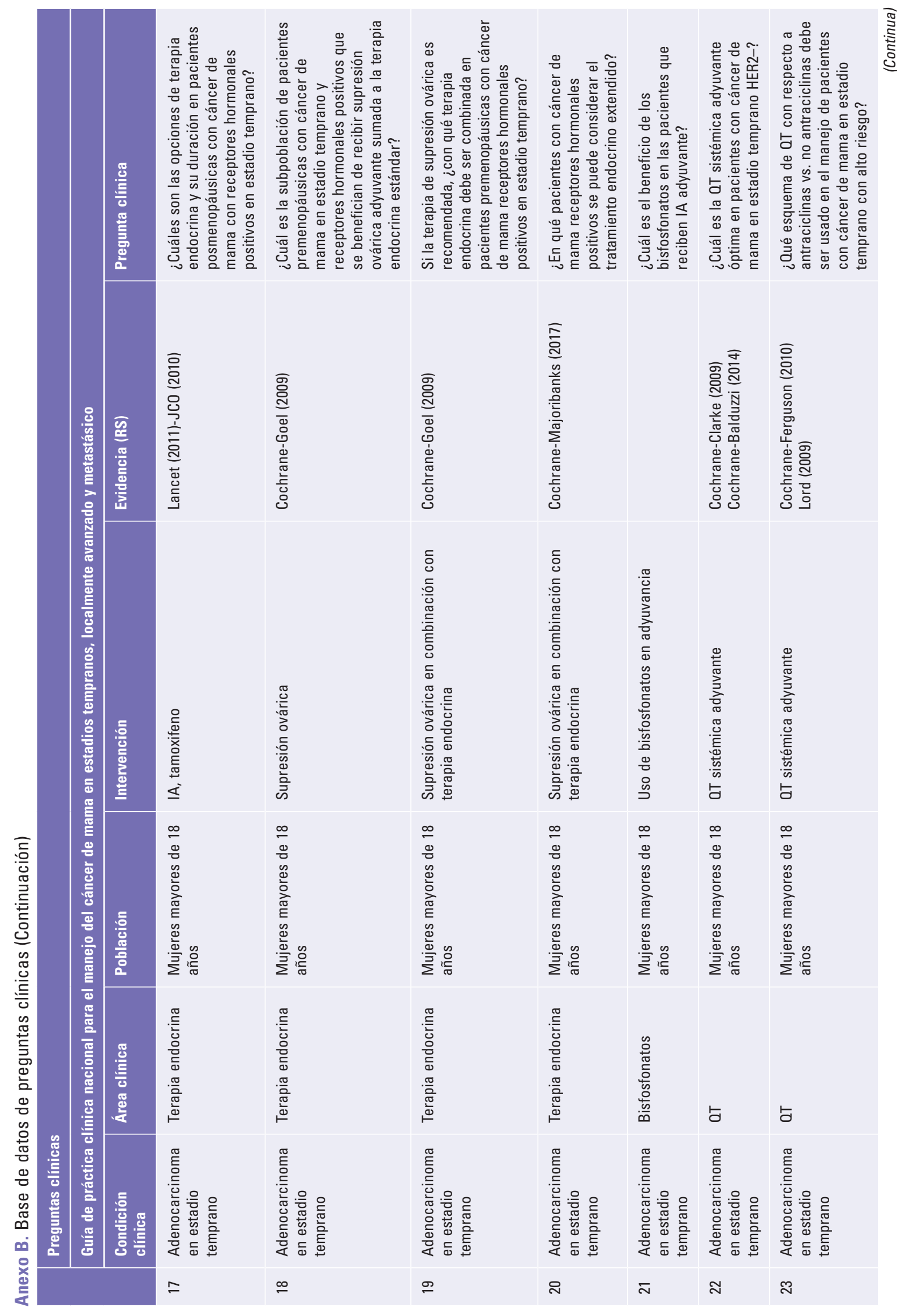




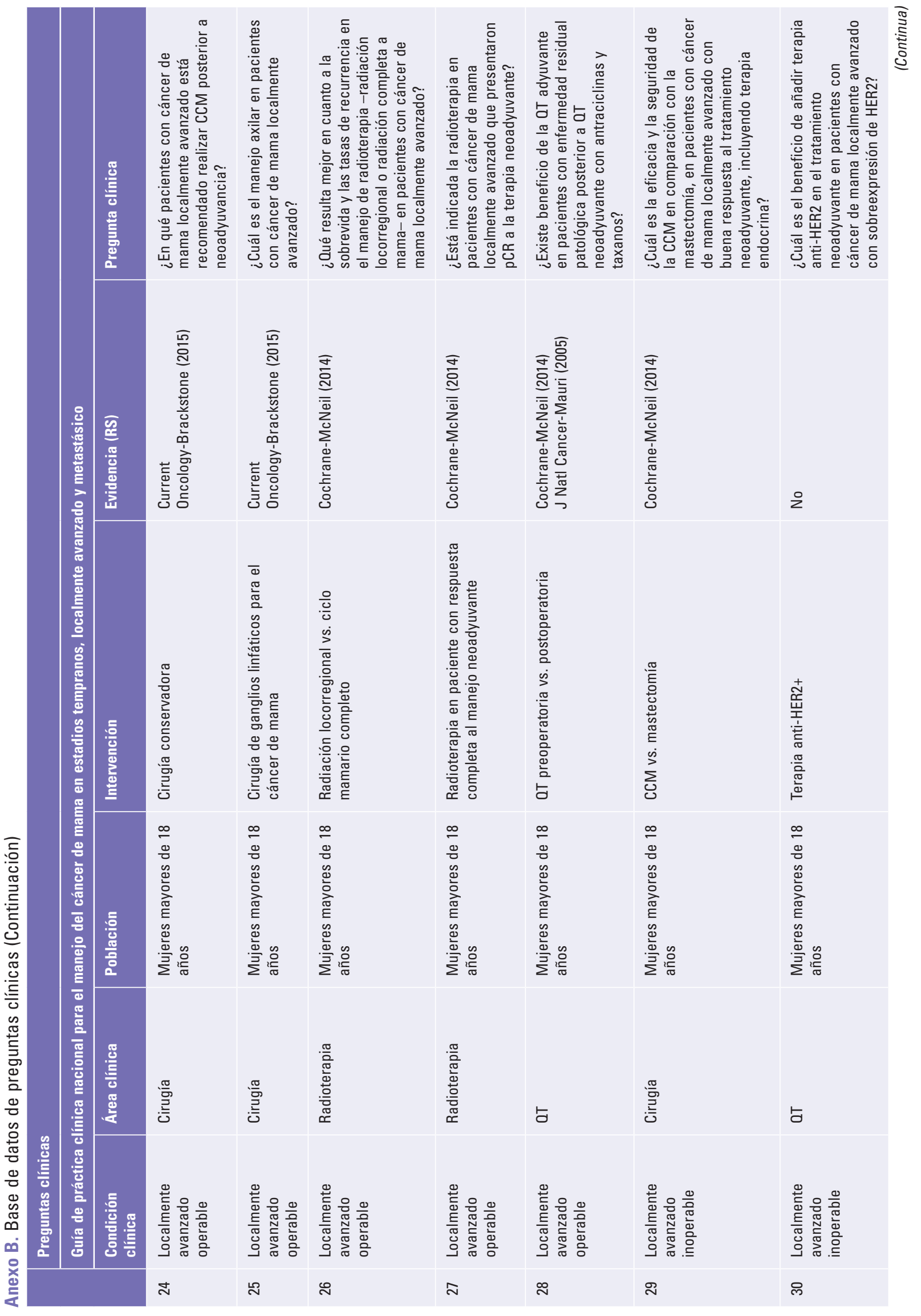



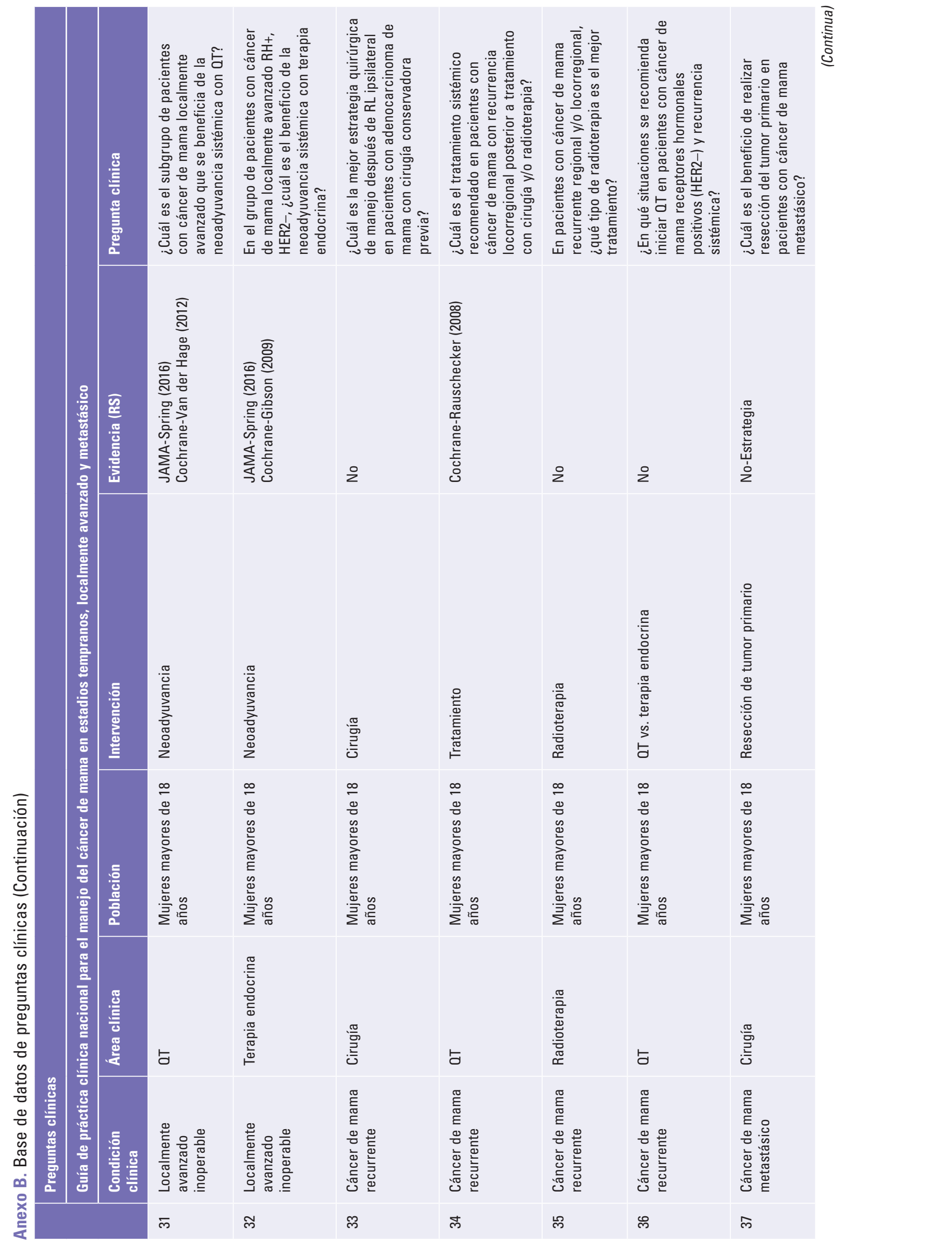


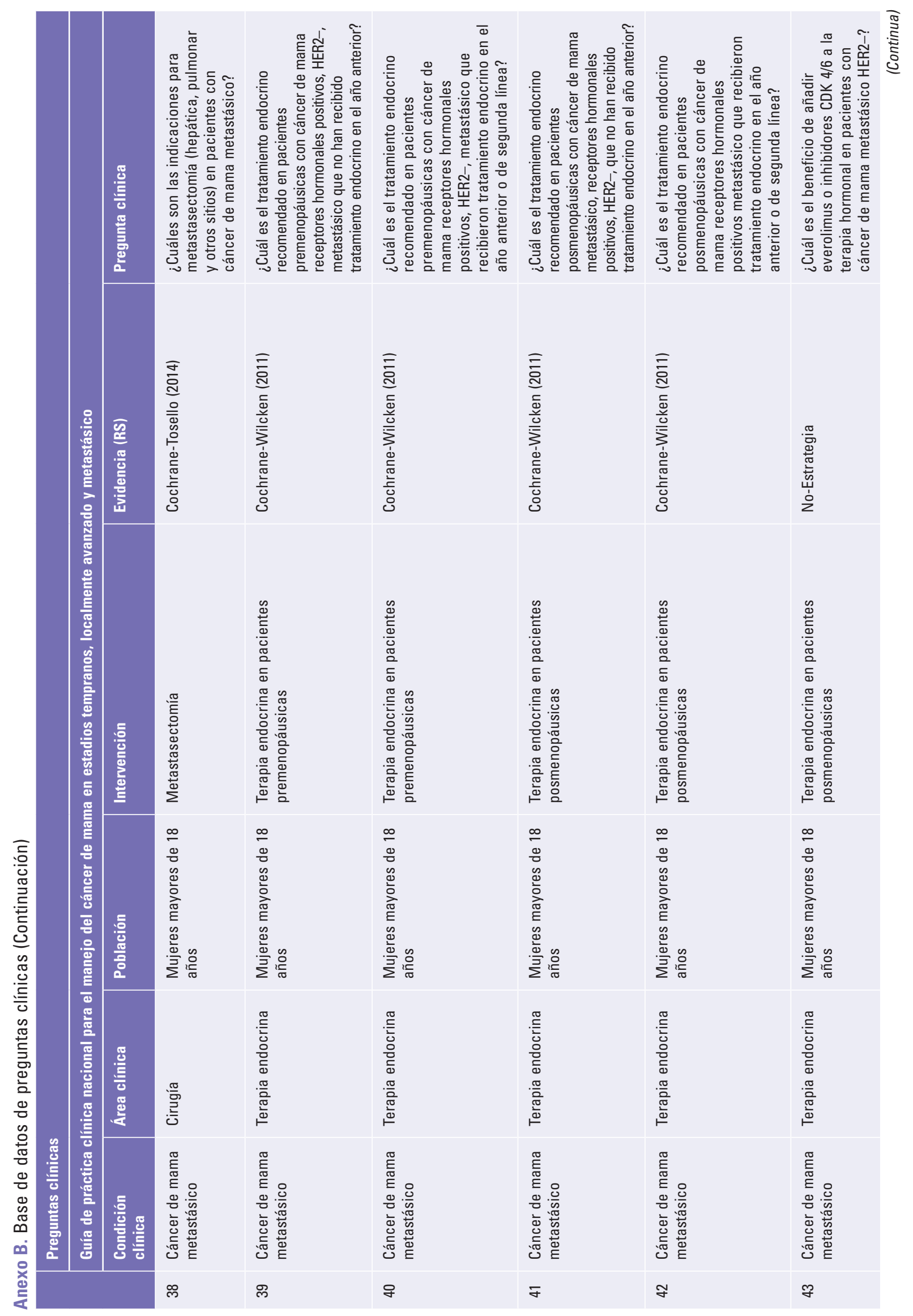




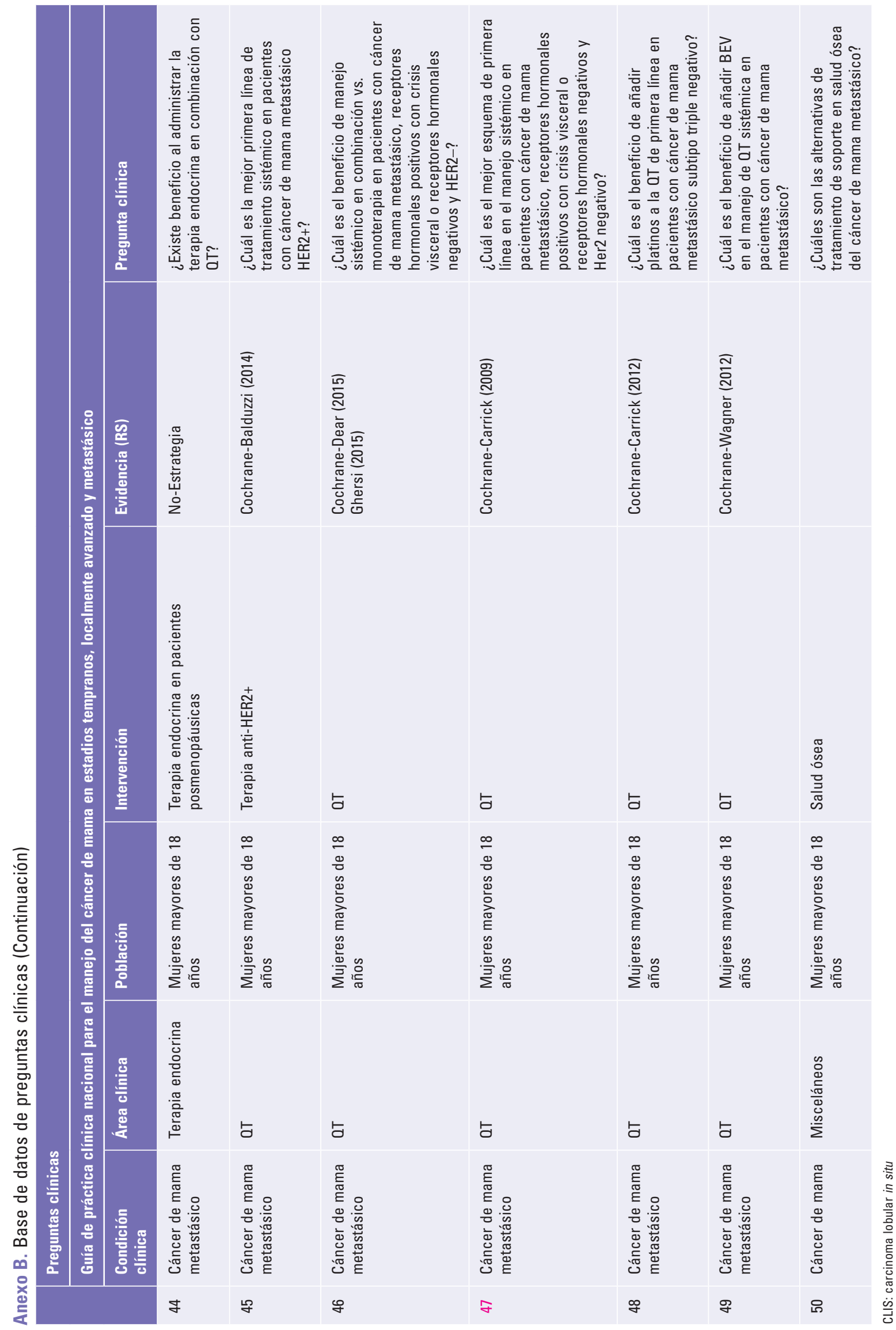




\section{Anexo C. Estrategias de búsqueda de la literatura médica y términos MeSH}

\section{PubMed y Embase}

( (()((“"cochrane database syst rev"[Journal]) OR meta analysis[MeSH Terms]) OR meta-analysis[Publication Type]) OR systematic review[Title/Abstract]))) AND (((breast neoplasms[MeSH Terms]) OR breast neoplasm[MeSH Terms]))) AND ((()((((partial breast irradiation[Title/Abstract]) OR whole breast irradiation[Title/Abstract]) OR whole breast radiotherapy[Title/Abstract]) OR brachytherapy[Title/Abstract]) OR accelerated partial breast irradiation[Title/Abstract]) OR adjuvant radiotherapy[MeSH Terms]) OR adjuvant radiotherapies[MeSH Terms]) OR high energy radiotherapy[MeSH Terms])

(()((()“cochrane database syst rev"[Journal]) OR meta analysis[MeSH Terms]) OR meta-analysis[Publication Type]) OR systematic review[Title/Abstract]))) AND (((breast neoplasms[MeSH Terms]) OR breast neoplasm[MeSH Terms] )) AND (((()(((taxanes[MeSH Terms]) OR agents, antineoplastic[MeSH Terms]) OR agent, combined antineoplastic[MeSH Terms]) OR agents, antineoplastic hormonal[MeSH Terms]) OR tamoxifen[Title/Abstract]) OR tamoxifen[Text Word]) OR paclitaxel[Title/Abstract]) OR paclitaxel[Text Word])

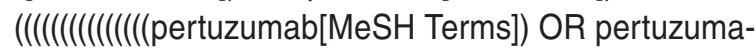
b[Supplementary Concept]) OR pertuzumab[Title/Abstract])) OR trastuzumab[Title/Abstract]) OR trastuzumab[Text Word]) OR trastuzumab emtansine[Title/ Abstract]) OR trastuzumab emtansine[Text Word])) OR Vascular Endothelial Growth Factor[Title/Abstract]) OR Angiogenesis inhibitors[Title/Abstract]) OR Vascular Endothelial Growth Factor[Text Word]) OR Angiogenesis inhibitors[Text Word])) AND (((((“"cochrane database syst rev"[Journal]) OR meta analysis[MeSH Terms]) OR meta-analysis[Publication Type]) OR systematic review[Title/Abstract]))) AND (((breast neoplasms[MeSH Terms]) OR breast neoplasm[MeSH Terms]))

(/((/((“"cochrane database syst rev"[Journal]) OR meta analysis[MeSH Terms]) OR meta-analysis[Publication Type]) OR systematic review[Title/Abstract]))) AND (((breast neoplasms[MeSH Terms]) OR breast neoplasm[MeSH Terms]))) AND (((((everolimus[MeSH Terms]) OR everolimus[Text Word]) OR everolimus[Title/Abstract]) OR RAD001[Text Word]) OR RAD001[Title/Abstract])

(((((oncotype[Text Word]) OR oncotype[Title/Abstract]) OR oncotype[Supplementary Concept]) OR endopredict[Text Word]) OR endopredict[Title/Abstract]) OR endopredict[Supplementary Concept]) OR mammaprint[Text Word]) OR mammaprint[Title/Abstract]) OR mammaprint[Supplementary Concept]))))) AND (((breast neoplasms[MeSH Terms]) OR breast neoplasm[MeSH Terms]))) AND (((((“cochrane database syst rev"[Journal]) OR meta analysis[MeSH Terms]) OR meta-analysis[Publication Type]) OR systematic review[Title/Abstract]))

(((((breast neoplasms[MeSH Terms]) OR breast neoplasm[MeSH Terms]))) AND (((((“cochrane database syst rev"[Journal]) OR meta analysis[MeSH Terms]) OR meta-analysis[Publication Type]) OR systematic review[Title/Abstract $]))$ AND (((metastasectomy[MeSH Terms]) OR metastasectomy[Text Word]) OR metastasectomy[Title/Abstract])

(((((breast neoplasms[MeSH Terms]) OR breast neoplasm[MeSH Terms]))) AND (((((“cochrane database syst rev"[Journal]) OR meta analysis[MeSH Terms]) OR meta-analysis[Publication Type]) OR systematic review[Title/Abstract]))) AND ((((fulvestrant[Supplementary Concept]) OR fulvestrant[Other Term]) OR fulvestrant[Text Word]) OR fulvestrant[Title/Abstract])

(((((“Axilla”[Mesh]) OR (“"Lymph Nodes”[Mesh] OR "Sentinel Lymph Node Biopsy"[Mesh] OR "Lymph Node Excision"[Mesh] OR "Sentinel Lymph Node"[Mesh])))) AND ((()(“cochrane database syst rev"[Journal]) OR meta analysis[MeSH Terms]) OR meta-analysis[Publication Type]) OR systematic review[Title/Abstract]))) AND (((breast neoplasms[MeSH Terms]) OR breast neoplasm[MeSH Terms]))

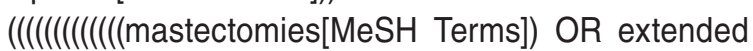
radical mastectomies[MeSH Terms]) OR extended radical mastectomy[MeSH Terms]) OR local excision mastectomies[MeSH Terms]) OR mastectomies, modified[MeSH Terms]) OR mastectomies, modified radical[MeSH Terms]) OR mastectomies, segmental[MeSH Terms]) OR mastectomies, simple[MeSH Terms]) OR lumpectomy[Title]) OR axilla[MeSH Terms]))) AND (((()“cochrane database syst rev"[Journal]) OR meta analysis[MeSH Terms]) OR meta-analysis[Publication Type]) OR systematic review[Title/Abstract]))) AND Breast Carcinoma In Situ[MeSH Terms]

((()((“Axilla”[Mesh]) OR (“Lymph Nodes”[Mesh] OR "Sentinel Lymph Node Biopsy"[Mesh] OR "Lymph Node Excision"[Mesh] OR "Sentinel Lymph Node"[Mesh]))))) AND ((()(“cochrane database syst rev"[Journal]) OR meta analysis[MeSH Terms]) OR meta-analysis[Publication Type]) OR systematic review[Title/Abstract]))) AND Breast Carcinoma In Situ[MeSH Terms]

(()((((“cochrane database syst rev"[Journal]) OR meta analysis[MeSH Terms]) OR meta-analysis[Publication Type]) OR systematic review[Title/Abstract]))) AND (((breast neoplasms[MeSH Terms]) OR breast neoplas$\mathrm{m}[\mathrm{MeSH}$ Terms]))) AND (((pertuzumab[MeSH Terms]) 
OR pertuzumab[Supplementary Concept]) OR pertuzumab[Title/Abstract])

()((breast neoplasms[MeSH Terms]) OR breast neoplasm[MeSH Terms])) AND (((()((trastuzumab[Title/ Abstract]) OR trastuzumab[Text Word]) OR herceptin[Title/Abstract]) OR herceptin[Text Word]) OR bevacizumab[Title/Abstract]) OR bevacizumab[Text Word]) OR lapatinib[Title/Abstract]) OR lapatinib[Text Word])) AND ((((“cochrane database syst rev"[Journal]) OR meta analysis[MeSH Terms]) OR meta-analysis[Publication Type]) OR systematic review[Title/Abstract])

(((((breast neoplasms[MeSH Terms]) OR breast neoplasm[MeSH Terms]))) AND ((((("cochrane database syst rev"[Journal]) OR meta analysis[MeSH Terms]) OR meta-analysis[Publication Type]) OR systematic review[Title/Abstract]))) AND ((cisplatin[MeSH Terms]) OR carboplatin[MeSH Terms])

( (()((()diphosphonates[MeSH Terms]) OR zoledronic acid[Title/Abstract]) OR zoledronic acid[Text Word]) OR Denosumab[Title/Abstract]) OR Denosumab[Text Word]) OR Anti-RANK antibody[Title/Abstract])) AND (((/("cochrane database syst rev"[Journal]) OR meta analysis[MeSH Terms]) OR meta-analysis[Publication Type]) OR systematic review[Title/Abstract]))) AND (((breast neoplasms[MeSH Terms]) OR breast neoplasm[MeSH Terms]))

( (()((““cochrane database syst rev"[Journal]) OR meta analysis[MeSH Terms]) OR meta-analysis[Publication Type]) OR systematic review[Title/Abstract]))) AND (((breast neoplasms[MeSH Terms]) OR breast neoplasm[MeSH Terms $])))$ AND $(((()((((($ mastectomies[MeSH Terms]) OR extended radical mastectomies[MeSH Terms]) OR extended radical mastectomy[MeSH Terms]) OR local excision mastectomies[MeSH Terms]) OR mastectomies, modified[MeSH Terms]) OR mastectomies, modified radical[MeSH Terms]) OR mastectomies, segmental[MeSH Terms]) OR mastectomies, simple[MeSH Terms]) OR lumpectomy[Title]) OR axilla[MeSH Terms])

()((()(“cochrane database syst rev"[Journal]) OR meta analysis[MeSH Terms]) OR meta-analysis[Publication Type]) OR systematic review[Title/Abstract]))) AND (((breast neoplasms[MeSH Terms]) OR breast neoplasm[MeSH Terms]))) AND (((()(((adjuvant chemotherapy[MeSH Terms]) OR chemotherapy[MeSH Terms]) OR antineoplastic chemotherapy protocol[MeSH Terms]) OR antineoplastic chemotherapy protocols[MeSH Ter$\mathrm{ms}]$ ) OR chemotherapies, combination[MeSH Terms]) OR chemotherapies, consolidation[MeSH Terms]) OR chemotherapies, induction[MeSH Terms]) OR chemotherapies, maintenance[MeSH Terms])

()(((/(“cochrane database syst rev"[Journal]) OR meta analysis[MeSH Terms]) OR meta-analysis[Publication
Type]) OR systematic review[Title/Abstract]))) AND (((breast neoplasms[MeSH Terms]) OR breast neoplasm[MeSH Terms]))) AND ((((()((tamoxifen[MeSH Terms]) OR tamoxifen[Title/Abstract]) OR anastrozole[Title/ Abstract]) OR exemestane[Title/Abstract]) OR letrozole[Title/Abstract]) OR anastrozole[Text Word]) OR exemestane[Text Word]) OR letrozole[Text Word])

( (()((““cochrane database syst rev”[Journal]) OR meta analysis[MeSH Terms]) OR meta-analysis[Publication Type]) OR systematic review[Title/Abstract]))) AND (((breast neoplasms[MeSH Terms]) OR breast neoplas$\mathrm{m}[\mathrm{MeSH}$ Terms]))) AND ((deoxycytidine[MeSH Terms]) OR gemcitabine[MeSH Terms])

((()(((“"cochrane database syst rev”[Journal]) OR meta analysis[MeSH Terms]) OR meta-analysis[Publication Type]) OR systematic review[Title/Abstract]))) AND (((breast neoplasms[MeSH Terms]) OR breast neoplasm[MeSH Terms] ))) AND (((()(((adjuvant chemotherapy[MeSH Terms]) OR chemotherapy[MeSH Terms]) OR antineoplastic chemotherapy protocol[MeSH Terms]) OR antineoplastic chemotherapy protocols[MeSH Ter$\mathrm{ms}]$ ) OR chemotherapies, combination[MeSH Terms]) OR chemotherapies, consolidation[MeSH Terms]) OR chemotherapies, induction[MeSH Terms]) OR chemotherapies, maintenance[MeSH Terms])

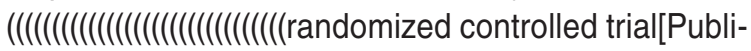
cation Type]) OR controlled clinical trial[Publication Type]) OR randomized controlled trial[MeSH Terms]) OR random allocation[MeSH Terms]) OR double-blind method[MeSH Terms]) OR single-blind method) OR clinical trial[Publication Type]) OR clinical trials[MeSH Terms]) OR clinical trial[Text Word]) OR singl*[Text Word]) OR doubl*[Text Word]) OR trebl*[Text Word]) OR tripl*[Text Word]) OR mask*[Text Word]) OR blin$d^{*}[$ Text Word]) OR latin square[Text Word]) OR placebos[MeSH Terms]) OR placebo*[Text Word]) OR random*[Text Word]) OR research design[MeSH Terms]) OR comparative study[MeSH Terms]) OR evaluation studies[MeSH Terms]) OR follow-up studies[MeSH Terms]) OR prospective studies[MeSH Terms]) OR crossover studies[MeSH Terms]) OR control*[Text Word]) OR prospectiv*[Text Word]) OR volunteer*[Text Word]))) AND (((breast neoplasms[MeSH Terms]) OR breast neoplasm[MeSH Terms]))) AND $(((()((($ adjuvant chemotherapy[MeSH Terms]) OR chemotherapy[MeSH Ter$\mathrm{ms}]$ ) OR antineoplastic chemotherapy protocol[MeSH Terms]) OR antineoplastic chemotherapy protocols[MeSH Terms]) OR chemotherapies, combination[MeSH Terms]) OR chemotherapies, consolidation[MeSH Ter$\mathrm{ms}]$ ) OR chemotherapies, induction[MeSH Terms]) OR chemotherapies, maintenance[MeSH Terms])) 